Portland State University

PDXScholar

Spring 6-8-2017

\title{
Drivers' Attitudes and Behaviors Toward Bicyclists: Intermodal Interactions and Implications for Road Safety
}

Tara Beth Goddard

Portland State University

Follow this and additional works at: https://pdxscholar.library.pdx.edu/open_access_etds

Part of the Urban Studies Commons

Let us know how access to this document benefits you.

Recommended Citation

Goddard, Tara Beth, "Drivers' Attitudes and Behaviors Toward Bicyclists: Intermodal Interactions and Implications for Road Safety" (2017). Dissertations and Theses. Paper 3645.

https://doi.org/10.15760/etd.5529

This Dissertation is brought to you for free and open access. It has been accepted for inclusion in Dissertations and Theses by an authorized administrator of PDXScholar. Please contact us if we can make this document more accessible: pdxscholar@pdx.edu. 
Drivers' Attitudes and Behaviors Toward Bicyclists:

Intermodal Interactions and Implications for Road Safety

by

Tara Beth Goddard

A dissertation submitted in partial fulfillment of the requirements for the degree of

Doctor of Philosophy

in

Urban Studies

Dissertation Committee:
Jennifer Dill, Chair
Kelly Clifton
Christopher Monsere
Kimberly Barsamian Kahn

Portland State University 2017 
(C) 2017 Tara Beth Goddard 


\begin{abstract}
Road safety concerns are a legitimate concern when promoting increased bicycle use. Currently, bicyclist traffic fatalities and injuries present both a public health concern and a disincentive to people taking up or continuing to bicycle for transportation. Bicycling is not an inherently a dangerous activity; automobile drivers pose the most risk of harm in crashes with bicyclists. Despite that, drivers' attitudes and behaviors toward bicyclists have not enjoyed much systematic study, particularly in the United States. This research explored the dimensions of drivers' attitudes toward bicyclists, including implicit bias and social attitudes, and examined the relationships between these attitudes and drivers' self-reported behaviors. The online survey included a cognitive test of respondents' implicit preference between drivers and bicyclists. The research questions are detailed in the introduction, followed by a review of selected literature (Chapter 2) and detailed methodology (Chapter 3). The first set of results (Chapter 4) explores the potential usefulness of the implicit method and the attitude measures developed for this research, and presents an analysis of drivers' attitudes and what predicts more positive attitudes toward bicyclists. The second set of results (Chapter 5) extends the analysis to drivers' self-report behaviors, and how demographics, individual travel behavior, attitudes, and the built environment predict drivers' behaviors related to bicyclist safety. The dissertation concludes with a discussion of the contribution to the literature on driver attitudes and behaviors, and the implications for both practice and research.
\end{abstract}




\section{Dedication}

This dissertation is dedicated to my parents, for providing me with all the opportunities in the world; my sister for her support and, when needed, tough love; and my niece, for whom I wish the brightest and happiest future. 


\section{Acknowledgments}

I would like to thank my dissertation committee for their guidance and expertise, and for helping rein me in when I wanted to study all the things right now. Jennifer Dill has been the exact type of advisor I didn't even know I needed helping me navigate academia and be strategic about where to put my energy, while enthusiastically supporting my unorthodox approach to combining seemingly disparate approaches.

Funding during my academic career, and in particular for this dissertation, was generously provided by the Federal Highway Administration's Eisenhower Fellowship Program, the National Institute for Transportation and Communities, the Transportation Research and Education Center at Portland State, Portland State University's Institute for Sustainable Solutions, and several assistantships and scholarships.

I would not have made it through the challenges, nor as fully have enjoyed the opportunities (especially travel!), of a doctoral program without the friendship and mentorship of Arlie Adkins. My debt is immense, and I hope to pay it forward throughout my career. I'm also thankful for my "tribe" both inside and outside my academic life. Everyone should be so lucky to have friends like these. Final thanks to Bax, Smoky, Armando Christian Perez, Rachel Aviles, and most of all, my family. I love you. Thank you. 


\section{Table of Contents}

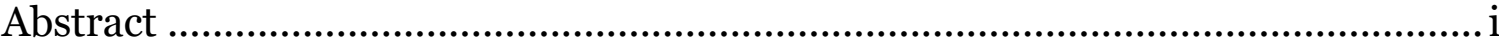

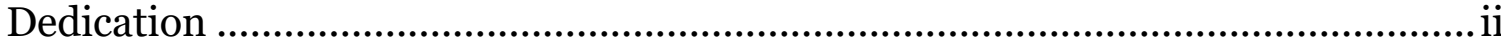

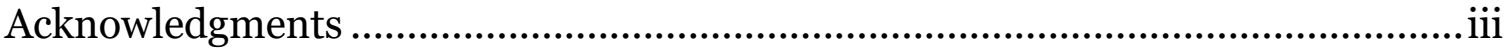

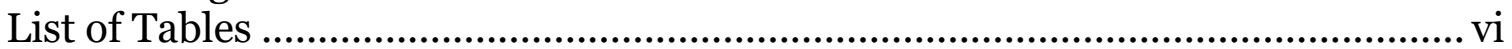

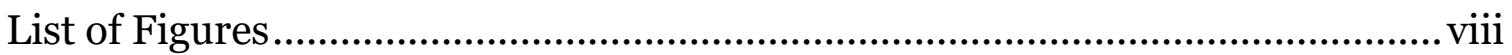

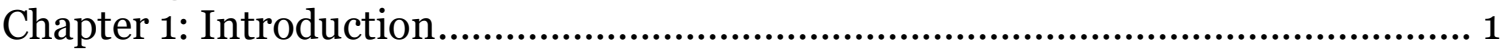

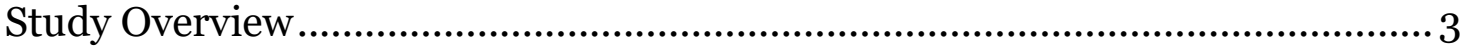

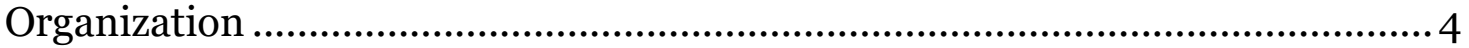

Research Questions and Hypotheses .................................................................. 4

Chapter 2: Literature review and conceptual model ............................................... 8

Understanding bicyclist safety ........................................................................

The social psychology of roadway interaction .....................................................11

Social psychology in the transportation context............................................... 12

The role of attitudes in roadway interactions .................................................. 12

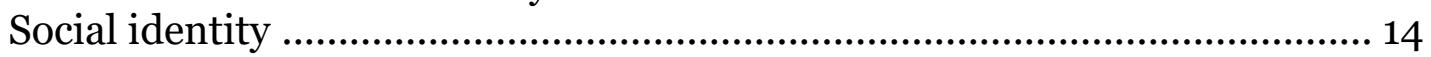

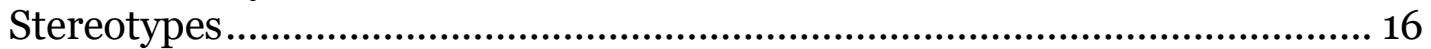

Social dominance and system justification .................................................... 16

The conceptual model of roadway interactions ................................................. 18

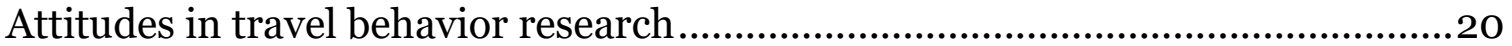

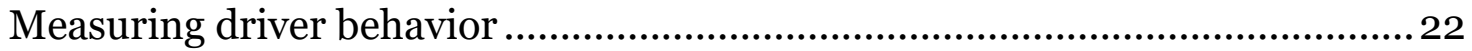

Measuring implicit attitudes .............................................................................2 23

Measuring the built environment and bicycle safety........................................26

Discussion ...................................................................................................... 27

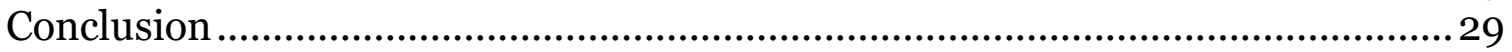

Chapter 3: Methodology ..................................................................................... 31

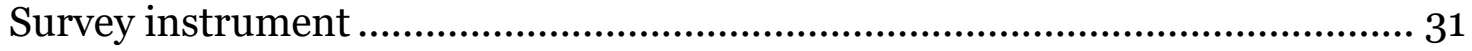

Implicit method ............................................................................................... 31

Explicit attitudes and behaviors ........................................................................ 37

Built environment measures .......................................................................40

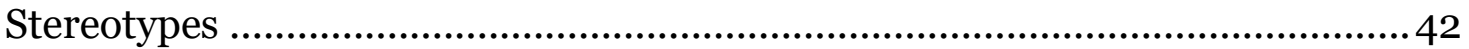

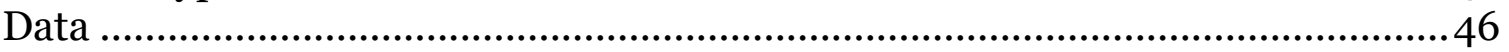

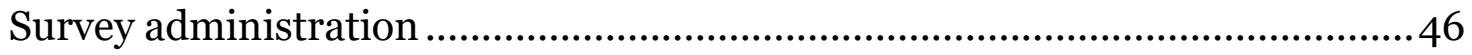

Population and sampling ……........................................................................ 47

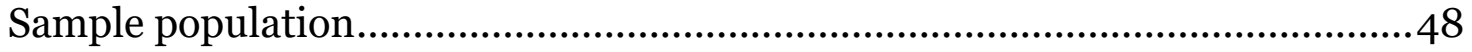

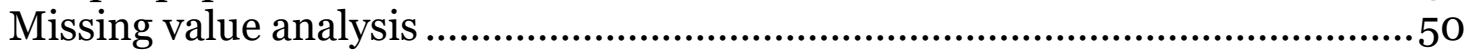

Individual travel behavior ..............................................................................50

Chapter 4: What are drivers' attitudes toward bicyclists as fellow roadway users,

and what predicts those attitudes? .................................................................... 52

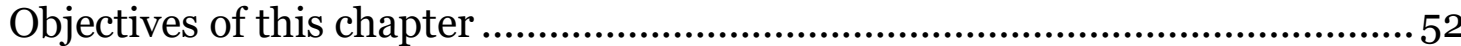

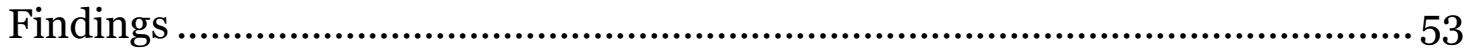

Descriptives.......................................................................................... 53

Association of Implicit Association Test score with demographics, explicit attitudes, travel behavior, and the built environment ...................................... 55

Drivers who bicycle - or not.......................................................................... 59 


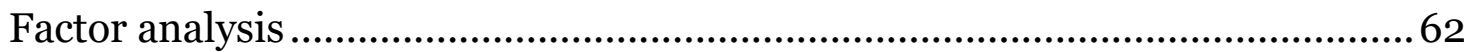

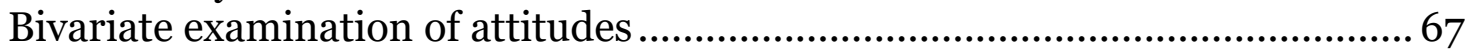

Regression models on explicit attitude scales.................................................. 84

Discussion of Chapter 4 Findings ................................................................. 99

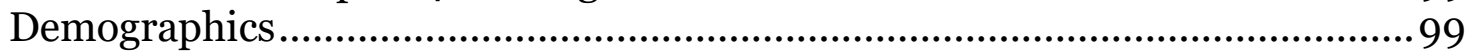

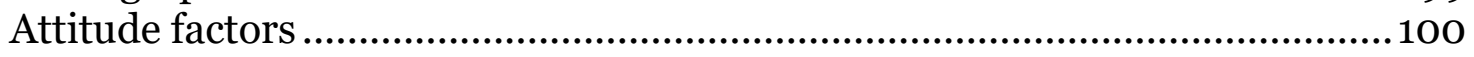

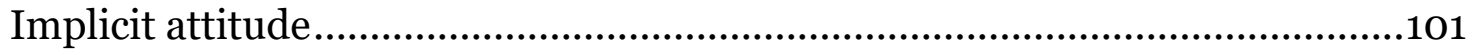

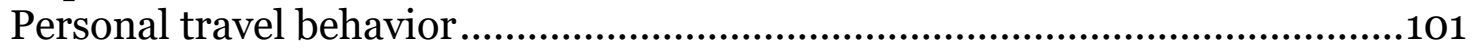

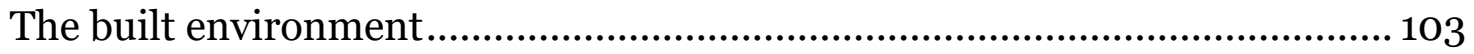

Chapter 5: Do drivers' attitudes toward bicyclists predict their behavior toward bicyclists? 104

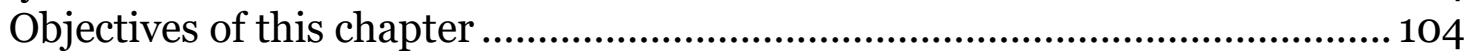

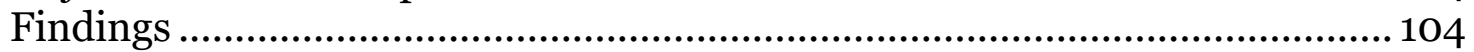

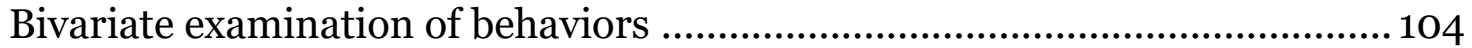

Regression models on behaviors ...................................................................119

Perceptual issues............................................................................................119

Pressure to overtake a bicyclist ........................................................................121

Expression of anger via honking, shouting, or gesturing ............................. 123

Checking for bicyclists before turning .......................................................... 125

Simplified models for comparison .................................................................127

Chapter 5 Results discussion............................................................................ 134

Chapter 6: Conclusion.....................................................................................137

Research Questions and Key Findings.............................................................137

Question 2: Do drivers' attitudes toward bicyclists predict their behavior toward bicyclists? ............................................................................................141

Implications for Practice .......................................................................... 147

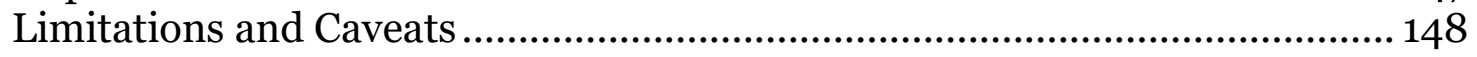

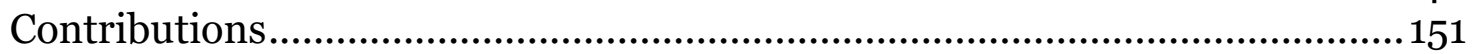

Directions for Future Research ......................................................................... 153

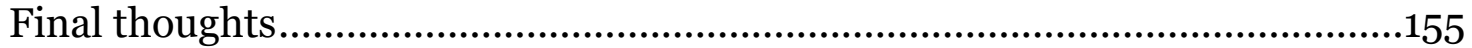

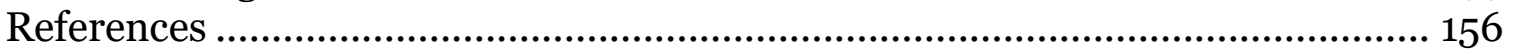

Appendix A: Survey instrument.................................................................. 171

Appendix B: Driver Attitude Questionnaire ....................................................... 192

Appendix C: Driver Behavior Questionnaire........................................................ 194 


\section{List of Tables}

Table 1. Dissertation Summary …………………….......................................

Table 2. Implicit Association Test concepts and attributes.................................33

Table 3 Schematic overview of the Implicit Association Test ............................34

Table 4 Summary of IAT Scoring Procedures Recommended by Greenwald et al.

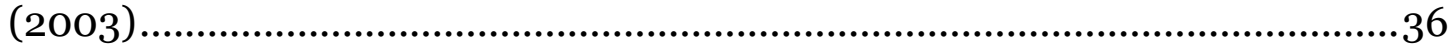

Table 5 Explicit attitude survey questions ........................................................38

Table 6 Behavior survey questions ....................................................................40

Table 7 EPA Smart Location Database selected BE measures ............................ 41

Table 8 Example answers from pre-test of bicyclist sub-types ..........................43

Table 9 Bicyclist sub-type silhouettes feeling thermometer ..............................44

Table 10 Attribute list for bicyclist sub-types ...................................................45

Table 11 Example qualitative responses about bicyclist sub-type attributes ...46

Table 12 Sample demographics compared to US national averages.................49

Table 13 Self-report travel characteristics ..........................................................50

Table 14 Descriptives for the implicit and explicit attitude measures ..............54

Table 15 Bivariate correlations of implicit attitude and demographics, explicit attitudes, travel behavior, and the built environment......................................... 57

Table 16. Attitude differences between driver-bicyclists and driver non-bicyclists

Table 17 Factors for identity and attitudes .....................................................63

Table 18 Explicit attitude measures.................................................................64

Table 19 Association of explicit and implicit attitudes .......................................67

Table 20 Association of attitudes and built environment measures..................72

Table 21 Bivariate analyses of the Driver Identity measure ................................ 77

Table 22 Bivariate analsyes of the System support measure ……………….....79

Table 23 Bivariate analyses of the Social norms measure.................................. 81

Table 24 Bivariate analsyes of the Road user legitimacy measure ...................83

Table 25 Regression model of Driver Identity................................................86

Table 26 Regression model of System Support ................................................. 88

Table 27 Regression model of Social Norms .....................................................90

Table 28 Regression model of Roadway Legitimacy ….....................................92 
Table 29 Attitude models, comparisons

Table 30 Bivariate correlations of behaviors and continuous independent

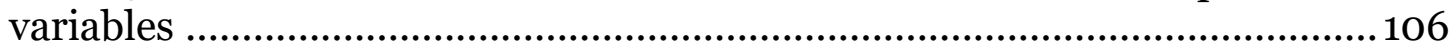

Table 31 Bivariate analyses of perceptual and performance skills...................112

Table 32 Bivariate analyses of pressure to overtake a bicyclist........................114

Table 33 Bivariate analyses of expressing frustration/anger toward a bicyclist116

Table 34 Bivariate analyses of not performaing a check for bicyclists before

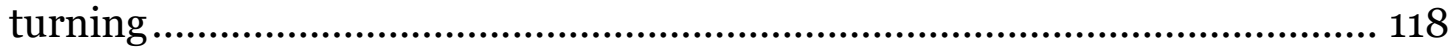

Table 35 Regression model for perceptual and performance issues............... 120

Table 36 Regression model for pressure to overtake ........................................ 122

Table 37 Regression model for expression of anger toward a bicyclist .......... 124

Table 38 Regresison model for checking for bicyclists before turning ........... 126

Table 39 Simplified regression models for comparison ................................... 128

Table 40 Summary of research questions and key findings ............................ 145 


\section{List of Figures}

Figure 1 Conceptual Model of Roadway Interactions......................................... 19

Figure 2 Implicit Association Test screen shot - instructions .............................34

Figure 3 Implicit Association Test screenshot - instructions part 2 ..................35

Figure 4 Implicit Association Test screenshot - Block 1......................................35

Figure 5 Map of Responses .........................................................................49

Figure 6 Distribution of implicit association test results .................................. 55

Figure 7 Driver Identity and Implicit Preference ...........................................58

Figure 8 Q-Q plot of the Driver Identity measure .............................................65

Figure 9 Q-Q plot of the system support measure .............................................65

Figure 10 Q-Q plot of the social norms measure ..............................................66

Figure 11 Q-Q plot of the road user legitimacy measure ....................................66

Figure 12 Relationship of implicit attitude and mean scores on the Driver Identity measure

Figure 13 Relationship of implicit attitude and mean scores on the system support measure...........................................................................................69

Figure 14 Relationship of implicit attitude and mean scores on the social norms measure .70

Figure 15 Relationship of implicit attitude and road user legitimacy measure 71 Figure 16 Relationship of implicit attitude and mean street network density 73

Figure 17 Relationship of implicit attitude and mean bicycle commute mode share

Figure 18 Relationship of Driver Identity measure and mean street network density

Figure 19 Relationship of system support measure and mean street network density

Figure 20 Relationship of system support and bicycle commute mode share 75

Figure 21 Relationship of social norms and bicycle commute mode share ......76

Figure 22 Conceptual relationships between explicit attitudes, demographics, travel behavior, the built environment, and implicit attitudes .85

Figure 23 Standardized residuals, Driver Identity regression model ...............87

Figure 24 Standardized residuals, System support regression model .............89

Figure 25 Standardized residuals, social norm regression model ................... 91 
Figure 26 Standardized residuals, road user legitimacy regression model .....93

Figure 27 Graph of standardized coefficients, Driver Identity model ..............95

Figure 28 Graph of standardized coefficients, system support model .............96

Figure 29 Graph of standardized coefficients, social norms model.................99

Figure 30 Graph of standardized coefficients, road user legitimacy model ....98

Figure 31 Relationship of implicit attitude and measure of perceptual and

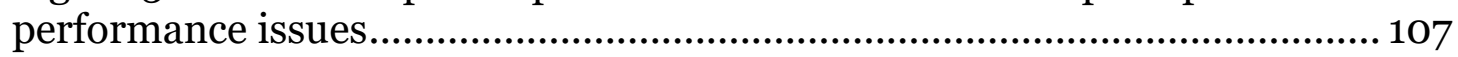

Figure 32 Relationship of implicit attitude and pressure to overtake a bicyclist108

Figure 33 Relationship of implicit attitude and expression of frustration or anger toward a bicyclist.. 109

Figure 34 Relationship of implicit attitude and not checking for bicyclists before

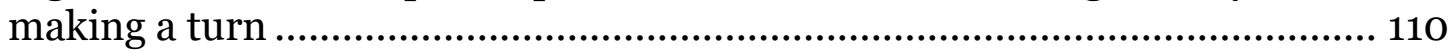

Figure 35 Graphical representation of perceptual issues model..................... 130

Figure 36 Graphical representation of pressure to overtake model ................131

Figure 37 Graphical representation of expressed anger model ...................... 132

Figure 38 Graphical representation of checking for bicyclists before turning model 133 


\section{Chapter 1: Introduction}

There is great interest in increasing bicycling for health and environmental reasons (Winters, Brauer, Setton, \& Teschke, 2010) but the overrepresentation of vulnerable road users in traffic injuries and deaths (Karsch, Hedlund, Tison, \& Leaf, 2012) represents a serious public safety issue. In 2014, 726 people were killed and 50,000 injured while bicycling (NHTSA, 2016), approximately double the share of traffic deaths that would be expected by bicycle mode share. Even as research into the role of infrastructure in bicyclist safety increases rapidly, the socially-imbued interactions between drivers and bicyclists have not enjoyed much systematic study, particularly in the United States. This reveals the need for a more comprehensive understanding what happens when drivers and bicyclists interact.

Road users came into conflict with each other long before the current era, perhaps even before the invention of the wheel. Whether on the rutted roads of ancient civilization or in the limited roadway space of more modern cities, traveling from one point to another has required humans to navigate around each other. Norms, customs, and the physical attributes of different forms of transport - carts, horses, bicycles, streetcars, cars, and so on - results in sometimes complex roadway hierarchies and competition for right of way. Due to the finite resources of space and time in the roadway, there have always been winners and losers in the negotiation of public roadways - often with fatal consequences As our transportation has become faster, larger, and more nimble, and our brains 
more cognitively taxed by the driving task in particular, old road safety problems persist (Elvik, 2010) and new ones arise (Daniels \& Risser, 2014). Consequently, the study of roadway users is not new (Hagenzieker, Commandeur, \& Bijleveld, 2014). Automobile drivers, because of their initial rapid increase in numbers, potential to cause harm, and effects on transportation generally, have been studied since at least the 1930s, at least in the realm of cognitive psychologists, who sought to understand the "visual and sensory requirements of automobile driving" (Groeger, 2002). Driving is so ubiquitous that researchers consider driving as an example of an "everyday cognition" - that is, one so commonplace, and at least partly automatic, that it is considered quotidian. The potentially injurious or fatal outcomes of negative roadway behavior, is anything but. The persistence and magnitude of these roadway problems, along with increased research into psychology, brought behavioral approaches into traffic safety research starting in earnest in the $1990 \mathrm{~s}$ (Hagenzieker et al., 2014), with a special issue on "traffic psychology" first appearing in 1994 and the first conference focused solely on traffic psychology first held in 2000 (Rothengatter \& Huguenin, 2004).

The inclusion of social psychology in travel behavior research has largely focused on how social cognitions, particularly attitudes, affect mode choice (Van Acker, Van Wee, \& Witlox, 2010) and driver behaviors like speeding. The role of attitudes in interactions between roadway users, however, is relatively rare in existing research. As is widely accepted in the social psychology field, attitudes may also have subconscious components that are subject to bias when measured 
with traditional transportation survey self-report methods (Hatfield, Fernandes, Faunce, \& Job, 2008). Using alternative methods to measure these potentiallybiased responses, particularly subconscious attitudes, is a nascent field but one that is increasingly showing promise (Fulcher, Parkhurst, Alford, \& Musselwhite, 2014).

This research incorporated several established social psychological concepts and applied them to interactions between roadway users. It introduced a conceptual model of roadway interactions as a framework for understanding the potential impacts and interactions of physical, individual, and sociocultural factors on the interactions of drivers and bicyclists. This model suggests that explicit or implicit biases, both at the individual and system level, might help explain the increased perceptions and realities of danger for bicyclists. Implicit bias between drivers and bicyclists was tested via a cognitive test, a well-established tool for measuring bias that had not previously been applied to roadway users.

\section{Study Overview}

This research explored drivers' attitudes and behaviors toward bicyclists. A survey of drivers across the United States was used to explore the dimensions of drivers' attitudes toward bicyclists, including implicit bias and stereotypes, and examine the relationships between these attitudes and drivers' self-reported behaviors. The online survey included a cognitive test of respondents' implicit preference between drivers and bicyclists. The survey was hosted a public site on implicit bias and respondents were randomly assigned from visitors to the site. The survey was available for six weeks, resulting in a final sample of 676 frequent 
drivers. Survey measures were collected for attitudes, behaviors, demographics, individual travel behavior, home zip code, and implicit bias. The data provided novel information about specific social psychological constructs that may provide insight into improving roadway interactions, both qualitatively and for safety.

\section{Organization}

This dissertation examined three related but distinct research questions. The over-arching goal was to explore drivers' attitudes toward bicyclists using theories and methods from the social psychological science of intergroup relations. A conceptual model of roadway interactions synthesizes these theories (Chapter 2), which guided the development of a survey instrument that included both an implicit method and novel explicit survey measures of driver attitudes (Chapter 3). Analyses examined drivers' explicit and implicit attitudes and what predicts them (Chapter 4), and modelled the relationships of drivers' attitudes and self-report behaviors with a focus on safety-related behaviors (Chapter 5). The final section (Chapter 6) discusses how the findings from chapters 4 and 5 contribute to the literature on driver attitudes and behaviors, and the implications for both practice and research. The questions and hypotheses are described in detail below.

\section{Research Questions and Hypotheses}

Chapter 4: What are drivers' attitudes toward bicyclists as fellow roadway users, and what predicts those attitudes?

1. Can drivers' implicit attitudes toward bicyclists be measured?

2. How are drivers' explicit and implicit attitudes related? 
3. Does measuring drivers' implicit attitudes add value to traditional survey methods?

4. What are drivers' explicit (i.e. self-report) attitudes about bicyclists as fellow roadway users?

5. How do demographic, driving frequency, implicit attitude, and built environment characteristics predict attitudes toward bicyclists?

6. Does personal experience as a bicyclist predict drivers' attitudes toward bicyclists?

Chapter 5: Do drivers' attitudes toward bicyclists predict their behavior toward bicyclists?

1. What are drivers' behaviors when interacting with bicyclists?

2. How do drivers' explicit attitudes toward bicyclists affect their selfreported behaviors?

3. Does an implicit measurement of drivers' attitudes explain additional variance in drivers' behaviors?

4. What are the predictors of negative safety-related behaviors toward bicyclists?

For the research questions in Chapter 4, I hypothesized that it would be possible to measure an implicit bias between drivers and bicyclists, and that many people would strong preference for drivers over bicyclists. Consistent with implicit bias in other areas, I hypothesized that implicit attitude would be related, but distinct from explicit attitudes; that is, I hypothesized that drivers with negative explicit attitudes would have negative implicit attitudes, but that some people would hold inconsistent attitudes and traditional survey-style questions would not be a perfect predictor of implicit bias. Additionally, I hypothesized that drivers would hold attitudes that would be consistent with social psychological theories of intergroup relations; that attitudes would differ based on sociodemographic 
characteristics, particularly age and gender, road characteristics, and implicit biases; and that personal experience would predict more positive behaviors, but riding only for recreation would not have the same moderating affect as riding for transportation purposes. For Chapter 5, my hypotheses were that drivers would report concerns and difficulties in maneuvering around bicyclists; that negative social attitudes would predict negative behaviors like expressing anger toward bicyclists; that implicit attitude would predict additional variance in behaviors related to automobile dominance of the road; and that trip purpose as a bicyclist would have similar relationship with behaviors as I hypothesized in Chapter 4 . 
Table 1. Dissertation Summary

\begin{tabular}{|c|c|c|c|}
\hline & Chapter $4 a$ & Chapter $4 \mathrm{~b}$ & Chapter 5 \\
\hline $\begin{array}{l}\text { Research } \\
\text { questions }\end{array}$ & $\begin{array}{l}\text { 1. Can drivers' } \\
\text { implicit attitudes } \\
\text { toward bicyclists be } \\
\text { measured? } \\
\text { 2. How are drivers' } \\
\text { explicit and implicit } \\
\text { attitudes related? } \\
\text { 3. Does measuring } \\
\text { drivers' implicit } \\
\text { attitudes add value } \\
\text { to traditional survey } \\
\text { methods? }\end{array}$ & $\begin{array}{l}\text { 1. What are drivers' } \\
\text { explicit (i.e. self-report) } \\
\text { attitudes about bicyclists } \\
\text { as fellow roadway users? } \\
\text { 2. How do demographic, } \\
\text { driving frequency, } \\
\text { implicit attitude, and } \\
\text { built environment } \\
\text { characteristics predict } \\
\text { attitudes toward } \\
\text { bicyclists? } \\
\text { 3. Does personal } \\
\text { experience as a bicyclist } \\
\text { predict drivers' attitudes } \\
\text { toward bicyclists? }\end{array}$ & $\begin{array}{l}\text { 1. What are drivers' self-report } \\
\text { behaviors when interacting } \\
\text { with bicyclists? } \\
\text { 2. How do drivers' explicit } \\
\text { attitudes toward bicyclists } \\
\text { affect their self-reported } \\
\text { behaviors? } \\
\text { 3. Does an implicit } \\
\text { measurement of drivers' } \\
\text { attitudes explain additional } \\
\text { variance in drivers' behaviors? } \\
\text { 4. What are the predictors of } \\
\text { negative safety-related } \\
\text { behaviors toward bicyclists? }\end{array}$ \\
\hline Data & $\begin{array}{l}\text { IAT d score; explicit } \\
\text { attitudes; individual } \\
\text { travel behavior }\end{array}$ & $\begin{array}{l}\text { IAT d score; explicit } \\
\text { attitudes; individual } \\
\text { travel behavior; BE }\end{array}$ & $\begin{array}{l}\text { IAT d score; explicit attitudes; } \\
\text { individual travel behavior; BE } \\
\text { measures; roadway behaviors }\end{array}$ \\
\hline Analysis & $\begin{array}{l}\text { Chi-square; } \\
\text { bivariate } \\
\text { correlation; ANOVA }\end{array}$ & $\begin{array}{l}\text { ANOVA; linear } \\
\text { regression }\end{array}$ & $\begin{array}{l}\text { ANOVA; linear regression; } \\
\text { logistic regression }\end{array}$ \\
\hline $\begin{array}{l}\text { Key } \\
\text { findings }\end{array}$ & $\begin{array}{l}\text { 1. It is possible to } \\
\text { measure an implicit } \\
\text { preference for } \\
\text { drivers or bicyclists. } \\
\text { 2. Implicit attitudes } \\
\text { toward bicyclists are } \\
\text { related to, but } \\
\text { distinct from, } \\
\text { consciously-held } \\
\text { attitudes toward } \\
\text { bicyclists. }\end{array}$ & $\begin{array}{l}\text { 3. Drivers attitudes } \\
\text { toward bicyclists can be } \\
\text { understood through } \\
\text { social psychological } \\
\text { theories of intergroup } \\
\text { relations. } \\
\text { 4. Implicit bias provides } \\
\text { additional explanatory } \\
\text { power in prediction of } \\
\text { these intergroup } \\
\text { attitudes, even after } \\
\text { controlling for } \\
\text { sociodemographics, } \\
\text { individual travel } \\
\text { behavior, and the built } \\
\text { environment. } \\
\text { 5. Only people who } \\
\text { bicycled for } \\
\text { transportation, not } \\
\text { recreation, were less } \\
\text { likely to justify the auto- } \\
\text { dominant system. } \\
\text { 6. Only weekly bicycling, } \\
\text { of the individual bicycling } \\
\text { behaviors, predicting } \\
\text { lower agreement that } \\
\text { bicyclists should register, } \\
\text { pay specific taxes, and be } \\
\text { licensed like drivers. }\end{array}$ & $\begin{array}{l}\text { 7. Social cognitions help } \\
\text { predict drivers' self-report } \\
\text { behaviors when interacting } \\
\text { with bicyclists, including } \\
\text { safety-relevant behaviors. } 8 \text {. } \\
\text { Personal experience as a } \\
\text { bicyclist often improved both } \\
\text { attitudes and behaviors toward } \\
\text { bicyclists. } \\
\text { 9. Bicycling trip purpose was } \\
\text { relevant to which attitudes and } \\
\text { behaviors were moderated by } \\
\text { personal experience. } \\
\text { 10. The perceived pressure to } \\
\text { overtake a bicyclist who is } \\
\text { going slowly is widely felt by } \\
\text { drivers, and not related to } \\
\text { personal travel behavior, the } \\
\text { built environment, or most } \\
\text { sociodemographics. } \\
\text { 11. Implicit bias against } \\
\text { bicyclists helped predict a lack } \\
\text { of checking for bicyclists even } \\
\text { after controlling for explicit } \\
\text { attitudes. }\end{array}$ \\
\hline
\end{tabular}




\section{Chapter 2: Literature review and conceptual model}

\section{Understanding bicyclist safety}

Road safety concerns are a legitimate concern when promoting increased bicycle use (J. P. Schepers \& Heinen, 2013). Bicycle planners and engineers need to incorporate injury prevention approaches so the benefits of increased bicycle use are not undone by increases in injury (Pollack et al., 2012). While there has been a relative proliferation in bicycle-related research in recent years, there is still a need for better data (Nordback, Marshall, \& Janson, 2014) and an evidence base for interventions that effectively and safely provide comfortable bicycling environments (Pollack et al., 2012). There is also a need for theoretical foundations and conceptual frameworks that simultaneously consider bicyclingspecific travel behavior (e.g. mode choice) and safety (e.g. crash risk) (P. Schepers, Hagenzieker, Methorst, van Wee, \& Wegman, 2014). Vulnerable road users (pedestrians, bicyclists, motorcyclists) comprise nearly half (46 percent) of traffic fatalities worldwide and the majority of severe traffic injuries and fatalities in large cities, despite their relatively small mode share, while car occupants, the dominant mode, represent fewer than 10 percent of fatalities (Shinar, 2012). In the United States, bicyclists are 12 times more likely to be killed in a traffic crash than people in cars (Pucher and Dijkstra, 2003). Bicycling is not, however, an inherently dangerous activity. Drivers represent the greatest danger to bicyclists, particularly where traffic speeds are high (Siman- 
Tov et al., 2012). Bicyclists in an automobile-involved collision are over three times as likely to suffer a serious injury (Rivara et al., 1997) and significantly more likely to suffer a traumatic brain injury (Juhra et al., 2012) than bicyclists in non-automobile-involved crashes. Crashes between drivers and bicyclists are frequently attributed to a driver's failure to see a bicyclist, due to inattention or "Looked but failed to see (LBFTS)" (Wood et al., 2009), and there is ample evidence from psychology that "seeing" is not purely objective but is influenced by socially directed thoughts and beliefs (Mack and Rock, 1998).

Existing research into the crash causation of bicycling traffic deaths has focused primarily on instrumental factors like intersection design or helmet use but little research has probed the role of attitudes or socio-cognitive mechanisms in interactions between roadway users (Musselwhite et al., 2010). It is a widely held, but incorrect, view that driving is mainly a perceptual-motor skill (Groeger, 2002), wherein people perceive everything in their environment and then merely need to respond accordingly by physically operating the vehicle. In reality, people do not attend to or process all information in their environment (Mack and Rock, 1998). Since much information processing is automatic, attitudes and biases can subconsciously affect how people attend to and process information (Ajzen and Fishbein, 2000). When humans interact, brain activity called "socio-cognitive processing" is automatically invoked, and research shows that interacting with bicyclists puts additional cognitive demands on drivers, in addition to the perceptual and motor skills involved in operating a vehicle (Walker, 2005). As humans have been shown to rely on social information in many other domains, 
particularly under time or cognitive constraints, it is likely that social judgments affect roadway interactions.

There is evidence that drivers do not treat all road users equally. The visible "humanness" of vulnerable road users, in particular, triggers automatic and involuntary (i.e. implicit) cognitions and processes (Walker, 2005). While the physical bodywork of a car essentially anonymizes drivers, bicyclists are visible in their variety of shapes, sizes, ages, gender, and "racialized bodies" (Urry, 2007, p. 48). Drivers have shown bias in yielding behavior by the race, apparent disabled status, or age of a crossing pedestrian (Goddard et al., 2015; Harrell, 1992; Rosenbloom and Nemrodov, 2006), while drivers in higher status cars were less likely to yield to a pedestrian (Piff et al., 2012). When interacting with bicyclists, drivers used greater passing distance when the bicyclist was unhelmeted or appeared female (Walker, 2007).

Although none of these studies tested drivers' attitudes or biases directly, it is clear that, all else being equal, drivers make conscious or subconscious decisions about how to behave around other roadway users based on visible features that have socially constructed importance. Furthermore, the bodywork of a car provides anonymity to drivers that acts as a social shield from behind which discrimination can be enacted with low chance of social reprisal (Urry, 2007). Considering the complexity of the roadway environment, visible humanness of bicyclists and anonymity of drivers, and disproportionate ability of automobiles to cause harm, it is important to understand the additive or multiplicative contributions of these factors to the experience and safety of bicyclists. 
In his foundational text Mobilities, the sociologist John Urry states that a "[mobility] turn is spreading in and through the social sciences, mobilizing analyses that have been historically static, fixed, and concerned with predominantly a-spatial 'social structures' " (Urry, 2007, p. 6). The corollary is also needed: to move away from a-social spatial approaches and incorporate tools from the social sciences. A practical approach to bicycle planning and promotion must include "the social dimensions and tacit meanings people make" about their everyday travel (Vivanco, 2013, p. 10). While anthropology and sociology provide valuable processes for understanding the roadway at the historical and sociostructural and systemic level, social psychological theories, methods, and empirical evidence provide useful tools for understanding these interpersonal and intergroup behaviors in roadway interactions.

\section{The social psychology of roadway interactions}

There is a need for more theoretical analysis of the social psychological aspects of travel behavior in general (van Acker et al., 2010). Transportation psychologists study the symbolic and affective factors of these interactions, but the literature on the social aspects of interactions between users of different modes is sparse. The following sections describe some key social psychological concepts and theories relevant to roadway interactions, including those most relevant for understanding potential impacts of bias in roadway interactions. Next, those concepts and theories are brought together in a conceptual model that provides graphical representation of the interrelationships of the social psychological concepts and theories. 


\section{Social psychology in the transportation context}

Social psychology explores the ways that an individual's thoughts, feelings, and behaviors are influenced by the real or imagined presence of others (Allport, 1994). Put another way, social psychology is the study of the individual embedded in the social context (Baumeister, 2008). Social psychological research demonstrates that behavior has both reasoned and unreasoned components, while social psychological theories can help operationalize perceptions, attitudes, and preferences (Van Acker et al., 2010).

A primary focus of social psychology is the attitude construct, which describes organization of often-enduring beliefs, evaluations of, and behavior toward objects, groups, or events (Ajzen and Fishbein, 2000). How humans perceive the world and respond to stimuli is not purely objective, but rather is affected by our attitudes (Fazio, 1990). Although attitudes are recognized in transportation research and planning as important to reasoned behaviors like mode choice, their potential effects on interpersonal roadway behaviors is not well-studied. Even less well-understood or researched is the role that subconscious attitudes may play, particularly in the complex, high-cognitive load environment of the roadway.

\section{The role of attitudes in roadway interactions}

Attitudes may help explain the interpersonal interactions between users of different modes (Goddard, 2016). Attitudes are a "disposition to respond favorably or unfavorably to an objection, person, institution, or event” (Ajzen, 2005, pg. 3). Attitudes have explicit and implicit components, which are related but distinct 
(Greenwald \& Banaji, 1995). Implicit attitudes reflect a person's expectation or evaluation of a person or situation based on previous experiences, stereotypes, or other affective evaluation, and the impact of those previous experiences are not known to the individual to be influencing their attitude to the current object or experience, and are not accessible for self-reporting or conscious awareness (Greenwald and Banaji, 1995). By definition, people are unaware that these implicit cognitions are influencing their response to the current situation (Greenwald \& Banaji, 1995). Explicit attitudes, by contrast, are available for selfreport (Ajzen, 2005). E Even if an individual chooses to give a socially acceptable answer that may be different than how they actually feel, they are, by definition, aware of their explicit attitudes.

Research on implicit attitudes is extensive (Nosek et al., 2007). In their 2013 book Blind Spot: Hidden Biases of Good People, Banaji and Greenwald share results from their decades of work on measuring implicit biases. As indicated by the title, many people truly want to believe they are egalitarian, but research shows that even people with explicit egalitarian beliefs display implicit biases and biased behavior (Banaji and Greenwald, 2013). All people hold stereotypes of one sort or another (Nosek et al., 2007), which likely manifest in roadway behavior as they do in a multitude of other domains, including interpersonal interactions in the workplace, shopping, healthcare, and policing (Dovidio, 2001; Dovidio et al., 2002; Hebl et al., 2002; Kahn and Davies, 2011). Drivers, those with the most power to harm or discourage bicyclists, are likely to be affected consciously or subconsciously by their biases, and the characteristics of the roadway 
environment may facilitate the enactment of negative, and potentially fatal, biases.

These negative attitudes neither develop nor exist in a vacuum. Social psychological theories, methods, and empirical evidence provide useful tools for understanding these interpersonal and intergroup behaviors in roadway interactions. The concepts of social identity, stereotypes, social dominance, system justification, and culture can help explain how these negative attitudes arise and are enacted, and how they may contribute to negative roadway interactions.

\section{Social identity}

The primary tenet of Social Identity Theory is that social behavior is explainable through intergroup behavior, and one outcome of relating through group membership is that humans are motivated to view their own group (the "ingroup") positively, while associating negative attributes with other groups (the “out-group”) (Tajfel and Turner, 2004). Group membership increases identification with the in-group and perceived competition with the out-group. We see evidence of this in drivers' positive views of the rule- following behavior of other drivers, and the negative views of bicyclists' rule-following (Goddard et al., 2016), despite evidence that bicyclists may be even more law-abiding than drivers (Thompson, 2015).

The specific characteristics of the roadway environment may move interactions further toward this "intergroup" end of the spectrum: the physical separation of the car removes the necessity to observe face-to-face etiquette (Urry, 2007), while 
bicyclists' social identities (i.e. group memberships), may be highly visible. In a study probing drivers' view of other roadway users, participants described people in cars in "object-based" language (e.g. car, traffic, it) but described people walking or using bicycles in "human-based" language (e.g. bicyclist, pedestrian, person, they) (Walker, 2005). This visible humanness of vulnerable roadway users may make social identities salient (Steinbach et al., 2011). Travel mode affects people's perceptions of their environment, particularly when the situation is ambiguous or social cues are unclear (Gatersleben et al., 2013).

The misidentification of visual cues may lead to more socially construed, and potentially incorrect, evaluations of other roadway users. When asked to evaluate a simulated interaction of kids on a playground from the perspective of a passing pedestrian or driver, Gatersleben et al. found that respondents who viewed the scene from the perspective of a driver were the most likely to rate the interaction as negative or threatening, while respondents who viewed the video as though they were pedestrians evaluated the playground interaction as positive and judged the kids to be engaged in play (Gatersleben et al., 2013). This suggests a roadway-specific intersectionality, in which mode and social cognitions interact. We do not perceive ourselves, or each other, to be just one thing; rather, our multiple identities intersect and can be cumulative (Purdie-vaughns and Eibach, 2008). To consider the intersectionality of mode and social identities, in particular, it is necessary to understand how stereotypes play a role in intergroup relations. 


\section{Stereotypes}

Stereotypes are positive or negative evaluations of an entire group, and are a normal (if often problematic) way for humans to give order to our world. People attribute a set of characteristics (good or bad) to all members of a group solely based on group membership (Fiske et al., 2002). This concept is well-understood from a modal standpoint, where media or pop culture portrayals of bicyclists are often reductionist and othering (Basford et al., 2002). Unfortunately, stereotypes are usually more negative than positive (Banaji and Greenwald, 2013). Negative racial attitudes, even subconscious ones, can cause people to avoid contact with people of color, use less eye contact or fewer words in an interaction (and thus appear unwelcoming or hostile), and enact microaggressions, often without being aware of their behavior. This aversive behavior more often arises among people who do not want to believe that they hold any implicit racial bias, and fear being seen as racist, hence their "aversion" to being in a potentially uncomfortable situation and their guarded and shortened interactions (Dovidio et al., 2002). In the context of roadway interactions, the avoidance of eye contact or an aversion to interaction could lead to potentially miscommunicated intentions and unintended, unsafe behaviors.

\section{Social dominance and system justification}

Group membership happens at the system level as well as the individual level. Across all cultures, humans organize into "group-based social hierarchies" in which dominant groups have privileged access to resources (Pratto et al., 2006). Social Dominance Theory describes the discriminatory effects of this privilege at 
the institutional, individual, and intergroup levels. The more legitimate a system is perceived to be, the greater in-group favoritism and out-group discrimination that dominant users will display (Pratto et al., 2006). Our automobile system, although less than a century old, is inarguably the dominant mode. The automobile is considered the default mode in much of the Western world, as evidenced by mode share and even the term "alternative transportation" applied to bicycling and walking. One distinguishing characteristic of social dominance is that "the degree of lethality ... is often orders of magnitude greater" by the dominant group toward the subordinate group (Pratto et al., 2006, p. 3). As discussed earlier, the roadway environment has a high degree of lethality: automobiles are a leading cause of preventable death (Pollack et al., 2012). Considering the many subordinate groups in the automobile-dominant system, one might expect more resistance to the existing system. According to System Justification Theory (SJT), however, sometimes subordinate group members will justify the dominant system, even when it goes against their own interests (Jost et al., 2004). As negative is the automobile on the system level, at the individual household level it still represents a convenient, autonomous, status-conferring option (Handy et al., 2005). At the individual level, this suggests that drivers might view bicyclists as not just a momentary annoyance, but a threat to their social identity as a driver, and the system that both creates and requires that identity.

Social Dominance Theory and System Justification Theory can thus contribute to critical approaches to road safety by understanding different road user types (i.e. 
modes) as delineating dominant and subordinate groups that compete for resources.

\section{The conceptual model of roadway interactions}

Synthesizing the social psychological theories above and applying them to the roadway environment yields a tripartite structure that considers the sociocultural context, the physical environment, and the individual (Figure 1). These three macro structures are found in the conceptual model of travel behavior advanced by van Acker et al. (2010), but here they are conceptualized as adjacent and overlapping, rather than nested, structures. There are contributions to roadway interactions that may be unique to one structure and other factors where any two structures overlap. The central space of this diagram describes the context in which a roadway interaction occurs. The salience and relative strength of any one or several of the contributing factors predicts whether that roadway interaction is civil or negative, whether roadway users behave safely toward each other or not, whether the environment separates users or facilitates safe and courteous behavior, whether users are attentive to the task and physically and mentally capable of safe roadway interactions, whether an individual's beliefs about other road users or their own right to the system affects their behavior, and even what infrastructure is being constructed.

The expansion of the theoretical constructs in this conceptual model not already discussed above is outside the scope of this chapter. For a thorough examination of automobility and roadway culture, refer to Urry (2007) and Furness (2010). 
For discussion of the way that decisions about public investment in facilities are both physical and sociocultural, refer to Incomplete Streets (Zavestoski and Agyeman, 2014).

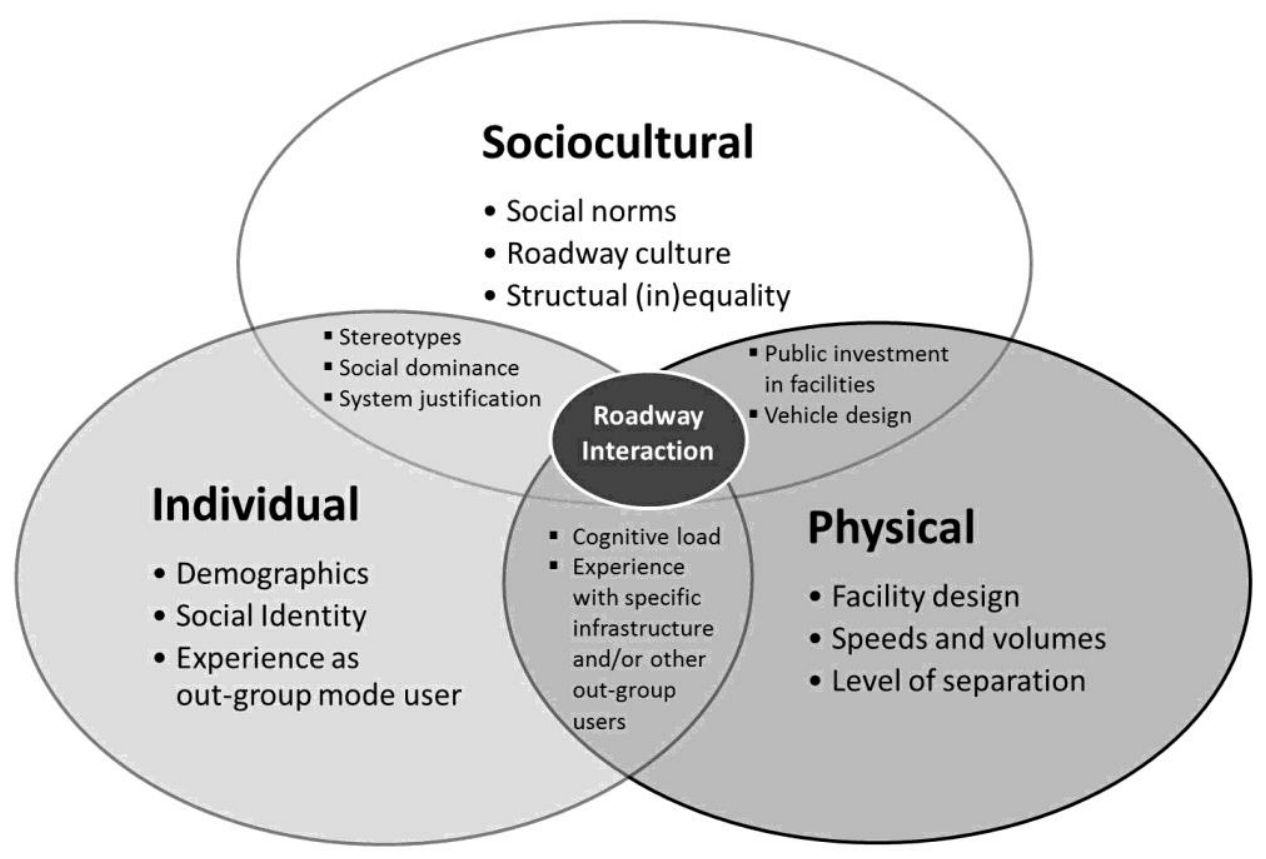

\section{Figure 1 Conceptual Model of Roadway Interactions}

Making use of safety frameworks is most effective with robust data. Having made the case for the importance of attitudes and behavior research in understand road user interactions, the next step is determining the most effective and efficient way to measure them. The next section focuses on the collection of implicit and explicit attitudes and self-reported driving behaviors. 


\section{Attitudes in travel behavior research}

Attitudes related to transportation, particularly whether those attitudes affect mode choice, have been a topic of interest in travel behavior research for more than a decade (Heinen, 2016). There are a variety of tools available for measuring attitudes, using both explicit and implicit methods or approaches. Explicit methods are already in common use in travel behavior attitude research, with surveys comprising the majority of those methods (Dillman, 2000). Surveys are easier and usually cheaper to administer (relative to sample size) than other methods, but rely on careful survey design and self-report data, which can be plagued by recall issues or social desirability biases (Fazio \& Olson, 2003). There are qualitative tools which, although they still rely on explicit (i.e. consciously accessible) responses, may offer more nuanced data. For example, Murtagh et al used the Twenty Statements Test to explore identity related to travel behavior (Murtagh, Gatersleben, \& Uzzell, 2012). This is a more indirect way to study attitudes, but still requires conscious and potentially-regulated responses. In recent years, a key social psychological theory on the role of attitudes and intentions in deliberate, conscious behaviors has been applied in travel behavior (Rowe et al., 2016). The Theory of Planned Behavior (TPB) posits that intentions moderate attitudes, subjective norms, and perceived behavioral control in determining behavior (Ajzen, 2014). The TPB has been used in transportationrelated research on mode choice (Collum \& Daigle, 2015; Gardner \& Abraham, 2008), traffic safety culture (Coogan, Campbell, Adler, \& Forward, 2014; Gehlert, Hagemeister, \& Özkan, 2014), pedestrian distraction, crossing behaviors and 
risk-taking distracted pedestrians (Barton, Kologi, \& Siron, 2016; Holland \& Hill, 2007; Zhou \& Horrey, 2010), and driver speeding and risk-taking (Musselwhite, Avineri, \& Susilo, 2014; Otto, Ward, Swinford, \& Linkenbach, 2014; Rowe et al., 2016). By definition, however, the TPB explains consciously-made "planned" behaviors, and is not directly applicable to behaviors that are reactive, that are made without forethought, happen with a high degree of automaticity, and which may also be guided by subconscious attitudes (Fazio, 1990).

Attitudes between roadway users have not enjoyed much systematic attention, particularly in the United States. Existing research largely focuses on drivermotorcyclist interactions. Potentially relevant to bicyclists as another type of vulnerable road user, studies have shown that personal experience as a motorcyclist improves attitudes and understanding of motorcyclist behavior (Haworth, 2012; Haworth et al., 2014; Rakotonirainy, Haworth, Darvell, Wilson, \& Haines, 2012). Similar results were found in a study of driver attitudes toward motorcyclists in the UK (Crundall, Bibby, Clarke, Ward, \& Bartle, 2008) and a study of drivers' attitudes toward "equine road users" (Chapman \& Musselwhite, 2011).

Few previous studies have examined attitudes toward drivers and bicyclists as roadway users, or the social norms, stereotypes, and social identity associated with mode (Gatersleben \& Haddad, 2010). The UK motorcyclist and equestrian studies reported drivers' concerns about vulnerable road user unpredictability, vulnerability, and law-breaking, all of which echo concerns voiced by drivers 
about bicyclists in previous research (Basford, Reid, Lester, Thomson, \& Tolmie, 2002; Gatersleben \& Haddad, 2010; Monsere et al., 2014).

A recent study of protected bikeway infrastructure in five US cities included questions on the courtesy, predictability, and law-abidingness of drivers, bicyclists, and pedestrians. They found that residents (who drove for most trips) were negative toward drivers, pedestrians, and bicyclists, but were significantly more negative toward bicyclists (Monsere et al., 2014). A survey of citizens in the UK probed respondents' attitudes about the behaviors, motivations, background, and personality they attribute to the "typical cyclist" (Gatersleben \& Haddad, 2010). In that study, perceiving bicyclists as "normal" people using a bicycle for everyday tasks was associated with respondents' own use of a bicycle, while respondents who did not bicycle viewed bicycling as more of a lifestyle choice.

\section{Measuring driver behavior}

Due to logistical, technological, and ethical issues, much research into driver behavior relies on drivers' self-reported behaviors. The most widely-used tool is the Driver Behavior Questionnaire (DBQ), first advanced by Reason, Manstead, Stradling, Baxter, \& Campbell (1990). Respondents indicated how often they commit various violations and errors on a six-point scale (never to nearly always). The commonly used DBQ includes only one bicyclist-related question and one pedestrian-related question: [how often do you:] "on turning right, nearly hit a cyclist who has come up on your inside" and "fail to notice that pedestrians are crossing when turning into a side street from a main road", 
respectively. Like any self-report measure, the DBQ is subject to concerns about social desirability biases. Despite this, the DBQ has repeatedly been validated as a reasonably accurate scale of driver self-reported driving errors, lapses, and violations with predictive validity for drivers' crash risk (Lajunen, Parker, \& Summala, 2004).

\section{Measuring implicit attitudes}

Fazio and Olson (2003) demonstrated that only methods are definitively implicit, rather than the attitude (or other construct). That is, an attitude may or may not be consciously accessible to the individual, but the method of measuring that attitude is done without the individual knowing that the attitude is being measured. Implicit methods explore these attitudes that are below conscious awareness(Fazio \& Olson, 2003). Even on issues where there is little social desirability effect and explicit measures can be expected to be valid, implicit methods measure related but distinct cognitions(Greenwald, Poehlman, Uhlmann, \& Banaji, 2009).

Implicit methods have enjoyed use in psychology for decades, but only recently have travel behavior researchers started to see the use of implicit methods to get around problems of social desirability and recall bias in self-report measures of driver behavior, particularly driver aggression and speeding (af Wåhlberg, 2010). In their 2014 review of implicit data collection methods in driver behavior research, Fulcher et al report that only a handful of studies have used implicit methods in driver behavior research, but implicit methods can be a valuable addition to research methods in travel behavior research (Fulcher et al., 2014). 
The most widely used implicit method is the Implicit Association Test (IAT), developed by researchers at Harvard and first published in 1998 (Greenwald, Mcghee, \& Schwartz, 1998). The IAT is a sorting task that uses response latencies to estimate respondents' associations between concepts and attributes (Nosek, Greenwald, \& Banaji, 2005). The underlying assumption is that concepts and attributes that are more closely associated in the mind will be sorted faster (Greenwald et al., 1998). By testing these associations with response latencies, the IAT measures subconscious attitudes and removes social desirability bias from self-reported measures (Greenwald, Nosek, \& Banaji, 2003). A meta-review of the first decade of studies to utilize the IAT found that a) the IAT measured implicit attitudes that were related to, but distinct from their corollary explicit attitudes; b) implicit bias measured via the IAT predicted positive behavior toward the "in-group" and negative behavior toward the "outgroup"; and, c) predicted automatic processes, stating "the IAT also predicts lower-level perceptual and cognitive events. The utility of the IAT to predict unobtrusive perceptual tasks and uncontrollable physiological measures suggests that more negative implicit attitudes toward a group leads to more top-down stereotypic processing” (Lane, Banaji, Nosek, \& Greenwald, 2007). These "unobtrusive perceptual tasks and uncontrollable physiological measures" may be particularly relevant in roadway interactions, which rely on perception and reaction at high levels of automaticity and often as high speeds. Despite widespread use in other areas, from racial and political attitudes to attitudes about women in STEM fields (Banaji \& Greenwald, 2013), to date only 
two published studies and one conference presentation utilized IATs related to travel behavior. Hatfield et al developed a speeding-related IAT, on which they assessed predictive validity by comparing IAT scores to behavior in a driving simulator and self-report measures (Hatfield et al., 2008). They found that implicit attitudes toward speeding successfully predicted behavior in the driving simulator and concluded that the IAT could be a valuable tool in assessing driver attitudes and behaviors (Hatfield et al., 2008).

The other published use of an IAT measured driver self-enhancement biases about driving ability and risk-taking (Harré \& Sibley, 2007; Sibley \& Harré, 2009a, 2009b). They found that drivers hold both explicit and implicit selfevaluations of driving ability, but the implicit associations are stronger, and that the two measures were not correlated, a surprising finding that they attributed to the social desirability bias of reporting on driver ability and risk-taking (Harré \& Sibley, 2007).

A team of researchers at MIT used an IAT to test respondents' implicit bias between driving and bus use, and found that the IAT captured a "car pride" that was not captured in the self-report measures, and which helped explain car mode choice (Moody, Goulet Langlois, Alexander, Campbell, \& Zhao, 2016). This use of the IAT is the most similar to the present use, in that it seeks to explore attitudes toward different types of road users. Their study focused on the mode, however, while the current study focused on the user. 


\section{Measuring the built environment and bicycle safety}

One widely recognized challenge in bicycling safety data is the lack of exposure data (Jacobsen, 2003). The absolute number of bicycle crashes and injuries is just one piece of the puzzle - crash rates (e.g. crashes per mile traveled, crashes per person-trip, etc) are necessary to better understand the magnitude of the problem and the contributing factors to crashes (Harris et al., 2011). Exposure data are robust for automobile users, but poor for bicyclists (Nordback et al., 2014). The primary nationally-comparable source for travel data is the National Household Travel Survey (NHTS). The NHTS has a sample size only three percent of the community-level data of the American Community Survey (ACS) and cannot be dis-aggregated to the city or community level (Buehler \& Pucher, 2012). Most cities do not collect bicycle-related data systematically (Buehler \& Pucher, 2012). The low levels of bicycling in many communities likely leads to a difficulty in capturing bicycle data, as does a lack of widely used methods for data collection for bicyclists (Nordback et al., 2014). Most available bicycle-trip data only captures commute data, which has limited usefulness. For example, when examining the 2009 NHTS, Pucher et al (2011) identified commute trips as only $12 \%$ of all bicycle trips. Thus relying on commute trips as a proxy for all bicycle trips is likely to be a poor measure (Buehler \& Pucher, 2012).

Without exposure data, it is difficult to understand the relationships of urban form with bicyclist safety (Gladhill \& Monsere, 2012). Mapping collision frequency assumes that bicyclists and bicycling levels are homogenously distributed over the study area, which is unlikely to be true (Yiannakoulias, 
Bennet, \& Scott, 2012). Additionally, urban form data related to bicyclists is often imprecise: "bike lane miles" are typically extrapolated from roadway centerline miles, and give no indication of whether bike lanes are on one side of the roadway or both or whether they are bi-directional facilities (Buehler \& Pucher, 2012). Even when an accurate measure of bike lane or path miles is available, the data does not include measures of design (Buehler \& Pucher, 2012). The US EPA's Smart Location Database (SLD) includes "street intersection density" and "multimodal links per mile" (US EPA, n.d.), which provide only a very rough proxy for "bikeability", since they suggest number of links and thus route choice and directness, but do not account for travel speeds, numbers of auto lanes, or the presence or absence of bike infrastructure.

\section{Discussion}

Even if planners and engineers accept that attitudes and biases may play a role in roadway behavior and the safety and experiences of bicyclists, it can be difficult to see what we can do about people's biases. Especially in questions of design and infrastructure, addressing intersectional modal and other social identity biases can feel like an insurmountable issue. However, because physical space is not the only factor structuring people's transportation choices (Lugo, 2013), people who advocate for, plan, design, and implement physical space for bicycle transportation are not exempt from trying to understand, and reduce, the impact of biased roadway behaviors. Interventions that address social identity, stereotypes, and attitudes are needed to broaden the possibilities for improved 
safety and roadway relations. Understanding the underlying psychology in roadway interactions is an important area for continued and expanded research, which can then be used to design interventions.

Infrastructure can be a form of a passive, population-based intervention that increases safety without individuals having to "opt in" (Teschke et al., 2012), but the majority of transportation studies evaluate behaviors related to infrastructure from an environmentally deterministic worldview, rather than considering the shaping role played by social norms and identity. For example, contact theory and its ability to reduce discomfort in interracial interactions (Singletary and Hebl, 2009) suggests that a prime area of research is potential interventions that increase understanding of other modes, particularly compensatory strategies that have shown promise in other domains. Compensatory strategies are concrete actions that people can take to counteract subconsciously held biases, by engaging in deliberate, rather than automatic, behaviors (Singletary and Hebl, 2009). Personal experience may also affect how we treat other road users; for example, experience as a bicyclist may impact a driver's understanding and behavior around bicyclists (Goddard et al., 2016; Jacobsen, 2003). Perhaps most directly relevant to planners and engineers is better understanding of what infrastructure or designs can effectively pre-empt biases and facilitate safer, more equitable behavior that can directly create a more just environment for bicyclists of all social groups. The psychology of driver-bicyclist interactions is understudied, and needed to understand the impact of encouragement programs and safety interventions in 
the short and long term. A greater understanding of roadway culture and the roadway as a system of dominant and subordinate groups may suggest how the non-dominant modes can be normalized and de-stigmatized. Efforts by bicycling advocates and planners, however, cannot continue to focus only on destigmatization of bicycling as a mode without recognizing the additional stigmas and discrimination faced by bicyclists as a user group.

\section{Conclusion}

Planners, engineers, advocates, researchers, and engaged citizens should understand that travel behavior is comprised of social interactions, and like any other social interactions are subject to automatic processing, stereotyping, and bias. Roadways are highly congested (and thus contested), publicly funded space, and both space and funding are a finite and limited resource. This results in the perception and reality of roadway competition as a zero-sum game between roadway users (Aldred, 2012). It may be that this "realistic" competition is a stand-in for social competition; that is, the roadway is a battle ground for social domination, rather than just access to physical space. Of course, not all roadway interactions result in conflict and notions of normalcy can shift, particularly when more people of all different social identities bicycle (Aldred \& Jungnickel, 2014). The goal of research in roadway interactions should be to understand when and why (or why not) conflict happens, and the roles that infrastructure, enforcement, and education play in avoiding or mitigating that conflict. Planning that engages with and is sensitive to local contexts can lead to environments with 
more equitable outcomes and greater possibility of avoiding conflict, including conflict caused by the social and literal collision of mode-based bias. Interactions between different types of roadway users, particularly between drivers and bicyclists, may be particularly influenced by social identity, social dominance and system justification, stereotype and stereotype threat, attentional and confirmation biases, fundamental attribution error, or other aspects of social psychology outside the scope of this chapter. Despite some empirical work in modal identity and intermodal interactions (Gatersleben et al., 2013; Murtagh et al., 2012; Salmon et al., 2014; Walker, 2005, to name a few), there is a need for a theoretical framework that ties together relevant theories from social psychology. The Conceptual Model of Roadway Interactions presented here is an attempt to create a theoretical model of roadway interactions that takes into account social psychological theories that address both interpersonal and intergroup relations. The next chapter details the present research approach, which utilized a survey that attempted to incorporate the theoretical, empirical, and methodological issues above. 


\section{Chapter 3: Methodology}

This chapter includes all of the information related to the development and administration of the research methodology, which was conducted via an online survey instrument. The first portion of the chapter focuses on the survey instrument, while the second describes the administration and data collection.

\section{Survey instrument}

The survey was developed between June 2015 and April 2016, following the successful colloquium (dissertation defense) on May 26, 2015. The survey comprised two different sections: a computerized test of implicit cognition, and a more traditional travel behavior survey. They are discussed in detail in the following sections.

\section{Implicit method}

The first portion of the survey instrument was the Implicit Association Test (IAT). Although an IAT can examine stereotypes, for example, the simplest version utilizes a more general good/bad comparison between two concepts (A. G. Greenwald et al., 1998). Because this was the first use of an IAT to examine preferences between road user types, this good/bad IAT was used to first test the general hypotheses that a) people do feel bias between drivers and bicyclists, and b) that bias is measurable. More nuanced or specific stereotypes, e.g. "scofflaw" behavior, is of interest but was not tested with this IAT.

The association tasks used one word and two images for each concept (i.e. driver, bicyclist) and six words for each of the positive and negative evaluations (i.e. 
pleasant and unpleasant attributes). Because there are few common synonyms for either driver or bicyclist, the terms "driver" and "bicyclist" were complemented with images developed from stock image silhouettes ("Can Stock Photo," n.d.) (Table 2).

Alteration of the stock silhouettes was done by the author. Images were sized for realistic relative scale and matching size on screen. The stimuli pleasant and unpleasant words are adapted from Greenwald et al. (1998); however, words with potential to evoke roadway-specific terms (e.g. "anger " or "rage", as in road rage) were changed to negative words without direct connections to roadway stereotypes or concepts (Table 2).

In the survey development and pre-testing phase, attempts were made to use gender-neutral images. This proved to be impossible, as all pre-testers were able to perceive gender of the driver and bicyclist. Because it is likely that gender and mode intersect to affect attitudes and behaviors (Walker, 2007), and testing both genders in one survey instrument would have effectively doubled the survey length, the final IAT used images that are perceived as men, since men dominate the bicycle mode share in the United States. Future studies will explore the effects of identities like gender and race in additional to modal identity. 
Table 2. Implicit Association Test concepts and attributes

\begin{tabular}{|l|}
\hline Concepts: \\
\hline "Driver" \\
\hline Attributes: \\
\hline Positive evaluations: Joyful, Lovely, Wonderful, Beautiful, Pleasant, Happy
\end{tabular}

An IAT presents stimuli (that is, concepts and attributes to be sorted) in a series of "blocks", which are alternated to control for handedness (e.g. right-hand dominance that might lead to faster response times for concepts and attributes on the right side of the screen). The IAT consists of seven blocks (Table 3), which first orient respondents to the procedure of sorting a concept or attribute correctly (Blocks 1 and 2), and then asks them to sort concept A with positive attributes and concept B with negative attributes (Blocks 3 and 4). Respondents are then re-oriented to the attributes (Block 5), which are now appear on opposite sides of the screen. The final two blocks (Blocks 6 and 7) require respondents to sort concept A with negative and concept B with positive. Research demonstrates that there is not an order effect in which blocks respondents see first (i.e. A/+ or 
A/-) (Nosek, Greenwald, \& Banaji, 2005). Several example screenshots from the IAT in this study are shown below (Figure 2Figure 3, Figure 4).

Table 3 Schematic overview of the Implicit Association Test

\begin{tabular}{|c|c|c|}
\hline Block & $\begin{array}{l}\text { Left key ("e") } \\
\text { assignment }\end{array}$ & $\begin{array}{l}\text { Right key ("i”) } \\
\text { assignment }\end{array}$ \\
\hline 1 & Bicyclist & Driver \\
\hline 2 & Positive & Negative \\
\hline 3 & $\begin{array}{l}\text { Bicyclist } \\
\text { Positive }\end{array}$ & $\begin{array}{l}\text { Driver } \\
\text { Negative }\end{array}$ \\
\hline 4 & $\begin{array}{l}\text { Bicyclist } \\
\text { Positive }\end{array}$ & $\begin{array}{l}\text { Driver } \\
\text { Negative }\end{array}$ \\
\hline 5 & Negative & \begin{tabular}{|l|} 
Positive \\
\end{tabular} \\
\hline 6 & $\begin{array}{l}\text { Bicyclist } \\
\text { Negative }\end{array}$ & $\begin{array}{l}\text { Driver } \\
\text { Positive }\end{array}$ \\
\hline 7 & $\begin{array}{l}\text { Bicyclist } \\
\text { Negative }\end{array}$ & \begin{tabular}{|l|} 
Driver \\
Positive
\end{tabular} \\
\hline
\end{tabular}

\section{Implicit Association Test}

Welcome to the Implicit Association Test. You will use the "e" and "i" computer keys to categorize items into groups as fast as you can. These are the four groups and the items that belong to each:

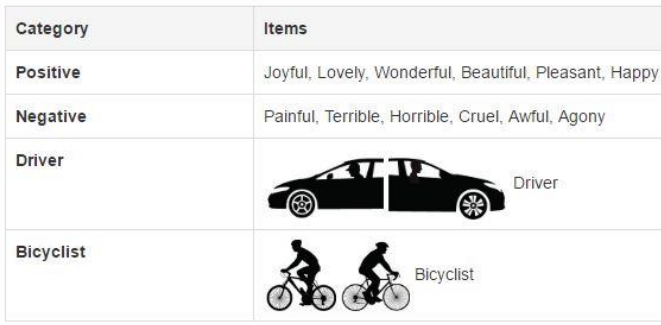

There are seven parts. The instructions change for each part. Pay attention!

\section{Continue}

Project Implicit

Figure 2 Implicit Association Test screen shot - instructions 


\section{Part 1 of 7}

Put a left finger on the $\mathbf{E}$ key for Driver images.

Put a right finger on the I key for Bicyclist images.

Items will appear one at a time.

If you make a mistake, a red $\mathbf{X}$ will appear. Press the other key to continue. $\underline{\text { Go }}$ as fast as you can while being accurate.

Press the space bar when you are ready to start.

Figure 3 Implicit Association Test screenshot - instructions part 2

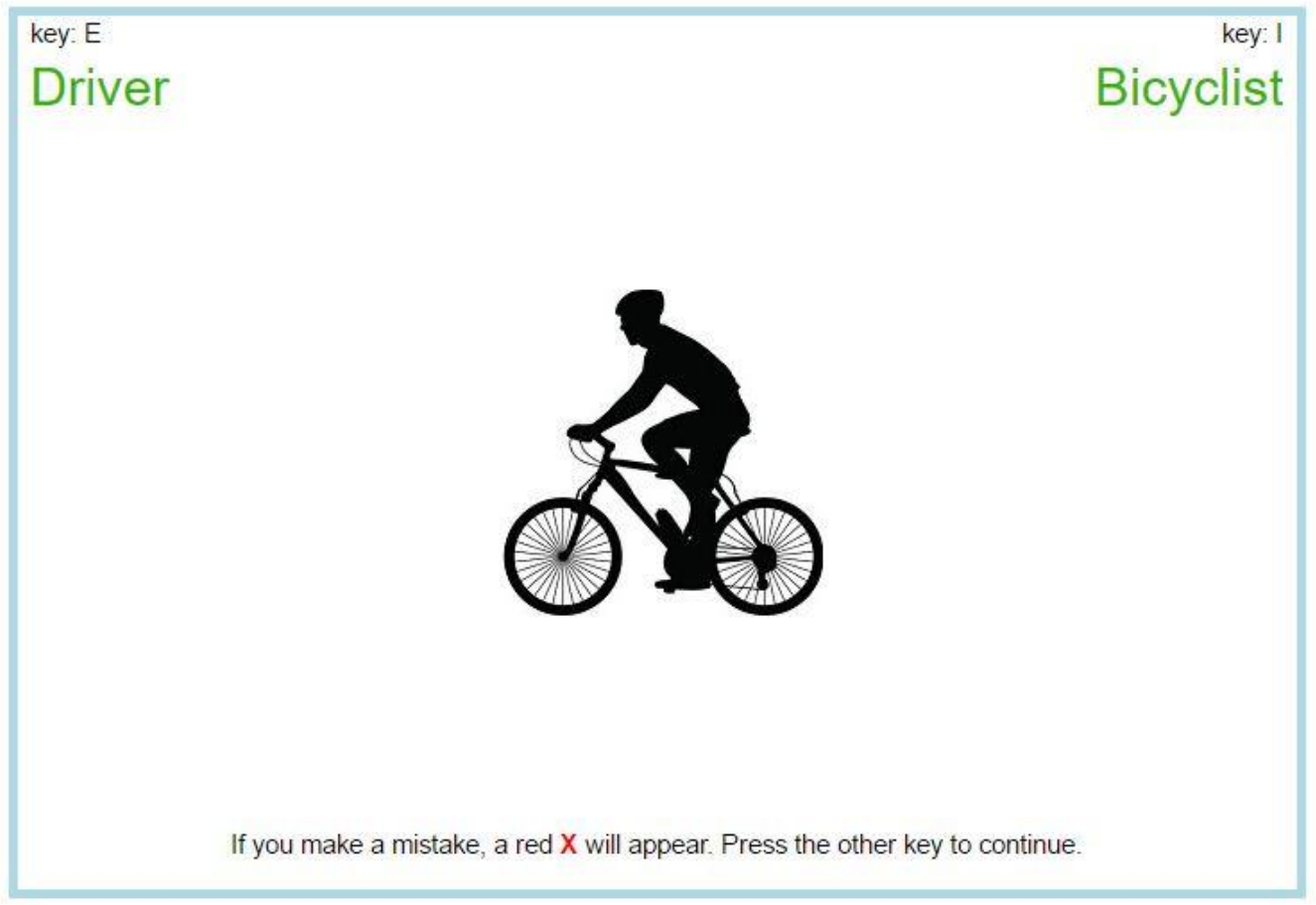

Figure 4 Implicit Association Test screenshot - Block 1 
Analysis of IAT responses results in a "D score" ("D" for difference) that provides a score for each respondent that reflects where they fall on a hypothesized normal distribution of responses, while controlling for their overall response rates (Table 4). The D score for this type of comparative, IAT represents the difference in speed of association between two concepts. Responses that are less than 300 msec or more than 10,000 msec are deleted; the former response time is too short to actually represent a deliberate keystroke response to the stimulus, and the latter is too long to reflect an subconscious, rather than conscious, association (Greenwald et al., 2003).

Table 4 Summary of IAT Scoring Procedures Recommended by Greenwald et al. (2003)

1 Delete trials greater than $10,000 \mathrm{msec}$

2 Delete subjects for whom more than $10 \%$ of trials have latency less than 300 msec

3 Compute the "inclusive" standard deviation for all trials in Blocks 3 and 6 and likewise for all trials in Blocks 4 and 7

4 Compute the mean latency for responses for each of Blocks 3, 4, 6, and 7

5 Compute the two mean differences (Mean of Block 6 - Mean of Block 3) and (Mean of Block 7 - Mean of Block 4)

6 Divide each difference score by its associated "inclusive" standard deviation

$7 \mathrm{D}$ score $=$ the equal-weight average of the two resulting ratios 


\section{Explicit attitudes and behaviors}

Survey items in this section were developed based on several sources, including a study of driver attitudes toward motorcyclists in the UK (Crundall et al., 2008), a study of drivers' attitudes toward "equine road users" (Chapman \& Musselwhite, 2011), a study about the courtesy, predictability, and law-abidingness of both drivers and bicyclists (Monsere et al., 2014), and the original Driver Behavior Questionnaire (Reason et al., 1990). Additionally, the questions were informed by the social psychological theories discussed in Chapter 2. To keep the survey to an approximate limit of 15 minutes to ensure a $60 \%$ completion rate, measures were winnowed down to focus on the research questions of this study.

To measure attitudes, the survey asked respondents whether they agreed or disagreed with a series of twelve statements about driving, other drivers, and bicyclists (Table 5). The items were scored on a six-point Likert-style scale from strongly disagree to strongly agree, with no neutral midpoint in a "forced choice" approach (Smyth, Dillman, Christian, \& Stern, 2006). There were seven statements about behaviors interacting with bicyclists, using the same measurement scale (Table 6).

Crundall et al (2008) focused their items on what they called "attitudes," "basic knowledge," and "perceptual skills and performance." Several of their questions (Appendix B) were adapted and used in this study, with wording changed from "motorcyclist" to "bicyclist" and to reflect aspects of interactions specific to drivers and bicyclists instead of motorcyclists. Additional questions attempted to probe the social psychological concepts in the conceptual model discussed in 
Chapter 2. Two questions collected beliefs about the courtesy, predictability, and law-abidingness of both drivers and bicyclists, similar to Monsere et al (2014). Although this section of the sur vey utilized attitude measures in previous research, there is not a widely-used measure of driver attitudes toward bicyclists (or any other road user) as a social group. This provided flexibility to include measures related to research questions, conceptual model, and hypotheses, but also limits the comparability to other research.

Table 5 Explicit attitude survey questions

Attitude statement as worded on survey*

In general, being a driver is important part of who I am

In most or all situations, I am a skilled driver

I care whether my friends and family think of me as a good driver

Bicyclists should have to pass a license test just like drivers do

When a driver and a bicyclist collide, it is typically the fault of the driver**

Bicyclists should be allowed to filter forward through lanes of slow or stopped car traffic**

Bicyclists should have to register and pay specific road taxes

Building infrastructure for bicyclists is a good investment of public funds**

Bicyclists should not hold up traffic

It makes me angry if I see other drivers breaking the rules of the road ${ }^{* *}$

It makes me angry if I see bicyclists breaking the rules of the road

In general, I see people similar to me bicycling on city streets**

*Strongly disagree (1) to Strongly agree (6)

** Reverse coded in analyses

Behavior questions (Table 6) were partially adapted from an updated version of the original Driver Behavior Questionnaire (DBQ) ((Lajunen et al., 2004; Reason et al., 1990), Appendix C) and to put them in language that makes sense for 
American English and the North American context (e.g. driving on the right side of the road, and bicyclists on the right), similar to Cordazzo, Scialfa, Bubric, \& Ross, 2014. Utilizing a similar structure to the DBQ, question wording was altered so that the questions of the DBQ relating to other drivers or to a generic "road user" all referred to bicyclists. The DBQ uses frequency of occurrence as response choices, but the fact that many drivers may have little experience interacting with bicyclists made this a potentially less useful answer structure. After pre-testing, it was determined that mirroring the 6-point Likert-style scheme of the attitude questions (i.e. strongly disagree to strongly agree) would capture nuanced information and reduce response burden on respondents. Additional behavior questions were developed based on professional bicycleplanning experience and specific interests, including overtaking and fear and nervousness around bicyclists.

The wording of the attitude and behavior questions were varied to avoid the appearance of a leading or biased survey. In analyses, both attitude and behavior items were coded so an increase in any item represented a more pro-driver or anti-bicyclist response. 


\section{Table 6 Behavior survey questions}

Behavior statement as worded on survey*

I am comfortable deciding how close or fast to pass a bicyclist going the same way as me on a street with no bike lane**

If I drive slowly behind a bicyclist without passing them, other drivers get annoyed with me I check for bicyclists before I make a turn in my car**

When my car is moving, it is difficult to judge how far a bicyclist is from my passenger side

It makes me nervous when I have to drive close to someone on a bicycle

I have honked, shouted, or gestured at a bicyclist who made me angry

It startles me when a bicyclist comes up on the driver's side

${ }^{*}$ Strongly disagree (1) to Strongly agree (6)

${ }^{* *}$ Reverse coded in analyses

Drivers were also asked whether they have ever been "involved in collision or near-collision with a bicyclist?", with the option to select all that apply from "Yes, a crash that resulted in the death or major injuries (ambulance required) of the bicyclist", "Yes, a crash that resulted in only minor injuries or no injuries to the bicyclist", "Yes, a near-collision with a bicyclist", and "No".

\section{Built environment measures}

A national, easily-accessible database of bicycle infrastructure does not currently exist. It was desirable, however, to use at least a rough measure of the built environment that might relate to drivers' attitudes toward bicyclists. The EPA Smart Location Database ("SLD") contains a variety of built environment variables at the census block group level (US EPA, n.d.). The following variables were chosen as a proxy for potential bikeability: total road network density; street intersection density, "weighted to reflect connectivity for pedestrian and bicycle 
travel"; multimodal network density; and pedestrian-oriented facility density (Table 5).

\begin{tabular}{llc}
$\begin{array}{l}\text { Table } 7 \text { EPA Smart Location Database selected BE measures } \\
\text { Built Environment (BE) } \\
\text { Measure }\end{array}$ & Unit & $\begin{array}{c}\text { SLD variable } \\
\text { name }\end{array}$ \\
\hline $\begin{array}{l}\text { Total road network density } \\
\text { Street intersection density }\end{array}$ & $\begin{array}{l}\text { Miles/acre } \\
\text { Intersections/acre, weighted, auto- } \\
\text { oriented intersections eliminated) }\end{array}$ & D3a \\
$\begin{array}{l}\text { Multimodal network density } \\
\begin{array}{l}\text { Pedestrian-oriented facility } \\
\text { density }\end{array}\end{array}$ & $\begin{array}{l}\text { Links/sq mi } \\
\text { Links/sq mi }\end{array}$ & D3amm \\
\hline
\end{tabular}

The survey collected zip codes as a measure of respondents' residential location, so it was necessary to re-calculate the density measures. This was accomplished using a combination of GIS, Excel, and SPSS manipulation. To first link each zip code with its related census block groups (i.e. the 1:N relationship of user zip codes to block groups), the SLD data was joined to the user zip code data using "CONTAINS" in the spatial join tool in ArcGIS. Next, each density measure was converted to miles or links by multiplying it by the acreage of its block group. All facility variables within each zip code were then weighted and summed, and divided by the total square miles of the zip code (the acreages were converted to square miles as appropriate). The composite density measures for each zip code were then joined to the respondents' zip codes.

As both a proxy for a bikeable built environment and as a measure of respondents' potential likelihood of driving around bicyclists, survey records were joined with the total bicycle commute mode share from the US Census American Community Survey 2011-2015 5-year estimate data set (ACS Table So801). Twenty-two percent of respondents were in areas with no measurable 
bicycle commute mode share, 60 percent were in areas with a bicycle commute mode share of 0.4 percent or less, and fewer than 5 percent were in areas with greater than 5 percent bike commute mode share. Forty-six (6.8\%) records did not have accurate zip code data or reported zip codes that were not represented in the ACS data.

\section{Stereotypes}

To explore drivers' stereotypes about bicyclists generally, they were asked to provide up to five words or phrases that come to mind when they hear the word "bicyclist." Then, to probe whether drivers hold different stereotypes about different types of bicyclist, three silhouettes were chosen to represent three distinct sub-types of bicyclist (Table 9). Twenty-nine pre-testers (friends and family) took a brief survey, administered via Qualtrics, to determine whether people would distinguish between different silhouettes. Twenty-six respondents answered "yes" to the question "Do you think these images portray different types of bicyclists?", while four respondents selected "Maybe/I'm not sure". The pretesters than were asked: "Please consider those same images. I'm interested in whether these different silhouettes mean different things to different people. There will be two questions with these images. In this first one, please write up to three words or phrases for each silhouette that you think describes this kind of bicyclist. It could be a word that describes what they are doing, where they are going, an aspect of their personality, their demographics (age group, income, race, etc), whatever you want. There are no wrong answers - just write down what 
comes to mind." Respondents provided a variety of terms that fit with a priori assumptions about the three sub-types. Example responses are shown in Table 8. Table 8 Example answers from pre-test of bicyclist sub-types

\begin{tabular}{|l|l|l|l|}
\hline & Bicyclist \#1 & Bicyclist \#2 & Bicyclist \#3 \\
\hline $\begin{array}{l}\text { Example pre-test } \\
\text { responses }\end{array}$ & Racer & Commuter & Bike person \\
& Spandex & Old & Student \\
& Impatient & Slow & Young \\
\hline
\end{tabular}

Each silhouette was first presented with a "feeling thermometer" (Alwin, 1997), to rate respondents' general feeling toward each bicyclist sub-type. 
Table 9 Bicyclist sub-type silhouettes feeling thermometer

Instructions: How do you feel about this kind of bicyclist? (each image was shown as a separate feeling thermometer)

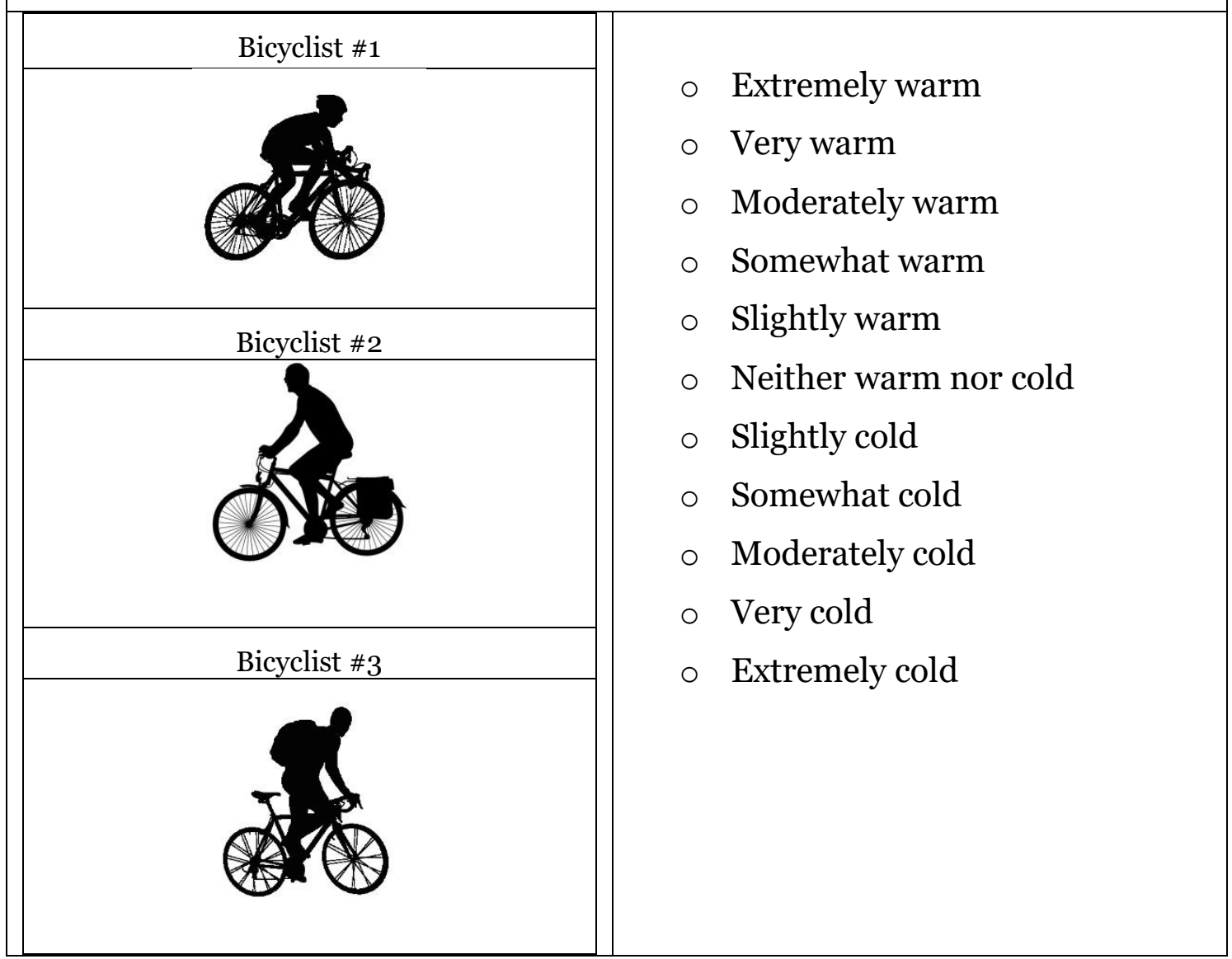

After each feeling thermometer, respondents were shown the bicyclist silhouette again and asked to "please select all of the terms that you most associate with this kind of bicyclist" and were presented with a list of terms (Table 10) to choose from. The terms were developed partially based on the pre-test open answers, and were chosen to represent a variety of positive or negative personality, motivation, or behavior attributes. 
Table 10 Attribute list for bicyclist sub-types

- Physically fit

- Young

- Follows the rules

- Aggressive

- Predictable on the road

- Avid about cycling

- Smug

- Courteous

- Risk-taker

- Poor

- Skilled

- Rude

- Other

If respondents selected "other" when choosing attributes for each bicyclist silhouette, they were then prompted to "please describe up to three words/phrases that you associate with this kind of bicyclist.” For bicyclist \#1, 15 respondents chose to add additional terms or phrases. Eighty-four respondents added terms about bicyclist \#2, and 49 respondents added terms about bicyclist \#3. Terms represented five types of attribute: demographic, physical, personality; motivation, and behavior. Several responses could not be categorized. Example responses for each sub-type are shown in Table 11. 
Table 11 Example qualitative responses about bicyclist sub-type attributes Attribute category Example responses

\begin{tabular}{|c|c|c|c|}
\hline & $\underline{\text { Bicyclist \#1 }}$ & $\underline{\text { Bicyclist \#2 }}$ & $\underline{\text { Bicyclist \#3 }}$ \\
\hline Demographic & Educated & Old & Student \\
\hline Physical & Strong & Slow & Fit \\
\hline Personality & Ambitious & Easy-going & Adventurous \\
\hline Motivation & Competitor & Casual rider & Commuter \\
\hline Behavior & Fast & Relaxed & Unsafe \\
\hline Other & "road kill" & "Wicked Witch!" & $\begin{array}{l}\text { "put on a } \\
\text { helmet dummy" }\end{array}$ \\
\hline
\end{tabular}

\section{Data}

\section{Survey administration}

The survey was hosted online and administered by Project Implicit to the specifications of the author, and hosted on their private servers. Project Implicit is a non-profit organization and international collaboration between researchers who are interested in implicit social cognition - thoughts and feelings outside of conscious awareness and control. The goal of the organization is to "educate the public about hidden biases and to provide a "virtual laboratory" for collecting data on the Internet” (“ProjectImplicit,” n.d.).

The contract with Project Implicit was signed on March 3, 2016, and notification of "exempt" status was received from the Portland State University Institutional Review Board on the same day. The survey was launched on May 20, 2016, and remained open until June 16, 2016 (28 days), when it passed the threshold of 
$60 \%$ completion rate of the 1,000 survey "starts" included in the contract. The data was cleaned and provided by Project Implicit on June 24, 2016. Respondents were able to complete the survey on a desktop PC or Mac. The survey tool was not available on mobile platforms. The sorting task at the beginning of the survey required a free plugin to run the program. This provided a quality control for differing internet or processor speeds. As with any remotelyadministered survey, there was no way to control for distractions or other barriers in respondents' environments. While in-vehicle distractions (from passengers to in-car technology) are growing in type and ubiquity, it cannot be assumed that environmental distractions during the test simulate distractions in the vehicle. Testing this assumption directly was not possible in the current study.

\section{Population and sampling}

The Project Implicit research pool is a public online data collection website where participants volunteer to register to take implicit bias related research studies (Greenwald et al., 2003). Over 1.5 million people have registered accounts at the public Project Implicit site. Most or all of the participants in this study, however, are likely to be users who registered after the survey was launched. During the course of the study, approximately 8,000 people registered at the site. Once registered, participants were randomly assigned to one of the studies in the pool for which they were eligible. For this study, participants were limited to legal adults (at least 18 years old) in the United States. Additionally, participants were asked to agree on the consent form (Appendix) that they hold a driver's license 
and drive at least a few days a month. Participants only had one chance to complete the study and could not be assigned to the study again.

\section{Sample population}

Respondents' were sampled from people who logged onto the Project Implicit site during the survey period, during which 1,561 people were randomly assigned to the survey. Of those, 1,108 (71 percent) agreed to the consent form and began the survey.

The final number of completed surveys was 676 , a completion rate of 43.3 percent. Because of the self-selection bias in using the public website, the sample was compared against national statistics (Table 12). Overall, the sample had a higher proportion of women respondents (66.4\%). The percentage of white respondents $(76.7 \%)$ is approximately representative of the US population $(77.1 \%$ white), but there were fewer Black (7.8\%) and Asian (3.3\%) respondents than in the US population (12.6\% and 4.8\%, respectively.) The sample was more than twice as likely to hold a Bachelor's degree or higher than the general US citizen. 
Table 12 Sample demographics compared to US national averages

\begin{tabular}{lrr} 
& Sample $(\mathrm{n}=676)$ & $\begin{array}{r}\text { US population } \\
\text { (2010 Census) }\end{array}$ \\
\hline Percent female & $66.0 \%$ & $50.8 \%$ \\
Average age & 41 & 35 \\
Age range & $19-82$ & $0-100+$ \\
Percent one-adult HHs & $24.1 \%$ & $16.6 \%$ \\
Percent of HHs with kids & $35.3 \%$ & $29.8 \%$ \\
Percent white & $76.7 \%$ & $72.4 \%$ \\
Percent Black/African- & & \\
American & $7.8 \%$ & $12.6 \%$ \\
Percent Asian & $3.3 \%$ & $4.8 \%$ \\
Percent Hispanic/Latino & $6.2 \%$ & $16.3 \%$ \\
Bachelor's degree or higher & $69.0 \%$ & $29.8 \%$ \\
\hline
\end{tabular}

Responses came from all over the United States (Figure 5), including Hawai'i and Alaska (not pictured). Using Census regional designations, there were 134 responses from the Northeast (21.2\%), 148 responses from the Midwest (23.5\%), 179 responses from the South (28.4\%), and 170 responses from the West (26.9\%). The remaining 45 responses did not provide a valid zip code.

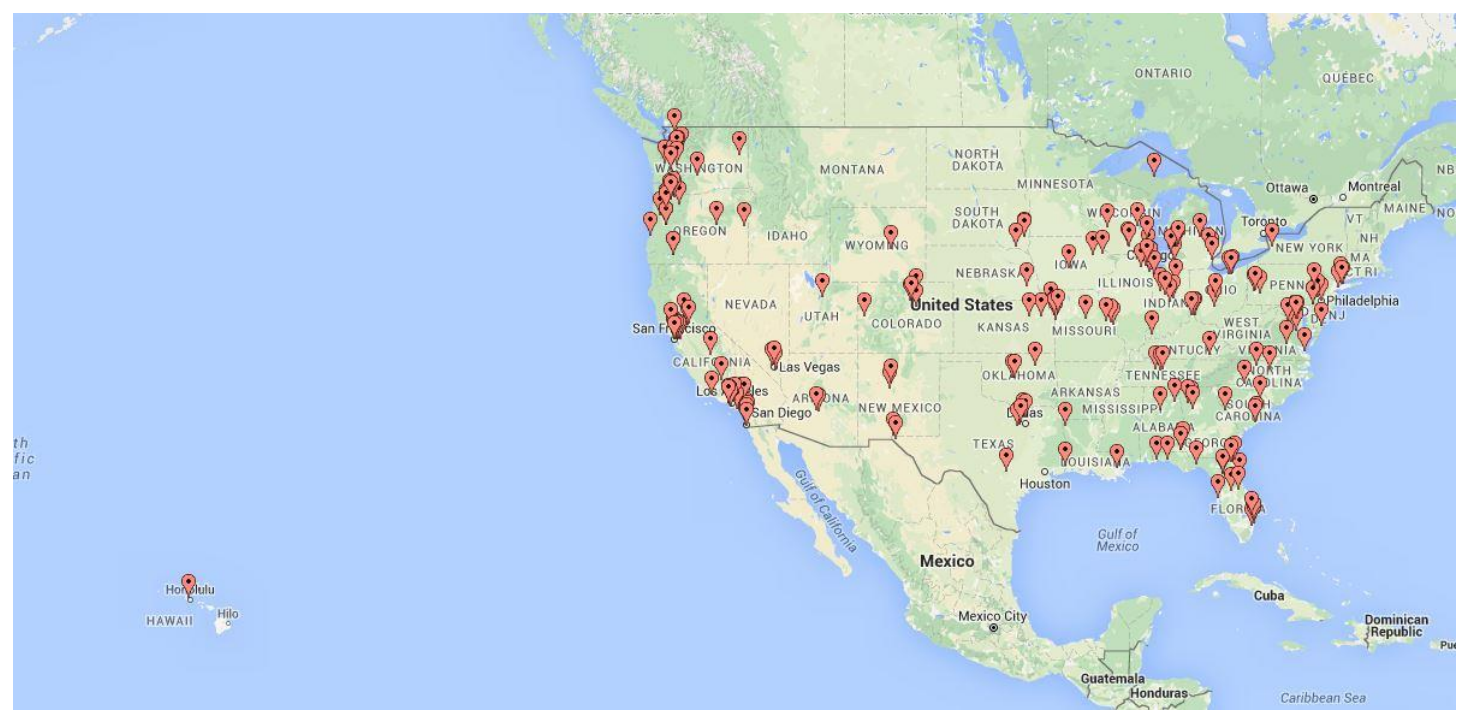

Figure 5 Map of Responses 


\section{Missing value analysis}

Missing value analyses were conducted on all demographic, travel behavior, and attitude variables. Fewer than three percent of cases had missing values for the travel and attitude variables. Ethnicity and household income were dropped from analyses presented here due to a higher percentage of cases with missing values (6.2\% and $15.2 \%$, respectively).

\section{Individual travel behavior}

Respondents were asked about their driving behavior (years driving and days driving in a typical week) and bicycling behavior (biked in last year, days bicycling in a typical week). As desired for the purposes of the study, and expected due to dominant travel patterns in the United States, the sample included a high percentage of frequent drivers (Table 13). Nearly all respondents reported both knowing how and being physically able to ride a bicycle. Just over half (54\%) had ridden a bicycle outside in the last year, while similarly, just over half (54\%) of those respondents ride at least once in a typical week with nice weather. Nearly all respondents also bicycled as a child.

\section{Table 13 Self-report travel characteristics}

Travel characteristics

Percent of

Percent of sample that drive 4 days/week or more respondents

Percent of sample that drive 7 days/week $87 \%$

Physically able to ride a bicycle $57 \%$

Know how to ride a bicycle $96 \%$

Bicycled outside in the last year $98 \%$

If bicycled outside in the last year, bicycle in the typical week $(\mathrm{n}=361)$ 
The analyses in Chapters 4 and 5 utilize data from various parts of the survey described in this chapter to answer the research questions described in Chapter 1. The research questions, data, analysis, and key findings of each chapter are summarized in Table 1 at the end of Chapter 1. 


\section{Chapter 4: What are drivers' attitudes toward bicyclists as fellow roadway users, and what predicts those attitudes?}

\section{Objectives of this chapter}

With the framework provided by theories of intergroup relations, evidence of the usefulness of the IAT in previous research, and the nascent potential for using an IAT to measure transportation-related attitudes, the objectives of the portion of the study were to:

- Develop an IAT to test association between drivers and bicyclists (the concepts) and positive and negative words (the attributes);

- Examine the relationships of IAT scores and self-report attitudes; and

- Test hypotheses that implicit and explicit attitudes toward bicyclists would be related but distinct, and that the relationships would be consistent with theories of intergroup relations, namely theories regarding social identity, social norms, and system support.

The results presented in this chapter address the following research questions

and sub-questions:

What are drivers' attitudes about bicyclists as fellow roadway users, and what predicts those attitudes?

a. What are drivers' explicit (i.e. self-report) attitudes about bicyclists as fellow roadway users?

b. Can drivers' implicit attitudes toward bicyclists be measured?

c. How are drivers' explicit and implicit attitudes related?

d. Does measuring drivers' implicit attitudes add value to traditional survey methods?

e. How do demographic, driving frequency, implicit attitude, and built environment characteristics predict attitudes toward bicyclists?

f. Does personal experience as a bicyclist affect drivers' attitudes toward bicyclists? 


\section{Findings}

\section{Descriptives}

Mean responses on the attitude variables were generally as expected, although the agreement with the statements about bicyclists needing to register and pay taxes was much smaller $(M=2.48)$ than might have been indicated by anecdotal data, and there was more agreement than expected that building infrastructure for bicycling is a good investment of public funds (shown below reverse coded, $M=2.40$ ). The remaining variables were all slightly anti-bicyclist or pro-driver, but with non-trivial standard deviations (Table 14). Several variables were skewed; in particular, "I am a skilled driver" was skewed, with 93 percent of the sample evaluating themselves as skilled, with over 23 percent of the sample responding "strongly agree" to the question of their skill-level. 
Table 14 Descriptives for the implicit and explicit attitude measures

\begin{tabular}{|c|c|c|c|}
\hline$x^{-2}+2-2$ & Mean & SD & Skewness \\
\hline Implicit attitude (IAT d score) & 0.0253 & 0.423 & -0.026 \\
\hline Being a driver is important part of who I am & 3.95 & 1.466 & -0.565 \\
\hline I am a skilled driver & 4.86 & 0.998 & -1.517 \\
\hline $\begin{array}{l}\text { I care if my family and friends think of me as a } \\
\text { good driver }\end{array}$ & 4.43 & 1.204 & -1.033 \\
\hline $\begin{array}{l}\text { Bicyclists should have to pass a license test just } \\
\text { like drivers do }\end{array}$ & 3.12 & 1.357 & 0.254 \\
\hline $\begin{array}{l}\text { If a driver and a bicyclist collide, it is typically } \\
\text { the fault of the driver (reverse coded) }\end{array}$ & 3.46 & 1.126 & 0.026 \\
\hline $\begin{array}{l}\text { Bicyclists should be allowed to filter forward } \\
\text { through lanes of slow or stopped car traffic } \\
\text { (reverse coded) }\end{array}$ & 3.95 & 1.39 & -0.268 \\
\hline Bicyclists should have to register and pay taxes & 2.48 & 1.198 & 0.862 \\
\hline $\begin{array}{l}\text { Building infrastructure for bicyclists is a good } \\
\text { investment of public funds (reverse coded) }\end{array}$ & 2.40 & 1.221 & 0.948 \\
\hline Bicyclists shouldn't hold up traffic & 4.38 & 1.139 & -0.624 \\
\hline $\begin{array}{l}\text { It makes me angry if I see other drivers } \\
\text { breaking the rules of the road (reverse coded) }\end{array}$ & 2.45 & 1.026 & 0.587 \\
\hline $\begin{array}{l}\text { It makes me angry if I see bicyclists breaking } \\
\text { the rules of the road }\end{array}$ & 4.09 & 1.297 & -0.379 \\
\hline $\begin{array}{l}\text { In general, I see bicyclists similar to me on city } \\
\text { streets (reverse coded) }\end{array}$ & 3.65 & 1.434 & 0.104 \\
\hline
\end{tabular}

Explicit attitude scores range from Strongly disagree (1) to Strongly agree (6)

(Valid $\mathrm{n}$ ranged from 660 to 676 )

For the entire sample, the IAT scores neared a normal distribution. The results are shown below in categories based Greenwald et al (2003) (Figure 6). When examining only the "moderate" and "strong" responses, 22.6 percent of respondents demonstrated implicit preference for drivers, while 18.7 percent showed a preference for bicyclists. 


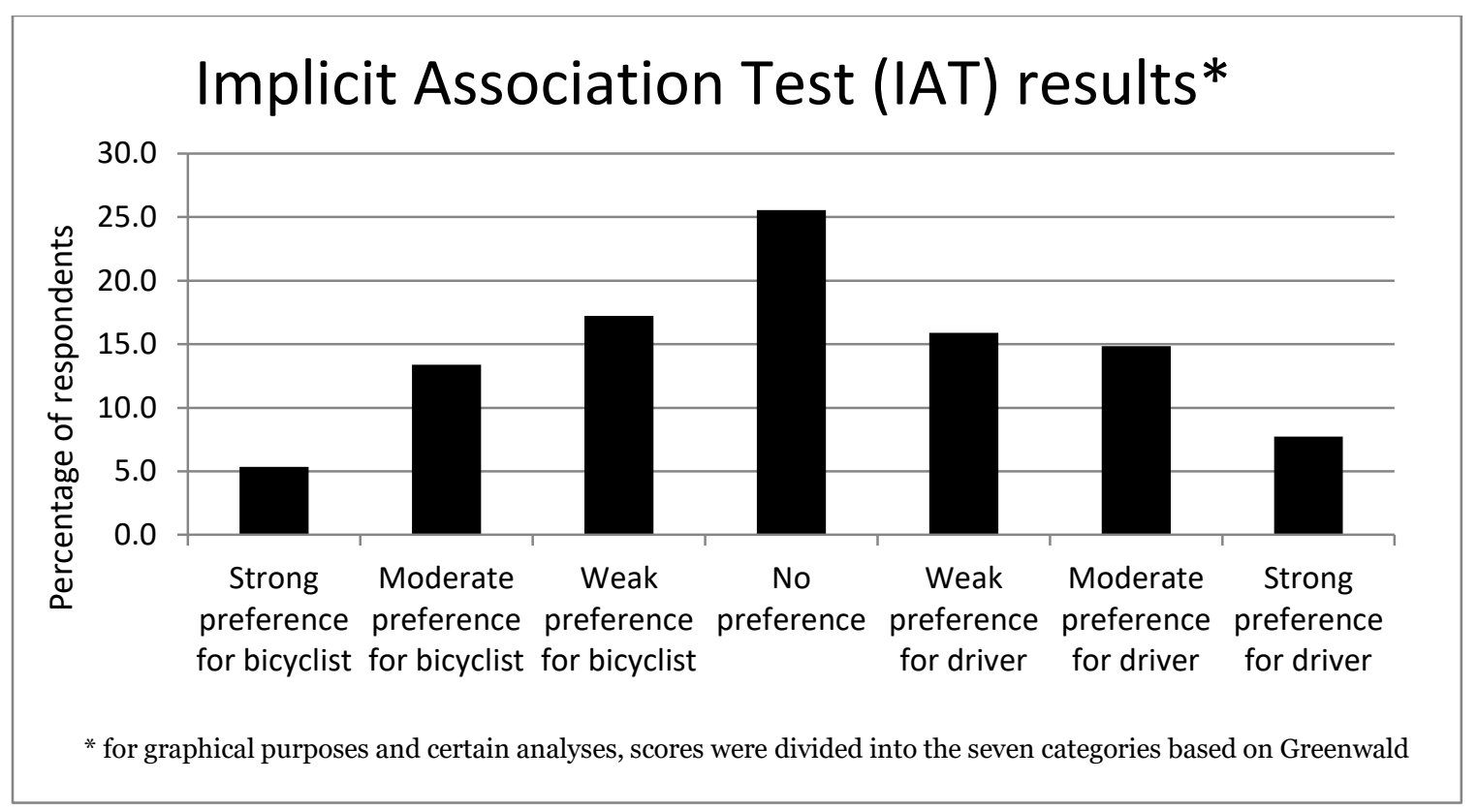

Figure 6 Distribution of implicit association test results

Association of Implicit Association Test score with demographics, explicit attitudes, travel behavior, and the built environment

One primary objective of this research was to determine whether a) it is possible to measure respondents' implicit preference between drivers and bicyclists, and b) how an implicit measure of preference is related to explicit attitude measures. To examine these questions, correlations of the IAT score with each survey item were examined (Table 15). The implicit attitude is represented by the IAT "d score", which explains the relative preference between drivers or bicyclists, and thus the bias toward one over the other (Greenwald et al., 2003). Significant correlations emerged between the IAT scores and several of the demographic, attitude, travel behavior and built environment items, although correlations were small, ranging from 0.073 to 0.175 . All associations were, however, in the 
hypothesized direction, with a preference for drivers over bicyclists positively correlated with stronger anti-bicyclist attitudes. The significant but small correlations with the explicit attitudes indicated that the IAT is measuring implicit preference and is not just random, and that implicit attitude is related but distinct from the explicit attitudes (Nosek et al., 2005).

Greater bicycling behavior and increased street intersection density (as a rough proxy for bikeability) were inversely correlated with implicit attitude, evidence that more bicycling is associated with more positive implicit attitudes toward bicyclists. Note, however, that it is frequent and/or utilitarian bicycling that were significantly related to implicit bias, and not recreational bicycling or accompanying a child, which may be primarily a recreational activity in most situations in the United States. Bicycling as a child was not significantly related to implicit bias about bicyclists. 
Table 15 Bivariate correlations of implicit attitude and demographics, explicit attitudes, travel behavior, and the built environment

Correlations

Implicit attitude

(d score)

Pearson

Correlation

Sig. (2tailed)

Age

$-.083^{*}$

.031

Gender

$-.023$

.549

Collapsed (simplified) education levels

$-.127^{* *}$ .001

Being a driver is important part of who I am

$.139 * *$

.000

I am a skilled driver

.017

.653

I care if my family and friends think of me as a good driver

.040 .298

Bicyclists should have to pass a license test just like drivers do

$$
.073
$$
.059

If a driver and a bicyclist collide it is usually not the fault of the driver

$.123^{* *}$

.002

Bicyclists should not be allowed to filter forward through lanes of slow or stopped car traffic

$.063 \quad .106$

Bicyclists should have to register and pay taxes

$.104 * *$

.007

Building infrastructure for bicyclists is not a good investment of public funds

$.160^{* *}$

.000

Bicyclists shouldn't hold up traffic

I do not see bicyclists similar to me on city streets

$.144^{* *}$

.000

It makes me angry if I see other drivers breaking the rules of the road

$.124 * *$

.001

It makes me angry if I see bicyclists breaking the rules of the road

How many days per week do you drive?

$.003 \quad .947$

Biked as a child yes or no

Bike weekly regardless of biking in last year

Bicycle for recreation

Bicycle for commuting

.064

.098

Bicycle for errands

$.078^{*}$

.044

Bicycle to accompany a child

Bicycle commute mode share

Total road network density

Street intersection density

$-.004 \quad .916$

Multimodal network density

$-.132^{* *}$

.001

$-.069$

.072

Pedestrian-oriented facility density

$-.168^{* *}$

.000

$-.175^{* *}$

.000

n $\{641,676\}$

* Correlation is significant at the 0.05 level (2-tailed).

** Correlation is significant at the 0.01 level (2-tailed). 
To further explore whether the implicit method appeared to be measuring a "real" (ie not related to chance) implicit bias, the means IAT score and the explicit measure of driver identity were plotted. This direct measure of identity centrality - "being a driver is an important part of who I am" - had a significant correlation with implicit preference $(\mathrm{r}=.139, \mathrm{p}=.000)$. There was a clear linear relationship between mean IAT score and response to the driver identity question (Figure 7), with relationship in the hypothesized direction; that is, the more strongly that respondents' identified as a driver, the greater their subconscious preference for drivers over bicyclists. The other significant correlations are not included here, but all had the similar trend, with strong pro-driver explicit attitude corresponding to implicit preferences for drivers, and vice versa.

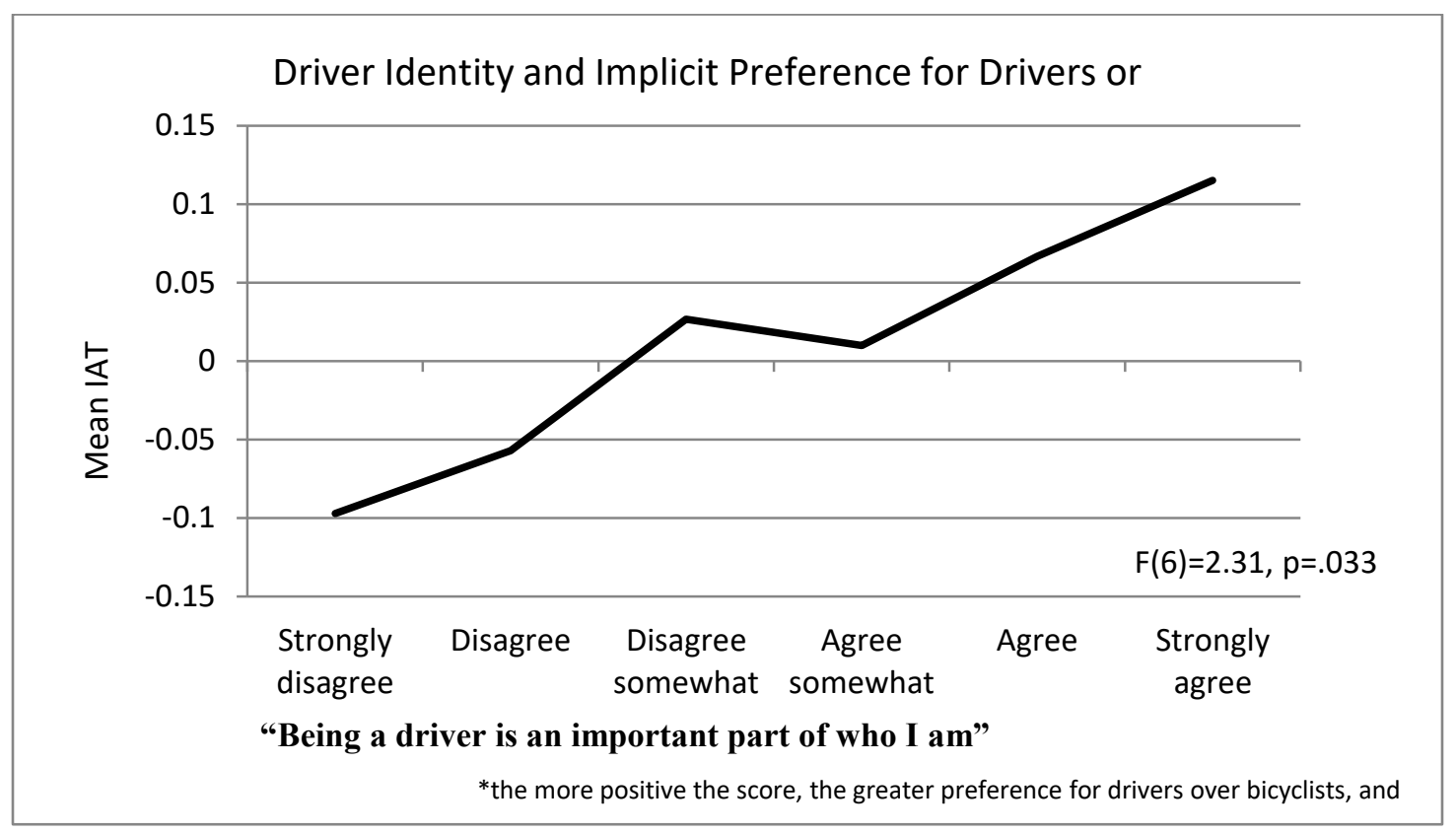

Figure 7 Driver Identity and Implicit Preference 


\section{Drivers who bicycle - or not}

To further explore the validity of the implicit and explicit measures, the IAT scores and attitudes were compared across respondents who also bicycle. It was hypothesized that drivers who also bicycle would have more positive attitudes toward bicyclists, and that there would be some threshold of bicycling regularity which shifted attitudes in a positive direction. To first examine attitudes between drivers who have not bicycled at all in the previous year with drivers who have at least "ridden a bicycle outside in the last year" (e.g. not in an exercise class), oneway ANOVAs were conducted for drivers who have bicycled outside in the last year but bicycle zero days in the typical week, only one of the attitudes even approached significance, and that was "I am a skilled driver" $(F=3.474, p=.063)$. None of the other measures varied between drivers who had bicycled in the last year and drivers who had not.

Significant differences emerged, however, when looking at drivers who bicycle regularly. Driver-bicyclists (DB) were defined as drivers who bicycled at least once a week in a "typical week with nice weather." Driver-non-bicyclists (DNB) may have bicycled outside at least once in the previous year but do not bicycle at least once a week. To examine the differences among DB and DNB on the individual attitudes, one-way ANOVAs were conducted (Table 16). Unlike the result using the driver identity scale, two of the driver identity measures did differ significantly between DB and DNB. Interestingly, driver-bicyclists had higher mean agreement on the measure "I am a skilled driver", which may reflect higher impression management regarding driving in the context of negotiating 
around bicyclists (Lajunen \& Summala, 2003). Driver-non-bicyclists had a higher mean agreement on the direct measure of driver identity. There was no significant difference between groups on the measure of being perceived as a good driver. As when combined in a scale format, none of the social norms attitudes were significantly different across groups. The only measure that fell out of significance when not used in a scale was the measure of culpability in the event of a crash, with DB and DNB sharing a mean weak agreement that drivers are usually not at fault in a crash between a driver and a bicyclist. 
Table 16. Attitude differences between driver-bicyclists and driver non-bicyclists

\begin{tabular}{|c|c|c|c|c|c|c|}
\hline Measure & $\begin{array}{l}\text { Driver } \\
\text { Bicyclist } \\
* \\
\text { (mean) }\end{array}$ & $\begin{array}{l}\text { Driver } \\
\text { Non } \\
\text { Bicyclist } \\
* \\
\text { (mean) }\end{array}$ & $\begin{array}{l}\text { SD } \\
\text { (pooled) }\end{array}$ & $\mathrm{F}$ & Sig. & $\begin{array}{l}\text { Effect } \\
\text { size }\end{array}$ \\
\hline Implicit attitude & -0.0622 & 0.0607 & 0.42327 & $\begin{array}{l}11.89 \\
1\end{array}$ & 0.001 & 0.3 \\
\hline I am a skilled driver & 5.02 & 4.79 & 0.998 & 7.147 & $\begin{array}{l}\mathbf{0 . 0 0} \\
8 \\
\end{array}$ & 0.2 \\
\hline $\begin{array}{l}\text { Being a driver is important } \\
\text { part of who I am }\end{array}$ & 3.84 & 3.99 & 1.466 & 1.314 & $\begin{array}{l}\mathbf{0 . 0 0} \\
8\end{array}$ & 0.2 \\
\hline $\begin{array}{l}\text { I care if my family and friends } \\
\text { think of me as a good driver }\end{array}$ & $4 \cdot 54$ & 4.38 & 1.204 & 2.549 & 0.111 & 0.1 \\
\hline $\begin{array}{l}\text { Building infrastructure for } \\
\text { bicyclists is not a good } \\
\text { investment of public funds }\end{array}$ & 2.09 & 2.53 & 1.221 & $\begin{array}{l}18.38 \\
3\end{array}$ & $\begin{array}{l}\text { o.oo } \\
\mathbf{o}\end{array}$ & 0.4 \\
\hline $\begin{array}{l}\text { Bicyclists should not be } \\
\text { allowed to filter forward } \\
\text { through lanes of slow or } \\
\text { stopped car traffic }\end{array}$ & 3.72 & 4.05 & 1.39 & $7 \cdot 55^{2}$ & 0.006 & 0.2 \\
\hline $\begin{array}{l}\text { If a driver and a bicyclist collide, } \\
\text { it is usually not the fault of the } \\
\text { driver }\end{array}$ & 3.43 & 3.47 & 1.126 & 0.179 & 0.673 & 0.1 \\
\hline $\begin{array}{l}\text { I do not see bicyclists } \\
\text { similar to me on city streets }\end{array}$ & 3.02 & 3.91 & 1.43 & 58.34 & $\begin{array}{l}\mathbf{0 . 0 0} \\
\mathbf{O}\end{array}$ & 0.6 \\
\hline $\begin{array}{l}\text { It makes me angry if I see other } \\
\text { drivers breaking the rules of the } \\
\text { road }\end{array}$ & 2.45 & 2.44 & 1.026 & 0.017 & 0.898 & 0.01 \\
\hline $\begin{array}{l}\text { Bicyclists shouldn't hold up } \\
\text { traffic }\end{array}$ & 4.29 & 4.41 & 1.139 & 1.725 & 0.190 & 0.1 \\
\hline $\begin{array}{l}\text { It makes me angry if I see } \\
\text { bicyclists breaking the rules of } \\
\text { the road }\end{array}$ & 3.99 & 4.13 & 1.297 & 1.519 & 0.218 & 0.1 \\
\hline $\begin{array}{l}\text { Bicyclists should have to } \\
\text { pass a license test just like } \\
\text { drivers do }\end{array}$ & 2.9 & 3.21 & 1.357 & 7.275 & $\mathbf{0 . 0 0 7}$ & 0.2 \\
\hline $\begin{array}{l}\text { Bicyclists should have to } \\
\text { register and pay taxes }\end{array}$ & 2.12 & 2.63 & 1.198 & $\begin{array}{l}25.16 \\
3 \\
\end{array}$ & $\begin{array}{l}\text { o.oo } \\
\mathbf{o}\end{array}$ & 0.4 \\
\hline
\end{tabular}

*Driver-Bicyclists bicycle at least once/week in a "typical week with nice weather", while Driver-Non-Bicyclists may or may not have bicycled outside in the last year, but bicycle zero days in the typical week with nice weather.

**Effect size is calculated as the absolute value of mean difference between driver-bicyclists and driver-non-bicyclists divided by the pooled standard deviation. Conventional small, medium, and large effect sizes are $0.2,0.5$, and 0.8 , respectively. 


\section{Factor analysis}

To examine whether the variables were correlated and whether they could be reduced to factors, an exploratory factor analysis was conducted using Principal Components Analysis with a Varimax rotation. The rotation was chosen for ease of interpretation (Cohen, 2011). Factor loadings below 0.5 were suppressed. Through this analysis, the items were reduced to four factors that explained 57 percent of the total variance (Table 17). Four factors emerged and were named based on the interpretation of what underlying constructs they measured, informed by social psychological theories of Social Identity Theory, System Justification Theory, and Social Dominance Orientation (see Chapter 2 for discussion). A fourth factor that was named "road user legitimacy" due to its composition of the two items measuring drivers' agreement that bicyclists need to be licensed, registered, and pay taxes to be legitimate roadway users like drivers. 
Table 17 Factors for identity and attitudes

Factor

Statement

Loading*

\begin{tabular}{llc}
\hline Driver identity & I am a skilled driver & 0.776 \\
& $\begin{array}{l}\text { Being a driver is important part of who I am } \\
\text { I care if my family and friends think of me as a good driver }\end{array}$ & 0.722 \\
& $\begin{array}{l}\text { Building infrastructure for bicyclists is a good investment } \\
\text { of public funds }\end{array}$ & -0.742 \\
\hline $\begin{array}{l}\text { Support for auto- } \\
\text { centric system }\end{array}$ & $\begin{array}{l}\text { Bicyclists should be allowed to filter forward through } \\
\text { lanes of slow or stopped car traffic }\end{array}$ & -0.595 \\
& $\begin{array}{l}\text { When a driver and a bicyclist collide, it is typically the } \\
\text { fault of the driver }\end{array}$ & -0.507 \\
\hline $\begin{array}{l}\text { Pro-driver/anti- } \\
\text { bicyclist social } \\
\text { norms }\end{array}$ & $\begin{array}{l}\text { It makes me angry if I see bicyclists breaking the rules of } \\
\text { the road }\end{array}$ & 0.659 \\
\hline $\begin{array}{l}\text { Bicyclists shouldn't hold up traffic } \\
\text { Road user }\end{array}$ & $\begin{array}{l}\text { It makes me angry if I see other drivers breaking the rules } \\
\text { of the road }\end{array}$ & $\begin{array}{l}\text { Bicyclists should have to pass a license test just like } \\
\text { drivers do } \\
\text { Bicyclists should have to register and pay taxes }\end{array}$ \\
\hline
\end{tabular}

${ }^{*}$ Represents the association (correlation) of each survey item with its factor

Although the measures had high factor loadings, the internal consistency was poor to modest, with Cronbach's alpha ranging from 0.397 to 0.575. It would not be recommended to consider these as comprehensive scales. Because of the high factor loadings and the ease of analysis, however, combined measures were created by taking the mean agreement of each set of items. Summary stats for the four measures are shown in Table 18. As expected by the skewness of the individual driver identity items, the driver identity scale was moderately skewed in the pro-driver direction. The system support and social norms measures were approximately symmetric, and the legitimacy measure was moderate skewed in 
the pro-bicyclist direction. Only the driver identity measure demonstrated kurtosis, with a high peak around mean agreement from 4.33 to 5 . Despite the issues of skew and kurtosis, the scales demonstrated close enough to normal distributions (Figure 8, Figure 9,Figure 1o, Figure 11) when combined with the large sample size, that justified (Cohen, 2011) the use of ANOVA and linear regression in later analyses.

Table 18 Explicit attitude measures

\begin{tabular}{|c|c|c|c|c|c|c|c|}
\hline & $\mathrm{N}$ & Min. & Max. & Mean & SD & Skewness & Kurtosis \\
\hline $\begin{array}{l}\text { Driver } \\
\text { Identity }\end{array}$ & 665 & 1 & 6 & 4.412 & 0.9085 & -0.915 & 1.647 \\
\hline $\begin{array}{l}\text { System } \\
\text { support }\end{array}$ & 642 & 1.25 & 6 & $3 \cdot 3649$ & 0.8021 & 0.107 & 0.072 \\
\hline Social norms & 655 & 1 & 6 & 4.3369 & 0.807 & -0.217 & 0.095 \\
\hline $\begin{array}{l}\text { Road user } \\
\text { legitimacy }\end{array}$ & 663 & 1 & 6 & 2.7986 & 1.0923 & 0.575 & 0.095 \\
\hline $\begin{array}{l}\text { Valid n } \\
\text { (listwise) }\end{array}$ & 625 & & & & & & \\
\hline
\end{tabular}




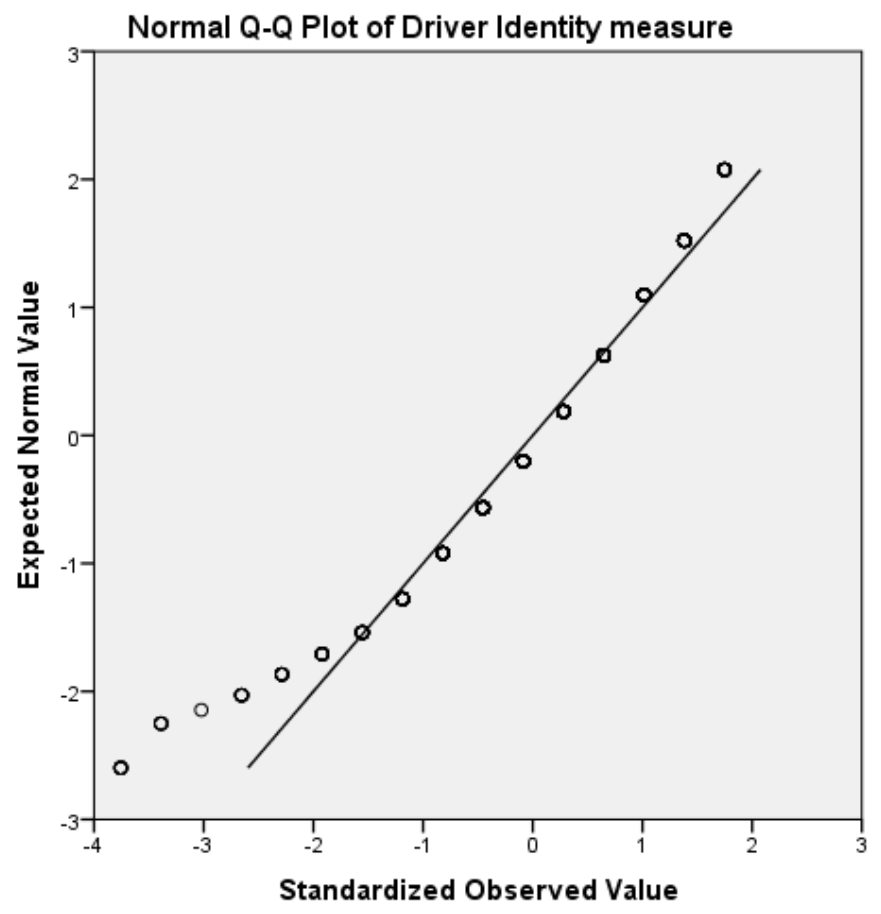

Figure 8 Q-Q plot of the Driver Identity measure

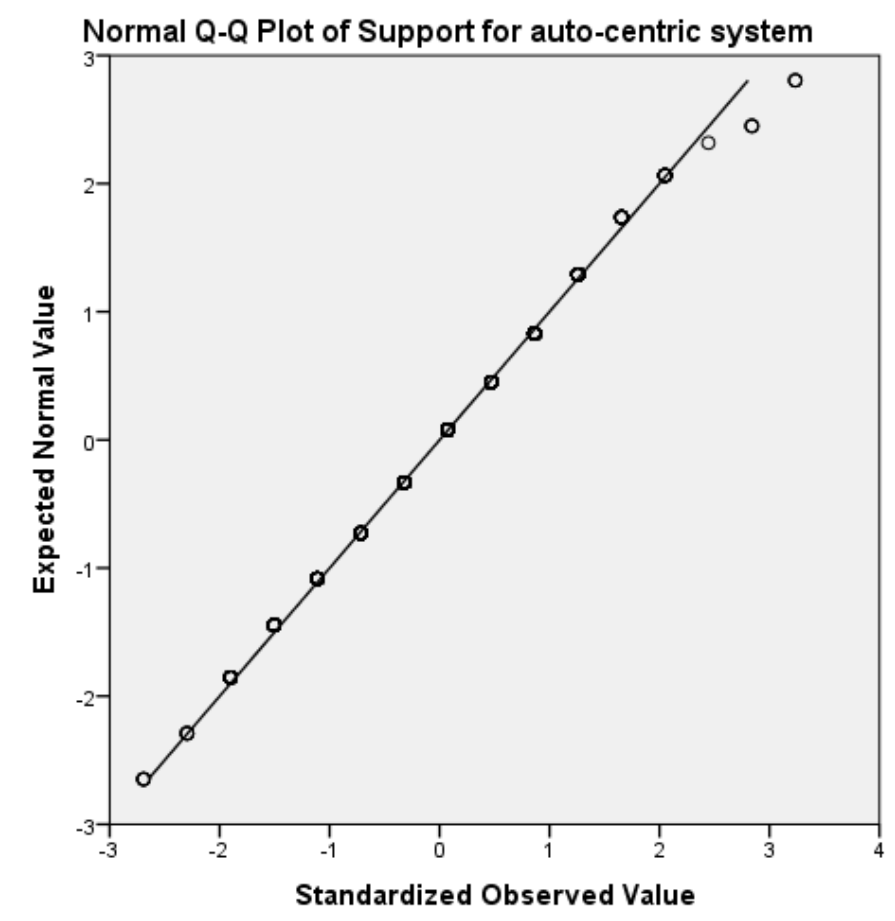

Figure 9 Q-Q plot of the system support measure 


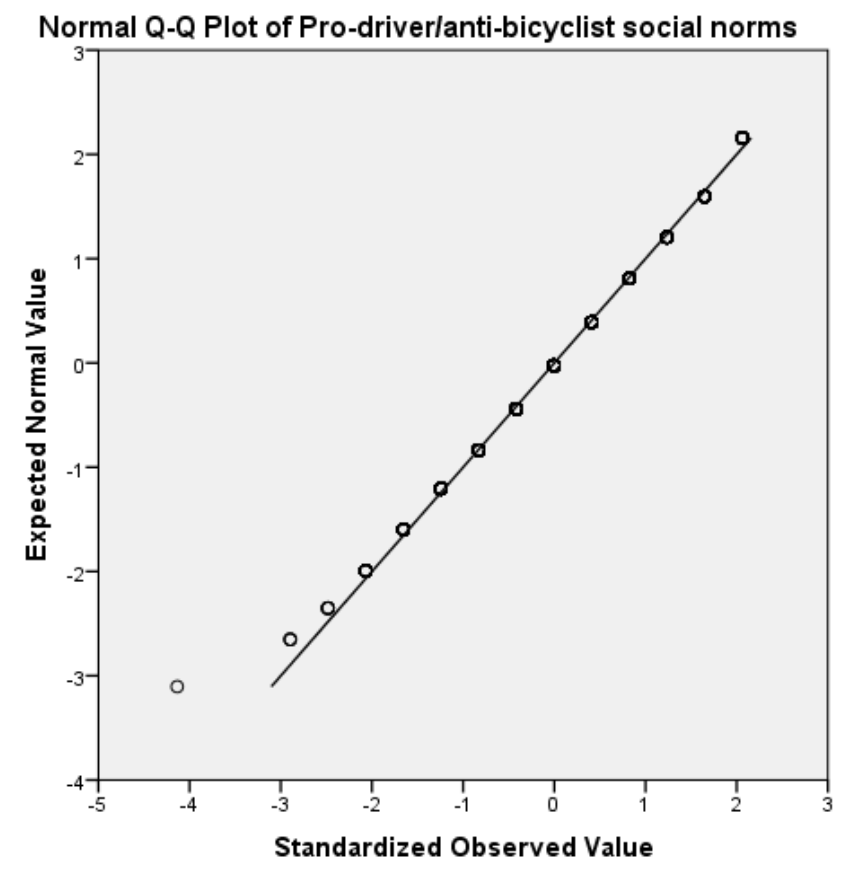

Figure 10 Q-Q plot of the social norms measure

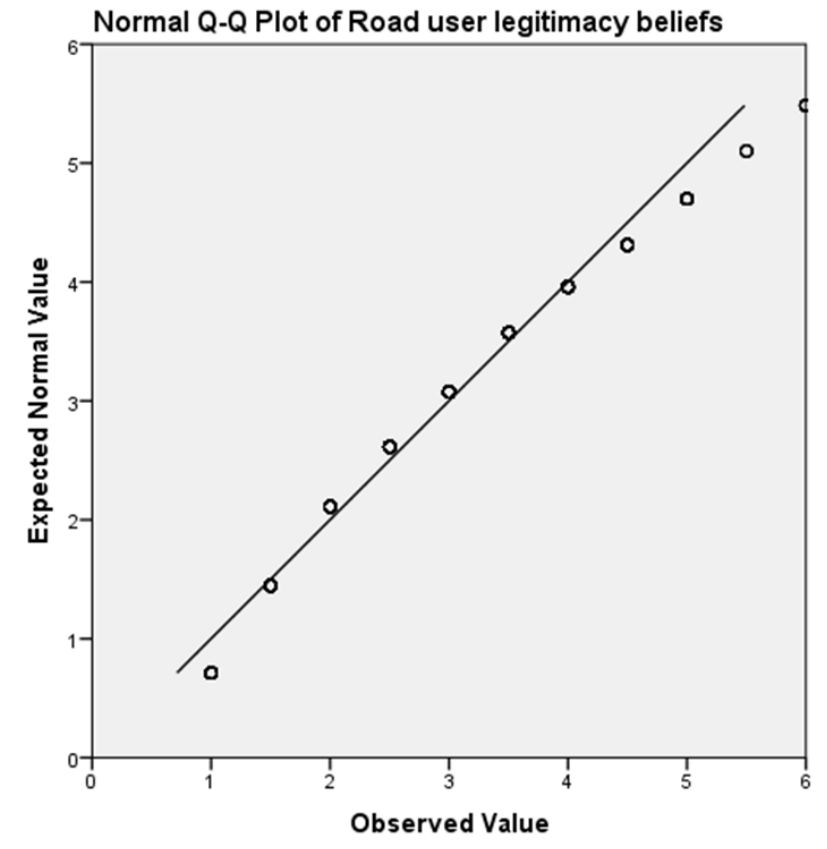

Figure 11 Q-Q plot of the road user legitimacy measure 


\section{Bivariate examination of attitudes}

To explore the relationships between explicit attitudes (i.e. the combined measures) and demographics, travel behavior, the built environment, and implicit attitudes, the data were first analyzed with correlations, one-way analysis of variance (ANOVAs), and simple linear regression with each explicit attitude as the dependent variable and the variable of interest as a single predictor variable. Significant correlations emerged between the IAT scores and all four attitude measures (Table 19), although correlations were small, ranging from 0.098 to 0.191. All associations were, however, in the hypothesized direction, with a preference for drivers over bicyclists positively correlated with stronger antibicyclist attitudes (Figure 12, Figure 13, Figure 14, Figure 15). The significant but small correlations with the explicit measures indicated that the IAT is measuring implicit preference and is not just random, and that implicit attitude is related but distinct from the explicit measures (Nosek et al., 2005).

Table 19 Association of explicit and implicit attitudes

\begin{tabular}{llllll} 
& $\begin{array}{l}\text { Implicit } \\
\text { attitude }\end{array}$ & $\begin{array}{l}\text { Driver } \\
\text { Identity }\end{array}$ & $\begin{array}{l}\text { System } \\
\text { support }\end{array}$ & $\begin{array}{l}\text { Social } \\
\text { norms }\end{array}$ & $\begin{array}{l}\text { Road user } \\
\text { legitimacy }\end{array}$ \\
\hline Implicit attitude & - & & & & \\
Driver identity & $.098^{*}$ & - & & & \\
System support & $\mathbf{. 1 6 8}^{* *}$ & -.032 & - & & \\
Social norms & $\mathbf{. 1 0 3}^{* *}$ & $\mathbf{. 1 4 3}^{* *}$ & $\mathbf{. 1 5 9}^{* *}$ & - & - \\
Road user legitimacy & $\mathbf{. 1 0 4}^{* *}$ & -.022 & $\mathbf{. 1 7 8}^{* *}$ & $\mathbf{. 2 6 7}^{* *}$ & \\
\hline *. Correlation is significant at the 0.05 level (2-tailed). & & \\
**. Correlation is significant at the 0.01 level (2-tailed).
\end{tabular}




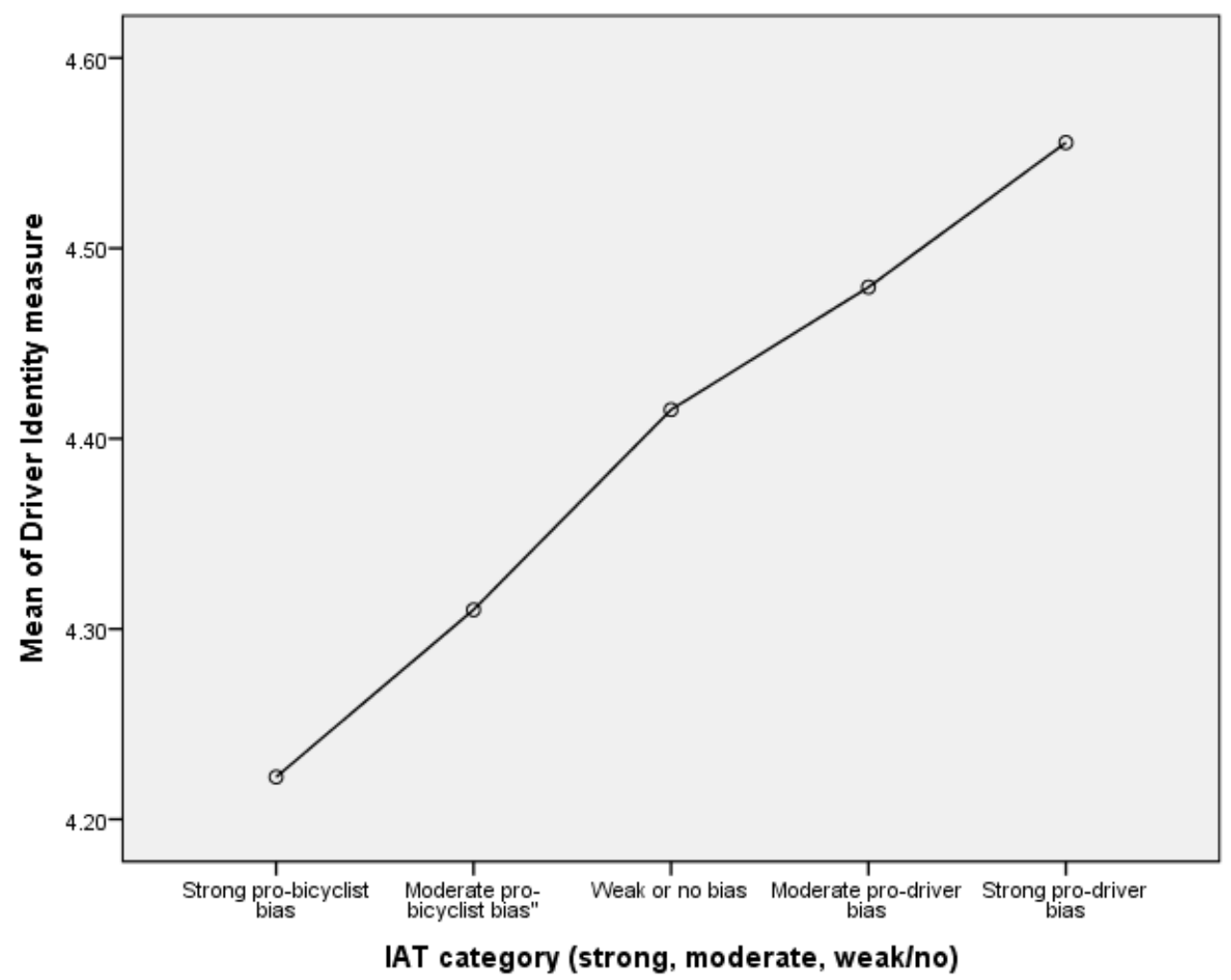

Figure 12 Relationship of implicit attitude and mean scores on the Driver Identity measure 


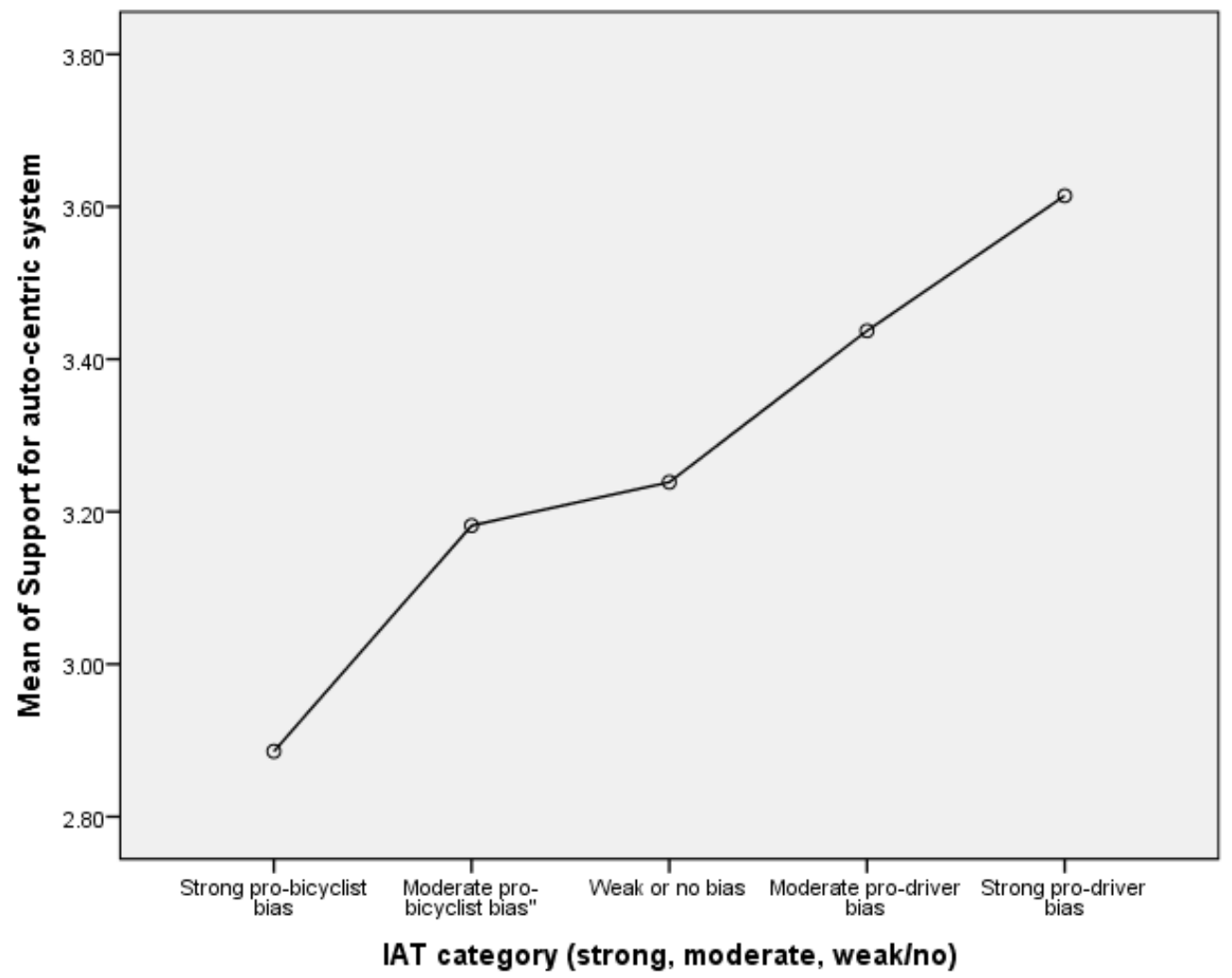

Figure 13 Relationship of implicit attitude and mean scores on the system support measure 


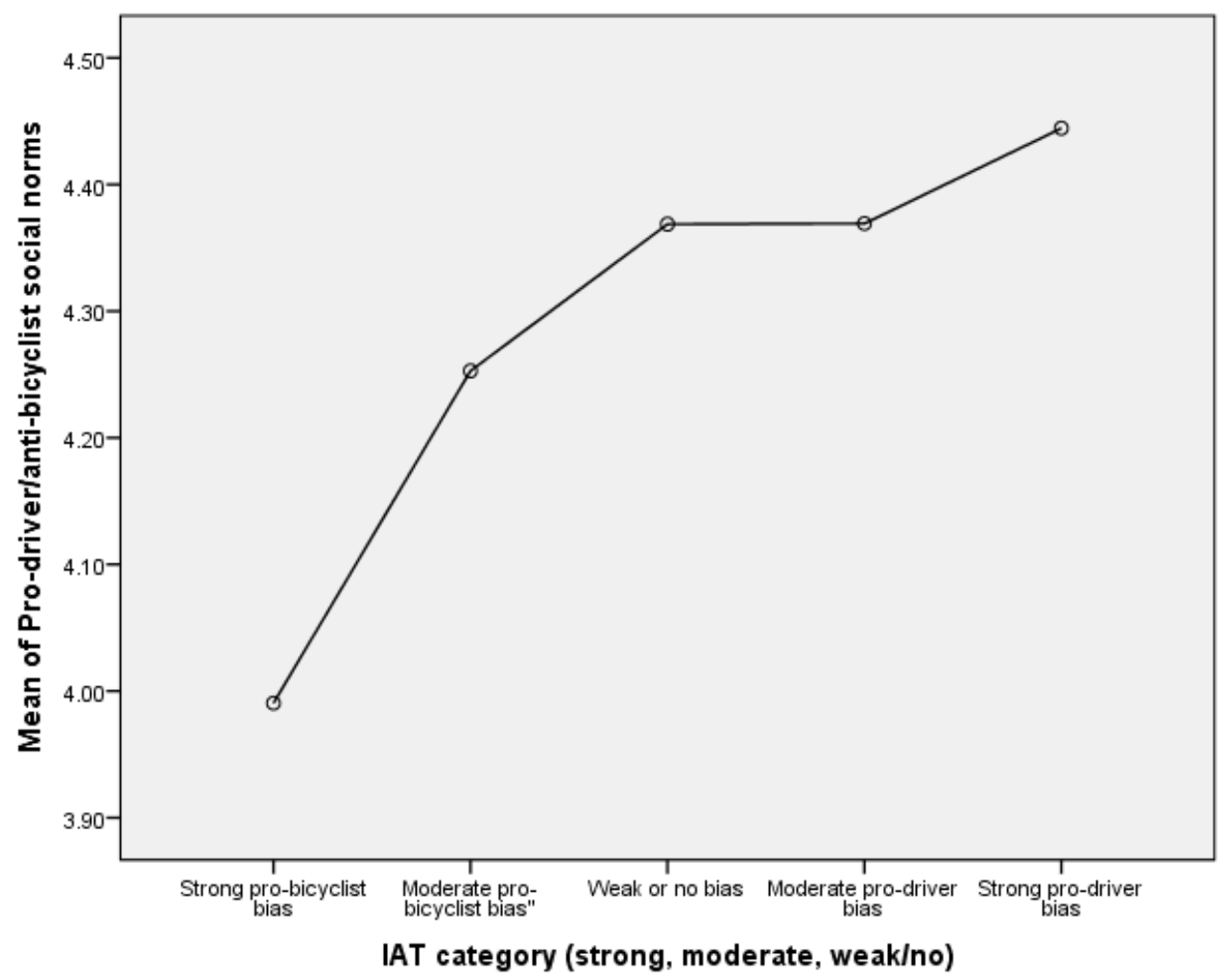

Figure 14 Relationship of implicit attitude and mean scores on the social norms measure 


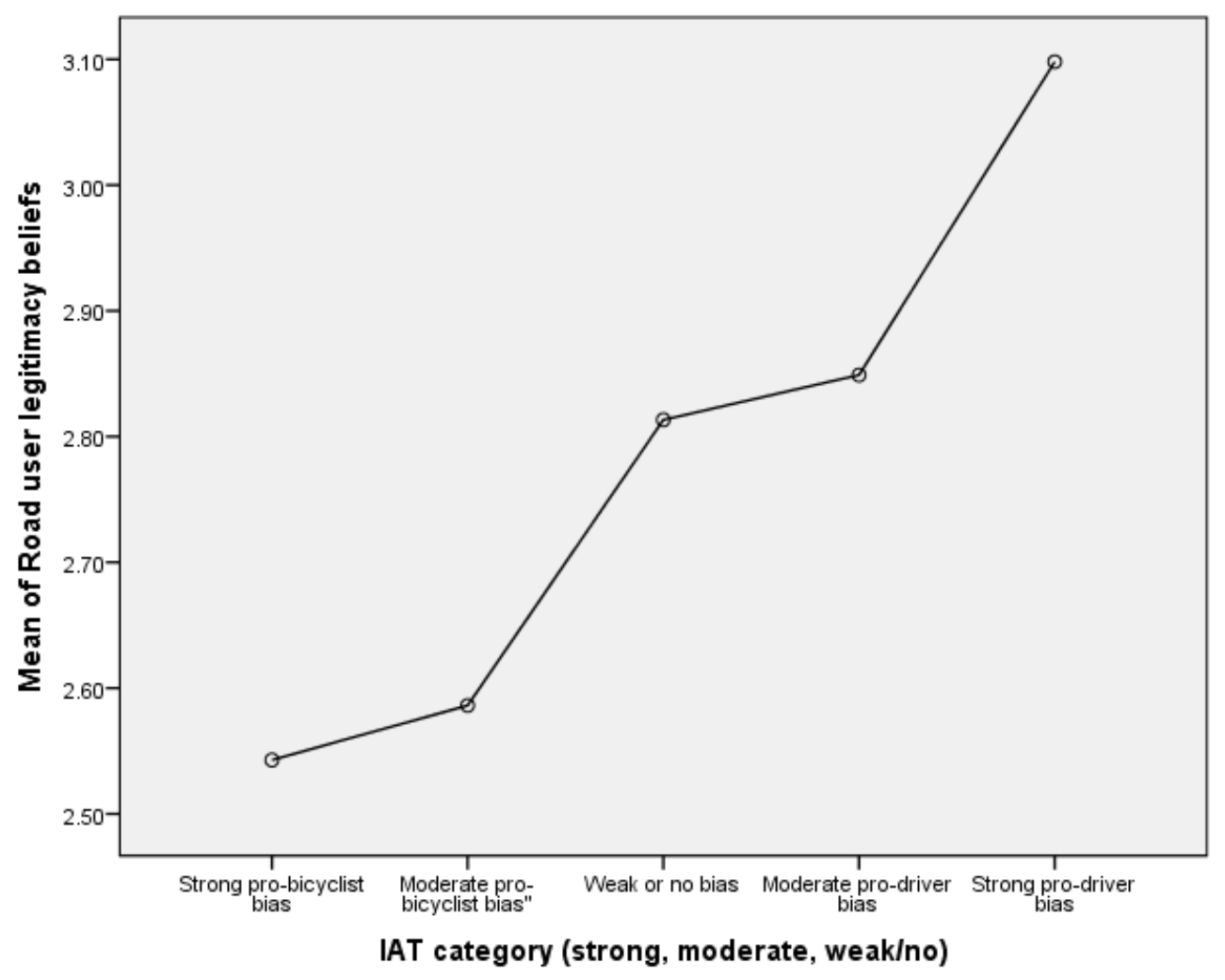

Figure 15 Relationship of implicit attitude and road user legitimacy measure 
Bicycle commute mode share and street intersection density are significantly but modestly correlated $(\mathrm{r}=.379, \mathrm{p}=.000)$, so both built environment measures are included in analyses. Implicit attitude (i.e. IAT d score) was significantly and inversely correlated with both street intersection density and bicycle commute mode share. Both driver identity and system support were inversely correlated with street intersection density. Social norms did not have a significant association with any of the built environment measures. Both system support and social norms were correlated with bicycle commute mode share. Neither of these built environment measures were correlated with the legitimacy measure. All of the significant correlations were weak in magnitude, but suggest that there exists a relationship between attitudes and the built environment, at least when not controlling for other factors or self-selection bias.

Table 20 Association of attitudes and built environment measures

Street intersection density Bicycle commute mode share

\begin{tabular}{lcc}
\hline Implicit attitude & $\mathbf{- . 1 1 1}^{* *}$ & $-\mathbf{. 1 2}^{* *}$ \\
Driver Identity & $\mathbf{. . 1 0 2}^{*}$ & -.043 \\
System support & $\mathbf{. . 1 3 2}^{* *}$ & $\mathbf{. 1 2 1}^{* *}$ \\
Social norms & -.033 & $-.088^{*}$ \\
Legitimacy & .034 & -.013 \\
\hline $\begin{array}{l}\text { Bicycle commute mode } \\
\text { share }\end{array}$ & $\mathbf{. 3 7 9}^{* *}$ & - \\
\hline
\end{tabular}

* Correlation is significant at the 0.05 level (2-tailed).

** Correlation is significant at the o.01 level (2-tailed).

Examining the relationships of the mean scores with the built environment revealed varying patterns of association, with implicit attitude and street intersection density having the most direct, linear association (Figure 16). The 
association of bicycle commute mode share and implicit attitude revealed that respondents with even moderate biases either toward bicyclists or drivers live in areas with approximately a 1 percent bicycle commute mode share (the national average is 0.6 percent), while a mean mode share of 2 percent was associated with strong pro-bicyclist implicit bias, and strong pro-driver implicit bias was associated with a mean bicycle mode share of less than 0.5 percent (Figure 17). The remaining significant correlations of the built environment measures and attitude measures are shown in Figures 17-20.

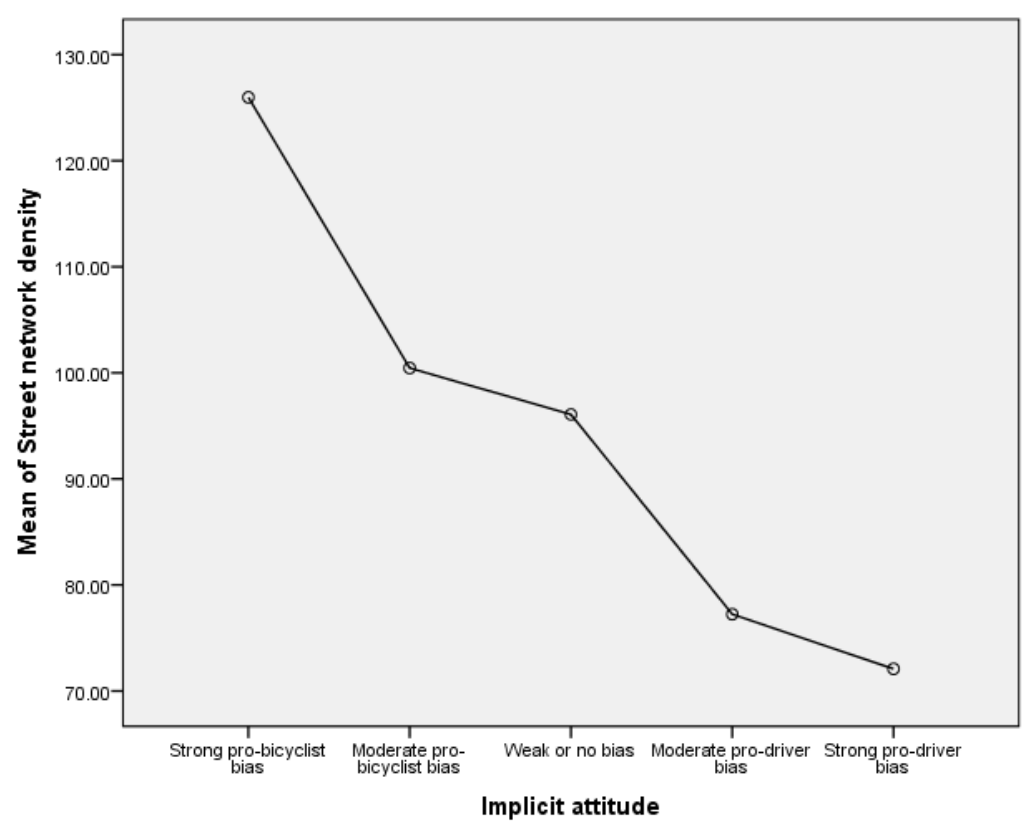

Figure 16 Relationship of implicit attitude and mean street network density 


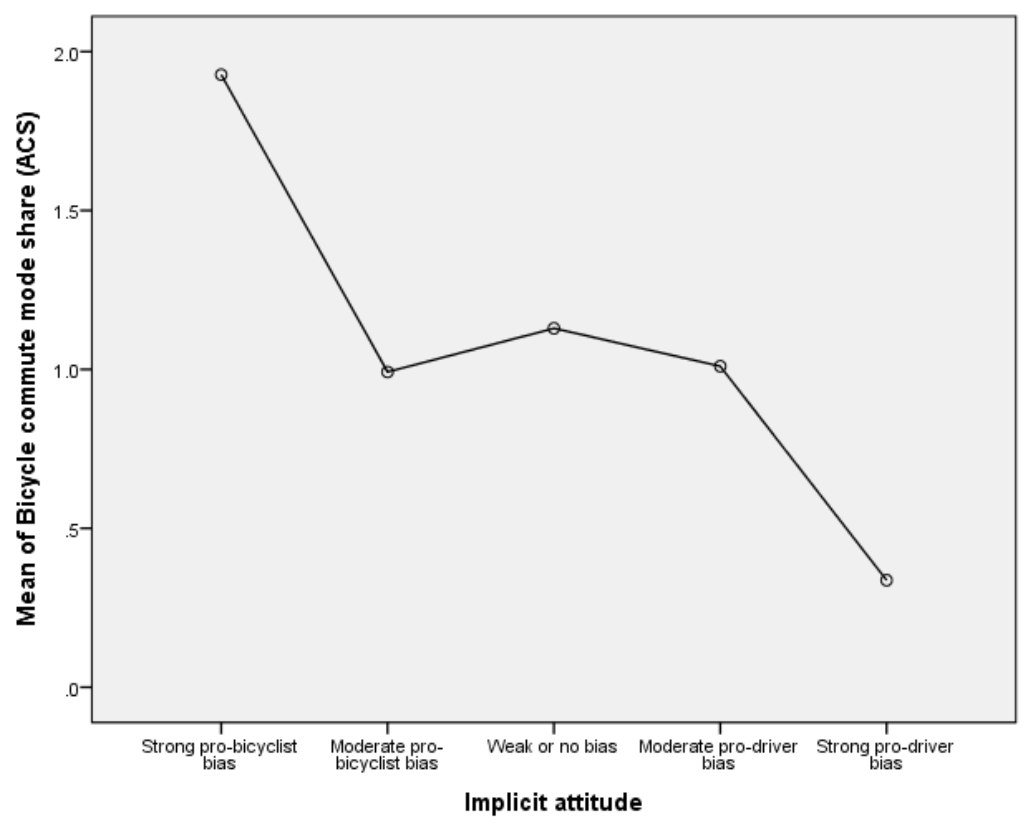

Figure 17 Relationship of implicit attitude and mean bicycle commute mode share

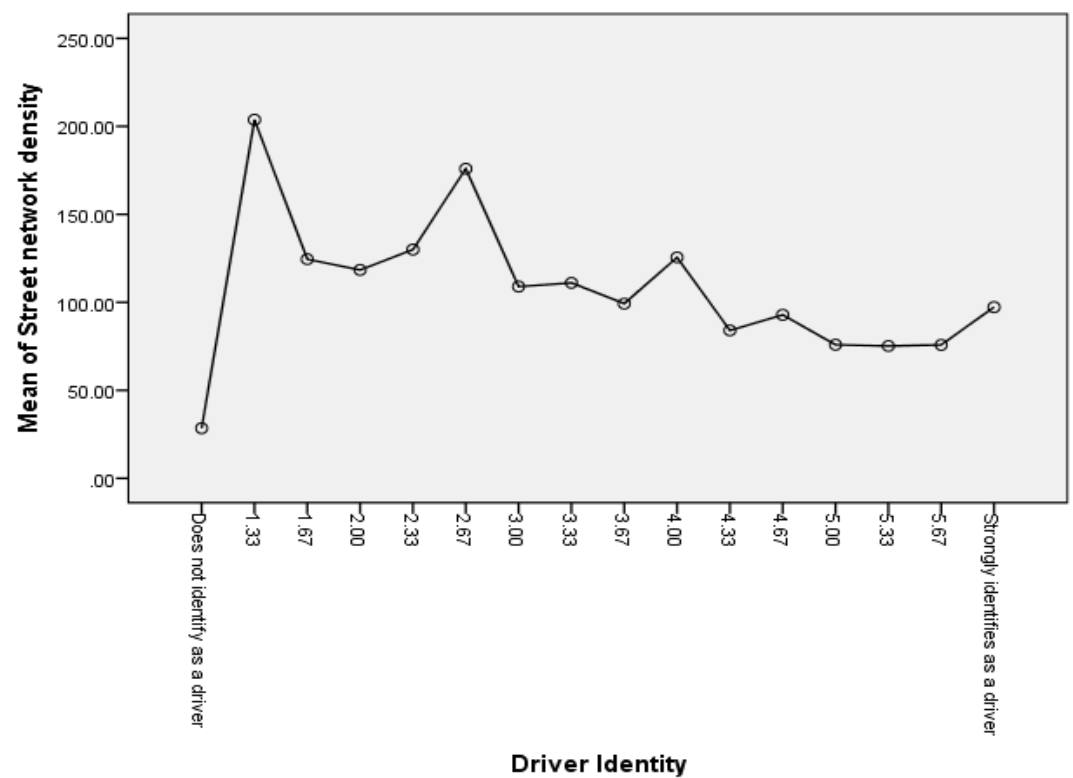

Figure 18 Relationship of Driver Identity measure and mean street network density 


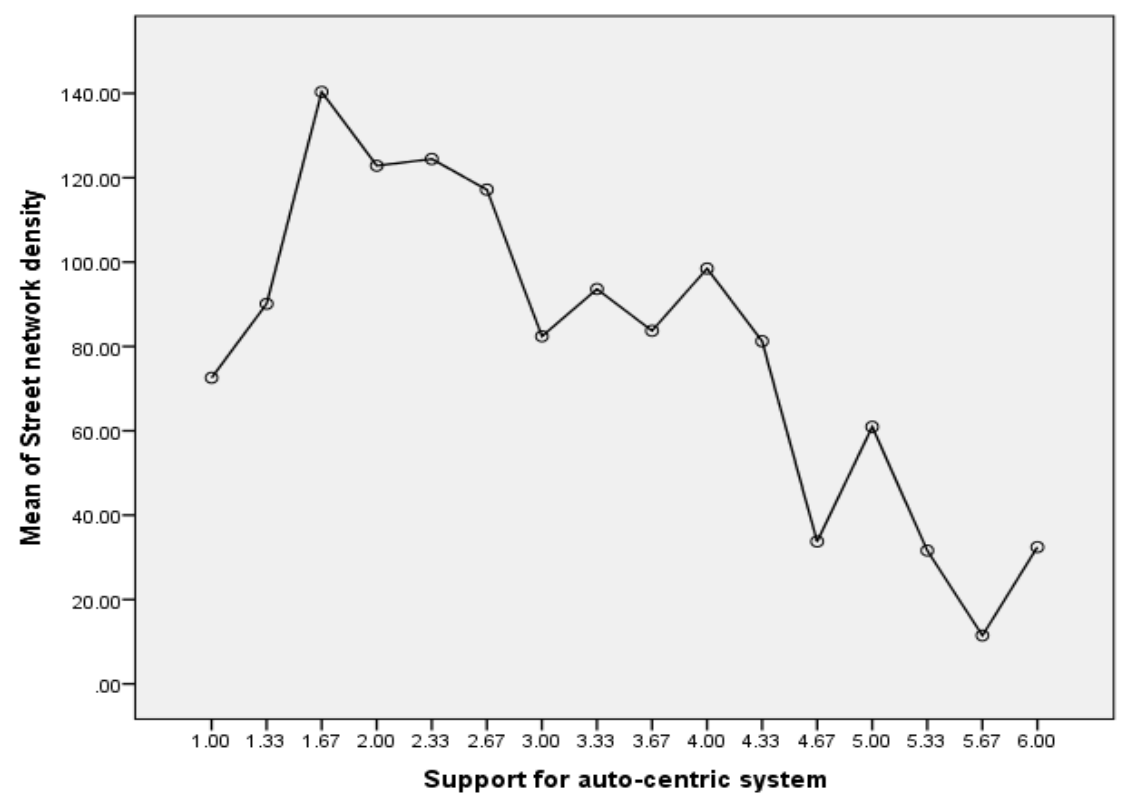

Figure 19 Relationship of system support measure and mean street network density

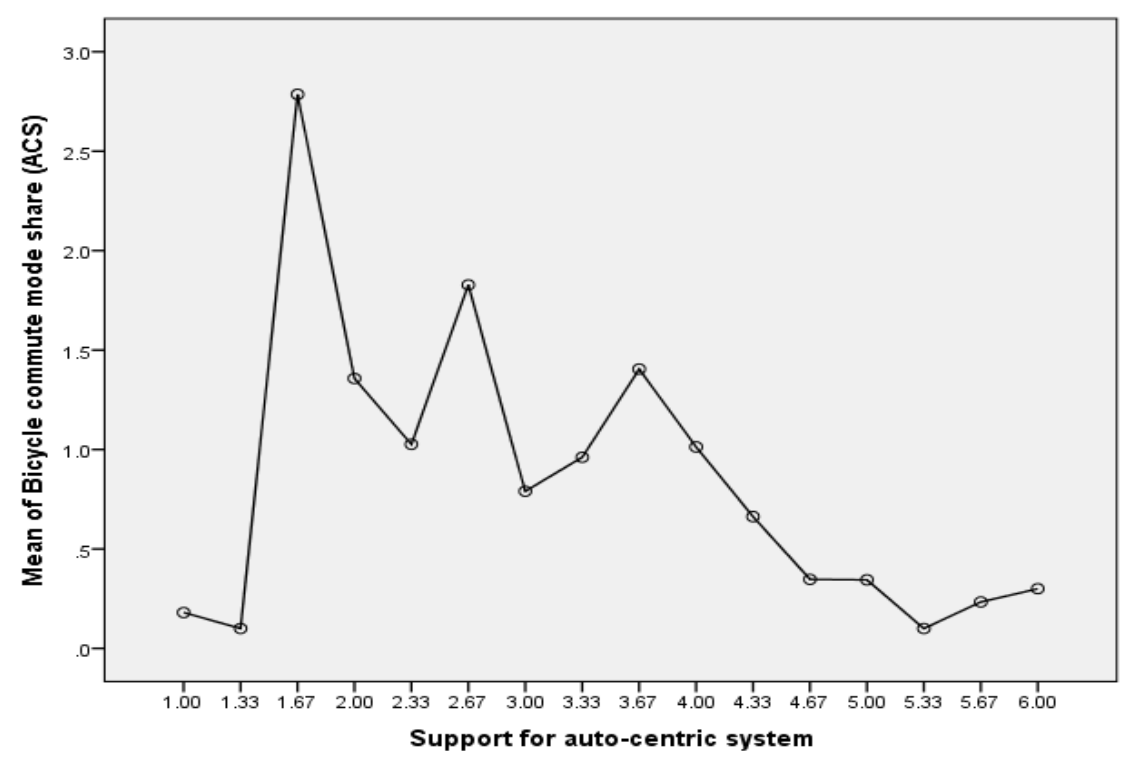

Figure 20 Relationship of system support and bicycle commute mode share 


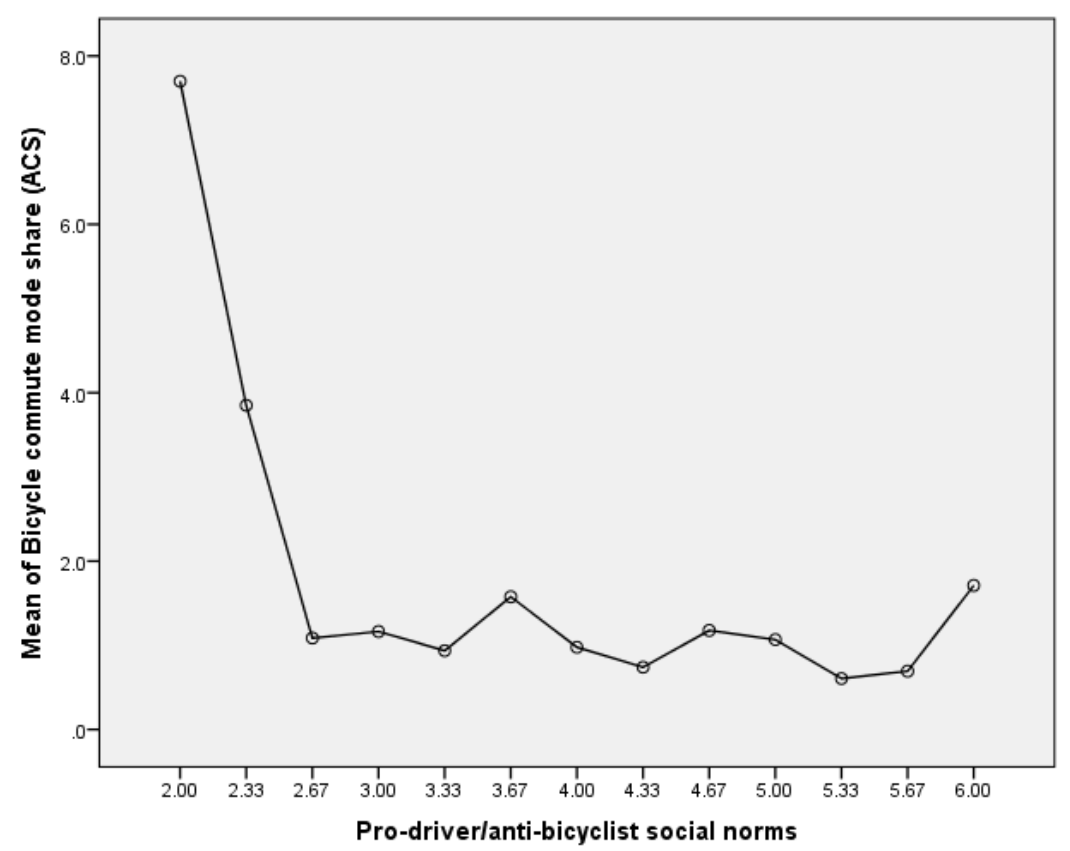

Figure 21 Relationship of social norms and bicycle commute mode share

Further bivariate analyses were conducted between each explicit attitude and the demographic and travel behavior measures. In the case of driver identity (Table 21), only two demographic measures were significant. Not having children in the household and older age were associated with stronger driver identity. Similarly, only two travel behavior measures were significant. Driving frequency was positively and strongly associated with driver identity $(\mathrm{r}=0.200, \mathrm{p}=0.000)$. Bicycling as a child was also positively associated with driver identity. 
Table 21 Bivariate analyses of the Driver Identity measure

Driver Identity

measure

Mean SD $\quad$-value*

Demographics

\begin{tabular}{lllll} 
Gender & Men & 4.48 & 0.90 & 0.204 \\
& Women & 4.38 & 0.91 & \\
\hline \multirow{2}{*}{ Race } & Race (white) & 4.40 & 0.88 & 0.805 \\
& Race (non-white & 4.43 & 0.97 & \\
\hline \multirow{2}{*}{ Children } & Have kids in HH & 4.36 & 0.89 & \multirow{2}{*}{$\mathbf{0 . 0 2 7}$} \\
& No kids in HH & 4.52 & 0.94 & \\
\hline \multirow{2}{*}{ Ege } & Baby Boomers & 4.49 & 0.91 & \multirow{2}{*}{$\mathbf{0 . 0 4 8}$} \\
& Gen X-ers & 4.47 & 0.88 & \\
& Millennials & 4.30 & 0.95 & \\
& Some college & 4.47 & 0.98 & \multirow{2}{*}{0.800} \\
& 2-year degree & 4.38 & 0.79 & \\
& 4-year degree & 4.38 & 0.99 & \\
& Some grad school & 4.52 & 0.91 & \\
& Master's & 4.39 & 0.77 & \\
& Adv degree & 4.46 & 0.78 & \\
\hline
\end{tabular}

Travel behavior

\begin{tabular}{llll} 
Driving frequency & 5.80 & 1.93 & $\mathbf{0 . 0 0 0}$ \\
\hline Bicycle weekly (no) & 4.39 & 0.90 & 0.234 \\
Bicycle weekly (yes, $\mathrm{n}=192)$ & 4.48 & 0.92 & \\
\hline Bicycle for recreation (no) & 4.38 & 0.94 & \multirow{2}{*}{0.300} \\
Bicycle for recreation (yes, $\mathrm{n}=320$ ) & 4.45 & 0.87 & \\
\hline Bicycle for commute/errands (no) & 4.44 & 0.90 & \multirow{2}{*}{0.151} \\
Bicycle for commute/errands (yes, $\mathrm{n}=110)$ & 4.31 & 0.94 & \\
\hline Bicycle to accompany child (no) & 4.42 & 0.88 & \multirow{2}{*}{0.626} \\
Bicycle to accompany child (yes, $\mathrm{n}=45$ ) & 4.35 & 1.21 & \\
\hline Bicycled as a child (no) & 4.10 & 0.94 & \multirow{2}{*}{$\mathbf{0 . 0 1 1}$} \\
Bicycled as a child (yes, $\mathbf{n = 6 0 5})$ & 4.44 & 0.90 & \\
\hline
\end{tabular}

*p-value for F-statistics for one-way ANOVA or simple linear regression

For system support (Table 22), age and education were significantly associated with driver identity. The youngest respondent age group ("Millennials") rated highest on the system support measure. Respondents in the three lowest 
education categories had the highest mean system support score $(r=-0.240$, $\mathrm{p}=0.000$ ), with people holding an Associate's degree most strongly supporting the automobile system. Driving frequency was significantly and positively correlated with system support $(\mathrm{r}=0.181, \mathrm{p}=0.000)$. Weekly bicycling and bicycling for both recreation and commute or errands were significantly associated with lower driver identity. Utilitarian trip purposes seemed to have a more significant effect: Using a bicycle to commute or run errands resulted in a mean difference in system support that was 2.67 times the mean difference of the recreation rider ( 0.48 versus 0.18 , respectively). 
Table 22 Bivariate analsyes of the System support measure

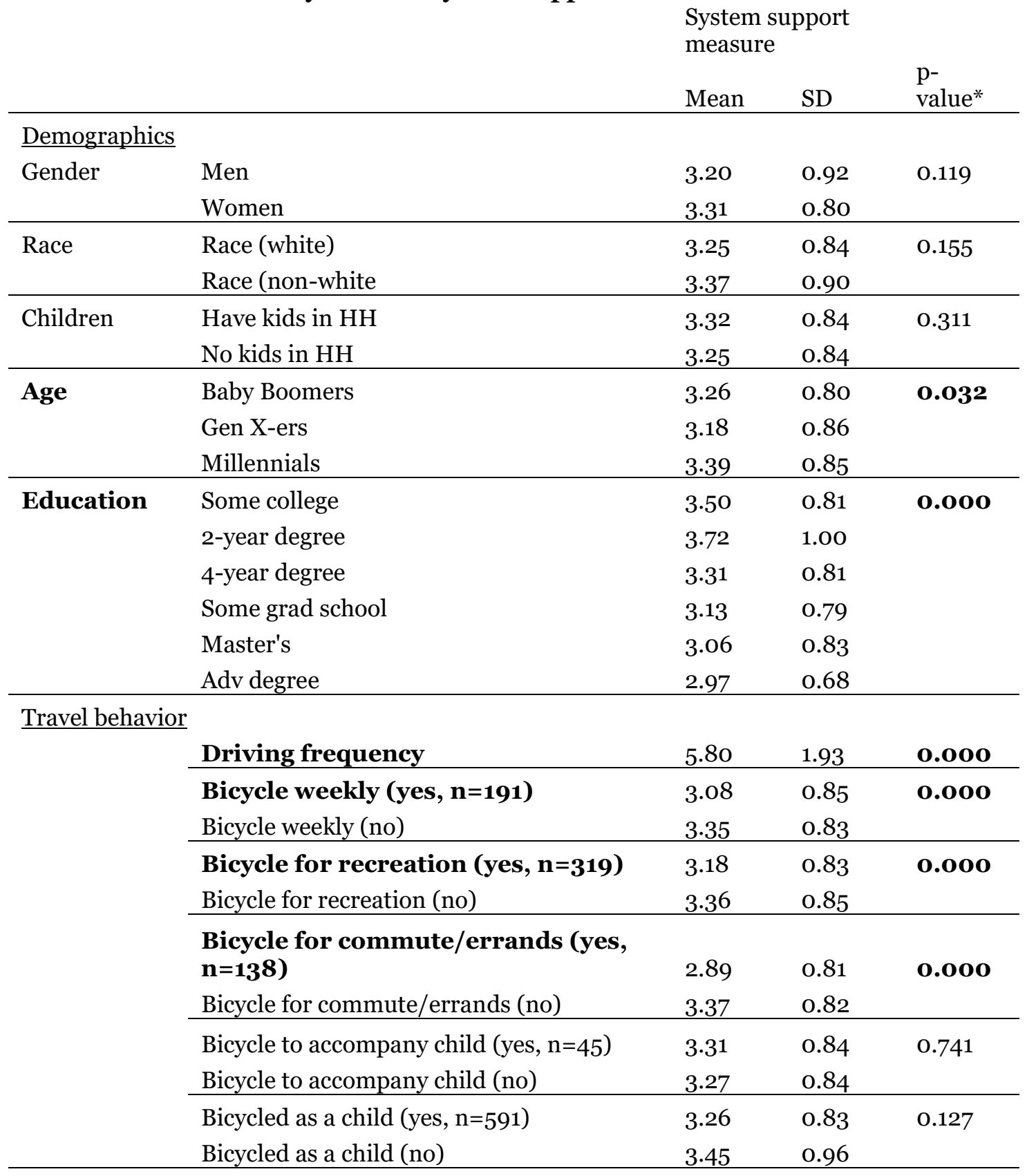

${ }^{*}$ p-value for F-statistics for one-way ANOVA or simple linear regression

In the analyses of the social norms measure (Table 23), age was significantly and negatively correlated $(\mathrm{r}=-0.106, \mathrm{p}=0.007)$ with social norms. Examining the age 
generations, Baby Boomers and Gen X-ers did not differ significant in social norms, but Millennials had higher mean social norms attitudes. None of the travel behavior measures were significantly associated with social norms in the bivariate analyses. 
Table 23 Bivariate analyses of the Social norms measure

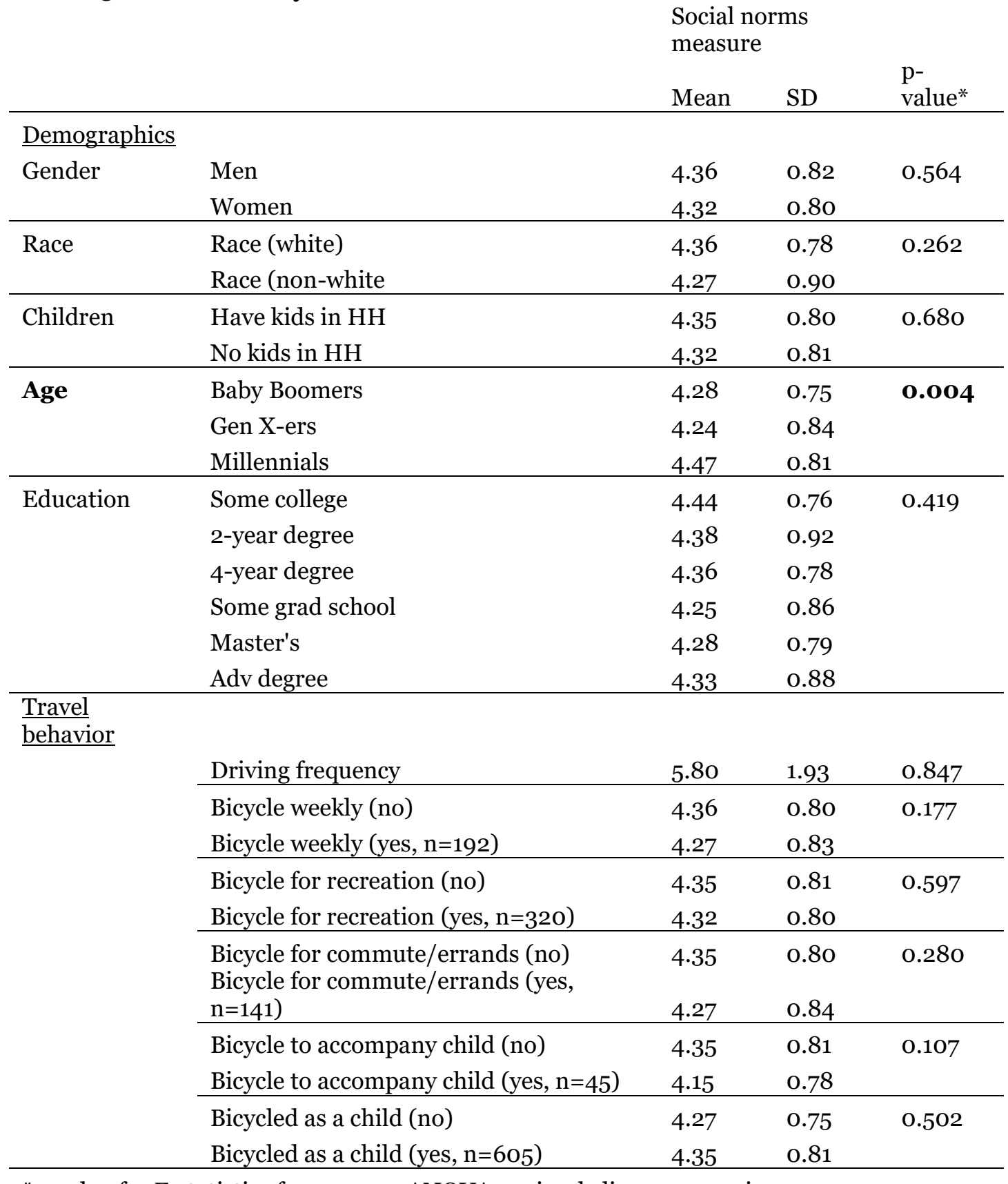

${ }^{*}$ p-value for F-statistics for one-way ANOVA or simple linear regression

In the case of roadway legitimacy (Table 24), both gender and age were significantly associated with the scale comprised of attitudes toward whether 
bicyclists should register and pay taxes and be licensed like drivers. Women, Baby Boomers, and all non-bicyclists had the highest agreement that bicyclists should be required to legitimize themselves. It should be noted, however, that mean agreement in all cases except childhood bicyclists was less than 3.0; that is, every group generally disagreed that bicyclists need registration or licensing. 
Table 24 Bivariate analsyes of the Road user legitimacy measure

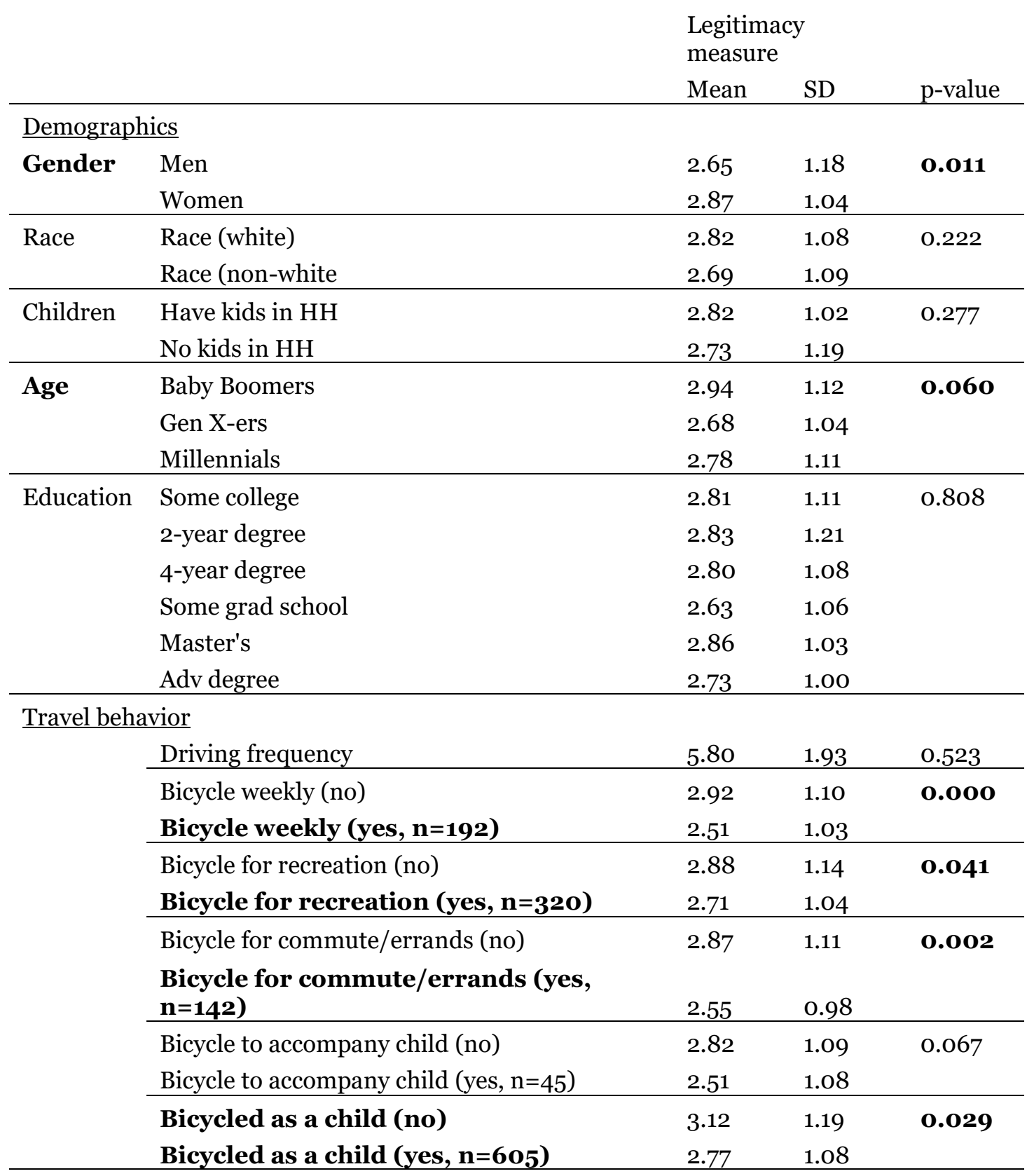

*p-value for F-statistics for one-way ANOVA or simple linear regression 


\section{Regression models on explicit attitude scales}

It is expected that some of these factors are related (Figure 22) and thus their relationships with the explicit attitudes required multivariate analyses. To better understand these multivariate relationships, a series of linear regressions were conducted. Each model used an explicit attitude scale measure as the dependent variable, and the demographic, travel behavior, built environment, and implicit attitude measures were entered in to the model in four steps, respectively. For parsimony, only the final model is presented in the following tables. 


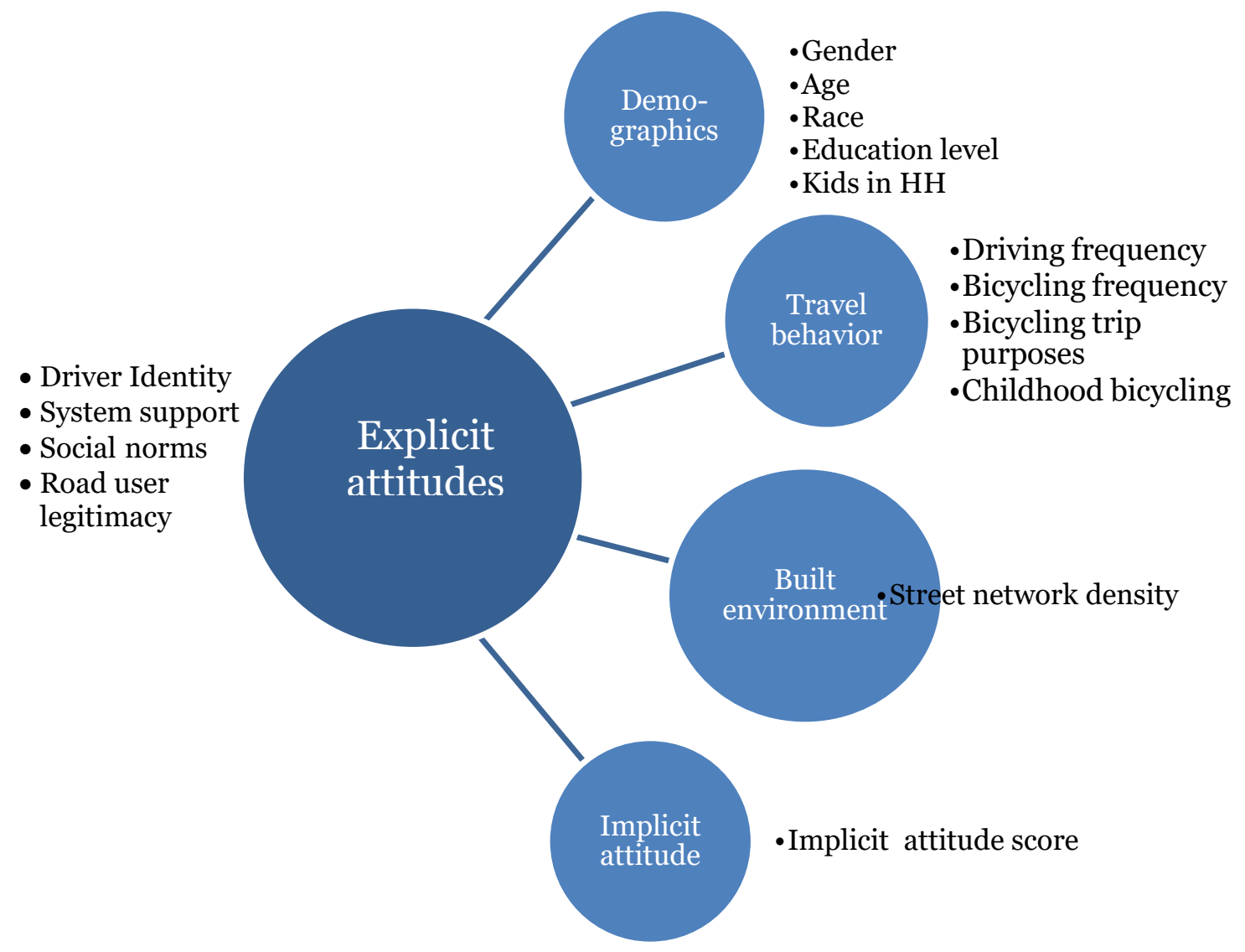

Figure 22 Conceptual relationships between explicit attitudes, demographics, travel behavior, the built environment, and implicit attitudes

In the final driver identity model (Table 25), age, driving frequency, and implicit attitude predicted driver identity, all in the positive (more pro-driver) direction. The presence of children in the household and having bicycled as a child approached statistical significance. Examining the standardized coefficients allows comparison of the relative effect between predictors (Cohen, 2011). Driving frequency had the largest relative effect on identifying as a driver. The addition of the implicit attitude score in the final step resulted in a significant Rsquared change, although the final model explained only $5.4 \%$ of the variance in driver identity. 
Table 25 Regression model of Driver Identity

Constant

\begin{tabular}{|c|c|c|c|}
\hline Coefficient & $\begin{array}{l}\text { Standardized } \\
\text { coefficient }\end{array}$ & t-statistic & $\mathrm{p}$-value \\
\hline 3.549 & & 14.988 & 0.000 \\
\hline
\end{tabular}

Demographic measures

\begin{tabular}{lllll} 
Gender & -0.072 & -0.038 & -0.937 & 0.349 \\
Age & 0.006 & 0.095 & 2.134 & $\mathbf{0 . 0 3 3}$ \\
Race (w/nonw) & 0.000 & 0.000 & 0.000 & 1.000 \\
Education level & -0.012 & -0.022 & -0.500 & 0.618 \\
Children in HH & 0.150 & 0.079 & 1.886 & 0.060 \\
\hline
\end{tabular}

Travel behavior measures

\begin{tabular}{lllll}
$\begin{array}{l}\text { Driving frequency } \\
\text { (days/wk) }\end{array}$ & 0.078 & 0.167 & 3.823 & $\mathbf{0 . 0 0 0}$ \\
Bicycles weekly & 0.165 & 0.082 & 1.579 & 0.115 \\
Bicycled for fun/exercise & 0.008 & 0.004 & 0.086 & 0.931 \\
Bicycled for commute/errands & -0.092 & -0.041 & -0.866 & 0.387 \\
Bicycled to accompany a child & -0.168 & -0.046 & -1.114 & 0.266 \\
Bicycled as a child & 0.254 & 0.074 & 1.822 & 0.069 \\
\hline
\end{tabular}

Built environment measures

Street intersection density

0.000

$-0.047$

$-1.041$

0.298

Bicycle commute mode share

0.021

0.050

1.118

0.264

Implicit attitude measure

IAT score

0.193

0.090

2.159

$\mathbf{0 . 0 3 1}$

$\begin{array}{ll}\mathrm{n} & 601 \\ \text { R-square (final model) } & 0.076 \\ \text { Adjusted R-square } & 0.054 \\ \text { Significance of final model } & \mathbf{0 . 0 3 1}\end{array}$

*Dependent variable: Driver Identity measure 


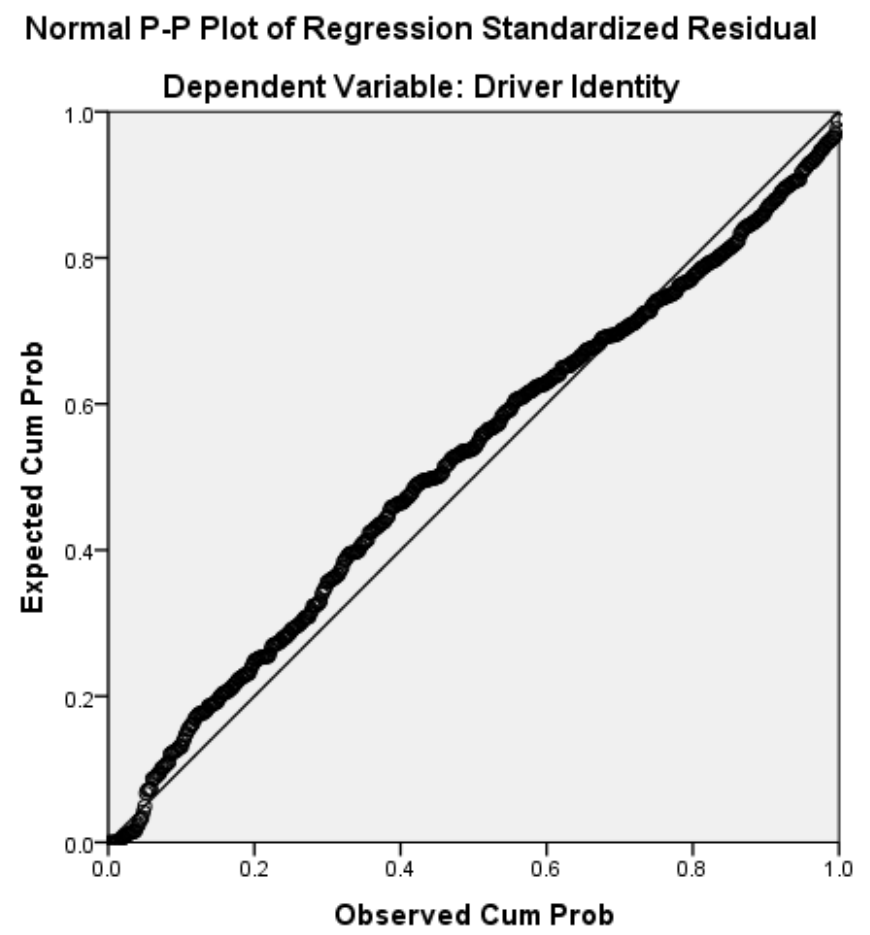

Figure 23 Standardized residuals, Driver Identity regression model

In the model of system support (Table 26), education was both negatively associated with greater system support. Bicycling for utilitarian purposes were inversely related to higher system support, while a higher pro-driver implicit bias and greater driving frequency were positively related to system support. The final model, with significant R-squared change due to the addition of the implicit attitude, accounted for $13 \%$ of the variance in system support. 
Table 26 Regression model of System Support

\section{Constant}

Coefficien

Demographic measures

Gender
Age
Race (w/nonw)
Education level
Children in HH
Travel behavior measures

\section{Driving frequency (days/wk)}

Bicycles weekly

Bicycled for fun/exercise

Bicycled to commute/errands

Bicycled to accompany a child

Bicycled as a child

Built environment measures

Street intersection density

Bicycle commute mode share

Implicit attitude measure

IAT score

0.072

$-0.001$

0.048

$-0.102$

$-0.050$

0.064

$-0.044$

$-0.019$

$-0.312$

0.171

$-0.194$

0.000

$-0.011$

0.176

0.088

2.212

3.508

$-0.466$

.000

$-0.023$

$-0.011$

$-0.232$

0.641

$-0.151$

$-3.305$

0.817

0.051

1.273

0.001

$-0.061$

$-1.562$

0.204

0.119 n

R-square (final model)

Adjusted R-square

Significance of final model
647

0.147

0.126

0.027

${ }^{*}$ Dependent variable: System support measure 


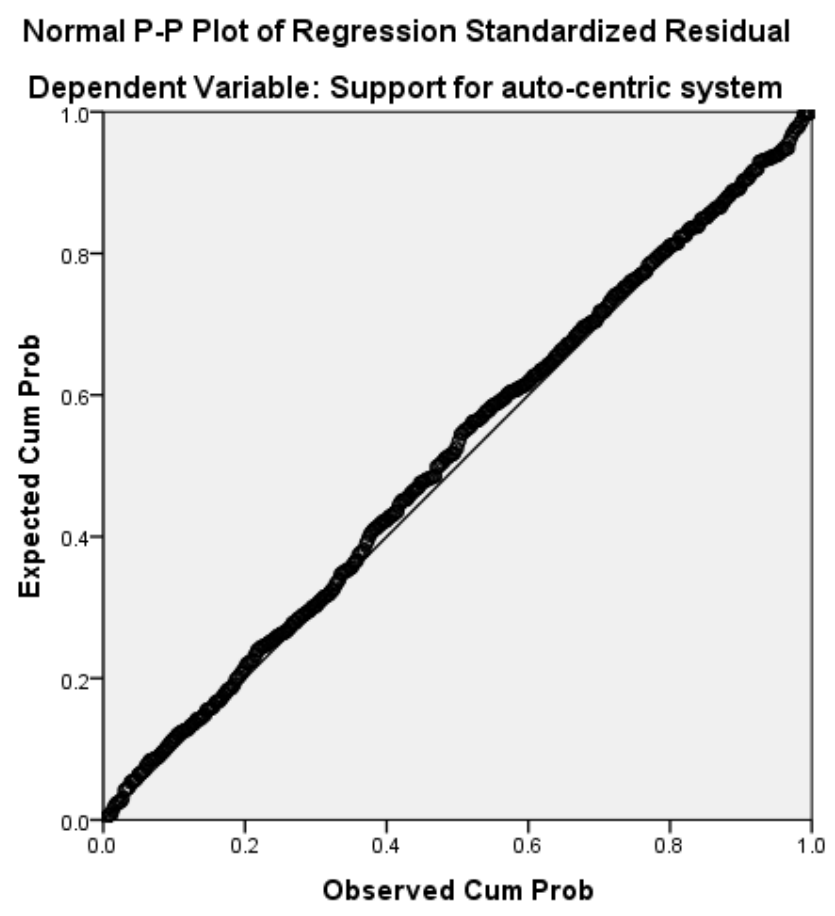

Figure 24 Standardized residuals, System support regression model

In the social norms model (Table 27), only age, race, and implicit attitude were significantly predictive of social norms scores. Pro-driving social norms decreased with age, while white respondents were more likely to express prodriving social norms. The addition of implicit bias to the model significantly improved the R-squared, although the final variance accounted for by the model was quite small. 
Table 27 Regression model of Social Norms

Constant

\begin{tabular}{llll} 
Coefficient & $\begin{array}{l}\text { Standardized } \\
\text { coefficient }\end{array}$ & $\begin{array}{l}\mathrm{t}- \\
\text { statistic }\end{array}$ & p-value \\
\hline 4.684 & & 21.880 & $\mathbf{0 . 0 0 0}$
\end{tabular}

Demographic measures

Gender

$\begin{array}{llll}-0.056 & -0.033 & -0.800 & 0.424\end{array}$

Age

Race (w/nonw)

$\begin{array}{llll}-0.006 & -0.124 & -2.726 & 0.007\end{array}$

Education level

$-0.167$

$-0.084$

$-1.991$

$\mathbf{0 . 0 4 7}$

Children in $\mathrm{HH}$

0.003

0.006

0.140

0.889

$-0.045$

$-0.027$

$-0.634$

0.527

Travel behavior measures

Driving frequency (days/wk)

Bicycles weekly

Bicycled for fun/exercise

Bicycled commute/errands

Bicycled to accompany a child

$\begin{array}{llll}-0.013 & -0.032 & -0.727 & 0.468 \\ -0.070 & -0.040 & -0.745 & 0.456 \\ 0.025 & 0.016 & 0.309 & 0.758 \\ -0.015 & -0.008 & -0.160 & 0.873 \\ -0.190 & -0.059 & -1.400 & 0.162 \\ 0.121 & 0.040 & 0.960 & 0.337\end{array}$

Bicycled as a child

0.12

0.040

0.960

.337

Built environment measure

Street intersection density

$0.000 \quad 0.016$

0.339

0.735

Bicycle commute mode share

$\begin{array}{ll}-0.035 & -0.094\end{array}$

$-2.07$

$\mathbf{0 . 0 3 8}$

Implicit attitude measure

\section{IAT score}

0.177

0.093

2.198

$\mathbf{0 . 0 2 8}$

n

R-square

0.042

Adjusted R-square

0.019

Significance of final model

0.028 


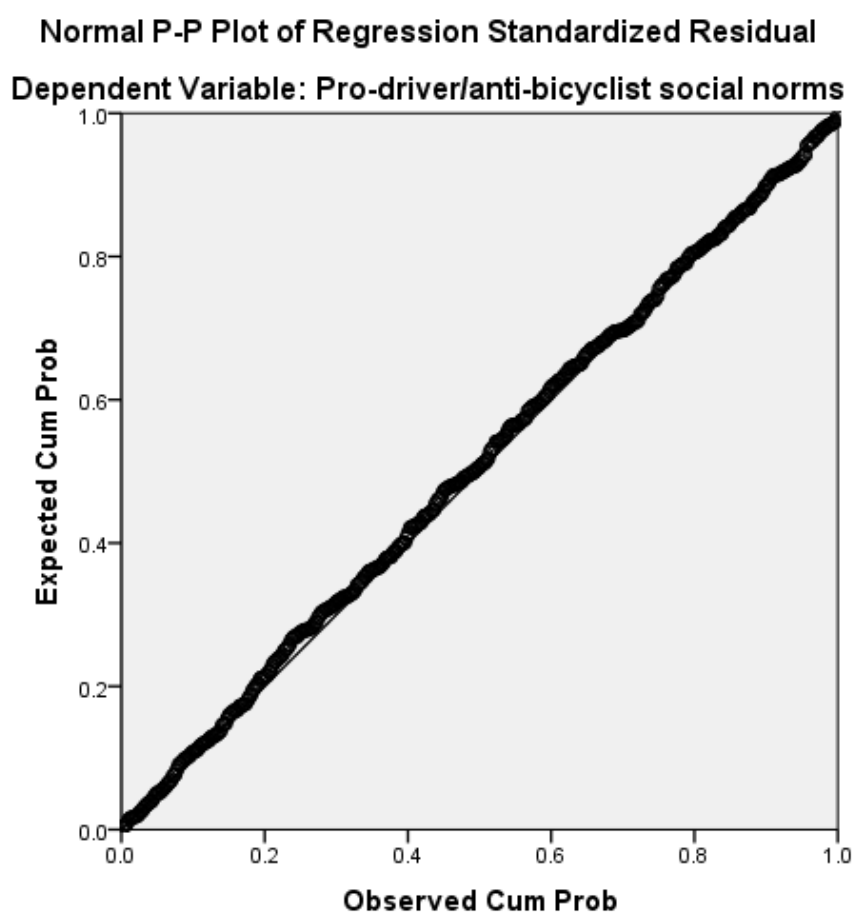

Figure 25 Standardized residuals, social norm regression model

In the road user legitimacy model (Table 28), being a woman was predictive of higher anti-bicyclist legitimacy attitudes. Implicit bias improved the model with a higher relative strength than gender. Even stronger, however, was weekly bicycling behavior, with weekly bicyclists between much less likely to think bicyclists need to achieve legitimacy via registration, taxes, and getting licensed. The final model accounted for $4.4 \%$ of the variance in legitimacy attitudes. 
Table 28 Regression model of Roadway Legitimacy

\begin{tabular}{lllll} 
& \multicolumn{5}{c}{$\begin{array}{c}\text { Standardized } \\
\text { Constant }\end{array}$} & $\begin{array}{l}\mathrm{t}- \\
\text { coefficient }\end{array}$ & statistic & p-value \\
\cline { 2 - 5 } & & & 10.595 & $\mathbf{0 . 0 0 0}$ \\
Demographic measures & & & & \\
Gender & 0.201 & 0.087 & 2.157 & $\mathbf{0 . 0 3 1}$ \\
Age & 0.006 & 0.081 & 1.802 & 0.072 \\
Race (w/nonw) & -0.177 & -0.065 & -1.574 & 0.116 \\
Education level & -0.026 & -0.041 & -0.911 & 0.362 \\
Children in HH & -0.036 & -0.016 & -0.371 & 0.711 \\
\hline
\end{tabular}

Travel behavior measures

\begin{tabular}{lllll}
\hline Driving frequency (days/wk) & -0.018 & -0.033 & -0.742 & 0.458 \\
Bicycles weekly & -0.369 & -0.153 & -2.919 & $\mathbf{0 . 0 0 4}$ \\
Bicycled for fun/exercise & 0.091 & 0.041 & 0.836 & 0.404 \\
Bicycled commute/errands & -0.077 & -0.029 & -0.600 & 0.549 \\
Bicycled to accompany a child & -0.195 & -0.045 & -1.075 & 0.283 \\
Bicycled as a child & -0.254 & -0.061 & -1.508 & 0.132 \\
\hline
\end{tabular}

Built environment measure

\begin{tabular}{lllll}
\hline Street intersection density & 0.000 & 0.051 & 1.125 & 0.261 \\
Bicycle commute mode share & -0.002 & -0.005 & -0.103 & 0.918 \\
\hline
\end{tabular}

Implicit attitude measure

\begin{tabular}{lllll}
\hline IAT score & 0.265 & 0.103 & 2.456 & $\mathbf{0 . 0 1 4}$ \\
\hline $\mathrm{n}$ & 601 & & \\
R-square & 0.067 & & \\
Adjusted R-square & 0.044 & & \\
Significance of final model & $\mathbf{0 . 0 1 4}$ & & \\
\hline
\end{tabular}

*Dependent variable: Road user legitimacy measure 


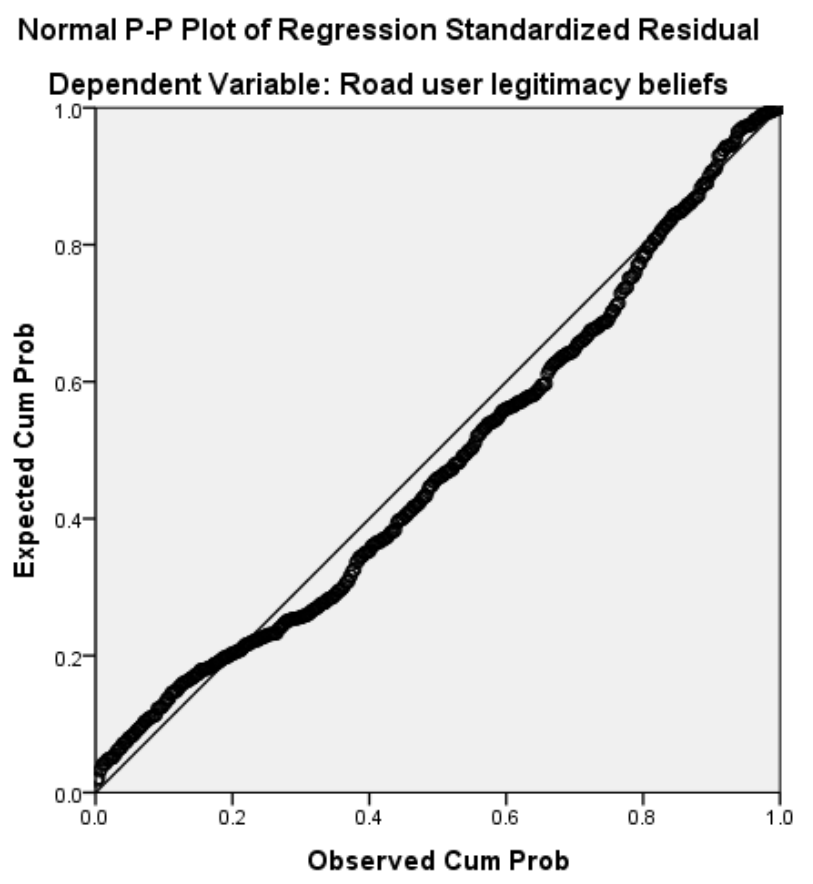

Figure 26 Standardized residuals, road user legitimacy regression model

To compare across all four models, the regressions were re-run with only variables that were significant in at least one of the individual attitude models (Table 29). Standardized coefficients were not significantly different than in the full models. The same results were visualized via bar graphs (Figures 26-29), where the sign indicates a direct or inverse relationship between the independent variable and the attitude measure, the color black indicates statistical significance $(\mathrm{p}<0.05)$, and the magnitude indicates the relative strength (i.e. the size of the standardized regression coefficient). 
Table 29 Attitude models, comparisons

\begin{tabular}{|c|c|c|c|c|c|c|c|c|}
\hline \multirow{2}{*}{ (Constant) } & \multicolumn{2}{|c|}{ Driver Identity } & \multicolumn{2}{|c|}{ System support } & \multicolumn{2}{|c|}{ Social norms } & \multicolumn{2}{|c|}{ Road user legitimacy } \\
\hline & & $\begin{array}{l}\text { Sig. } \\
\text { o.ooo }\end{array}$ & Beta & $\begin{array}{l}\text { Sig. } \\
\text { o.ooo }\end{array}$ & Beta & $\begin{array}{l}\text { Sig. } \\
\text { o.ooo }\end{array}$ & Beta & $\begin{array}{l}\text { Sig. } \\
\text { o.ooo }\end{array}$ \\
\hline \multicolumn{9}{|l|}{ Demographic measures } \\
\hline Gender $($ men $=0$, women $=1)$ & -0.04 & 0.291 & 0.04 & 0.260 & -0.03 & 0.416 & 0.09 & 0.024 \\
\hline Age & 0.08 & 0.051 & -0.03 & 0.478 & $-\mathbf{0 . 1 1}$ & 0.011 & 0.09 & $\mathbf{0 . 0 3 1}$ \\
\hline Education level & -0.03 & 0.516 & -0.20 & o.000 & 0.02 & 0.692 & -0.03 & 0.533 \\
\hline \multicolumn{9}{|l|}{ Travel behavior measures } \\
\hline Driving frequency (days/wk) & 0.19 & $\mathbf{0 . 0 0 0}$ & $\mathbf{0 . 1 4}$ & o.000 & -0.03 & 0.415 & -0.05 & 0.212 \\
\hline Bicycles weekly & 0.08 & 0.060 & -0.03 & 0.479 & -0.03 & 0.448 & -0.14 & 0.001 \\
\hline $\begin{array}{l}\text { Bicycled for commute/errands } \\
\text { Built environment measure }\end{array}$ & -0.04 & 0.344 & $-\mathbf{0 . 1 5}$ & 0.001 & -0.01 & 0.780 & -0.03 & 0.472 \\
\hline Bicycle commute mode share & 0.03 & 0.533 & -0.03 & 0.377 & -0.08 & $\mathbf{0 . 0 3 7}$ & 0.01 & 0.830 \\
\hline \multicolumn{9}{|l|}{ Implicit attitude measure } \\
\hline Implicit attitude (pro-driver bias) & 0.09 & $\mathbf{0 . 0 2 0}$ & $\mathbf{0 . 0 9}$ & 0.014 & 0.08 & 0.045 & 0.09 & 0.022 \\
\hline Adjusted R-square and significance & 0.048 & $\mathbf{0 . 0 0 0}$ & 0.123 & $\mathbf{0 . 0 0 0}$ & 0.017 & $\mathbf{0 . 0 1 3}$ & 0.041 & $\mathbf{0 . 0 0 0}$ \\
\hline
\end{tabular}




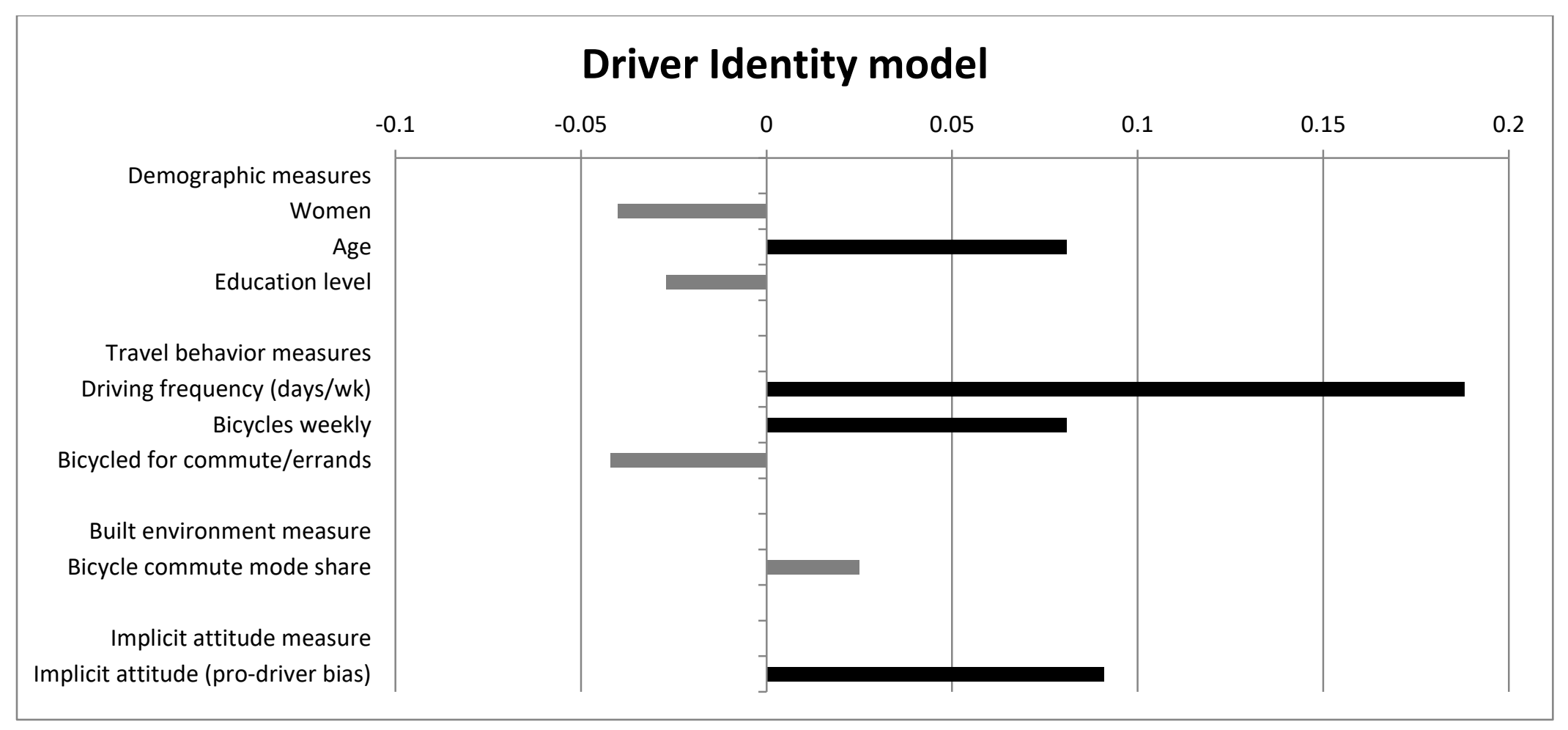

Figure 27 Graph of standardized coefficients, Driver Identity model 


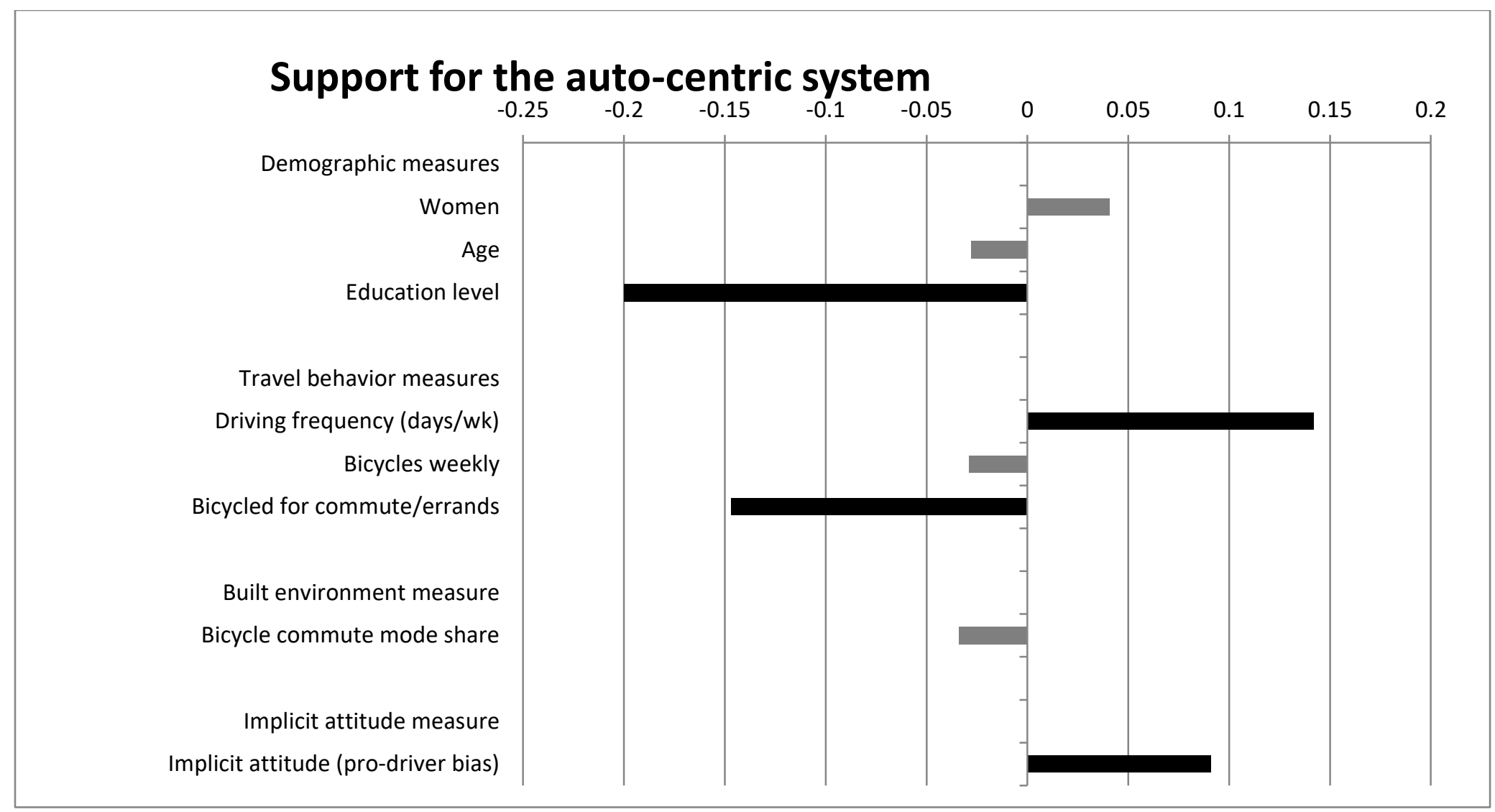

Figure 28 Graph of standardized coefficients, system support model 


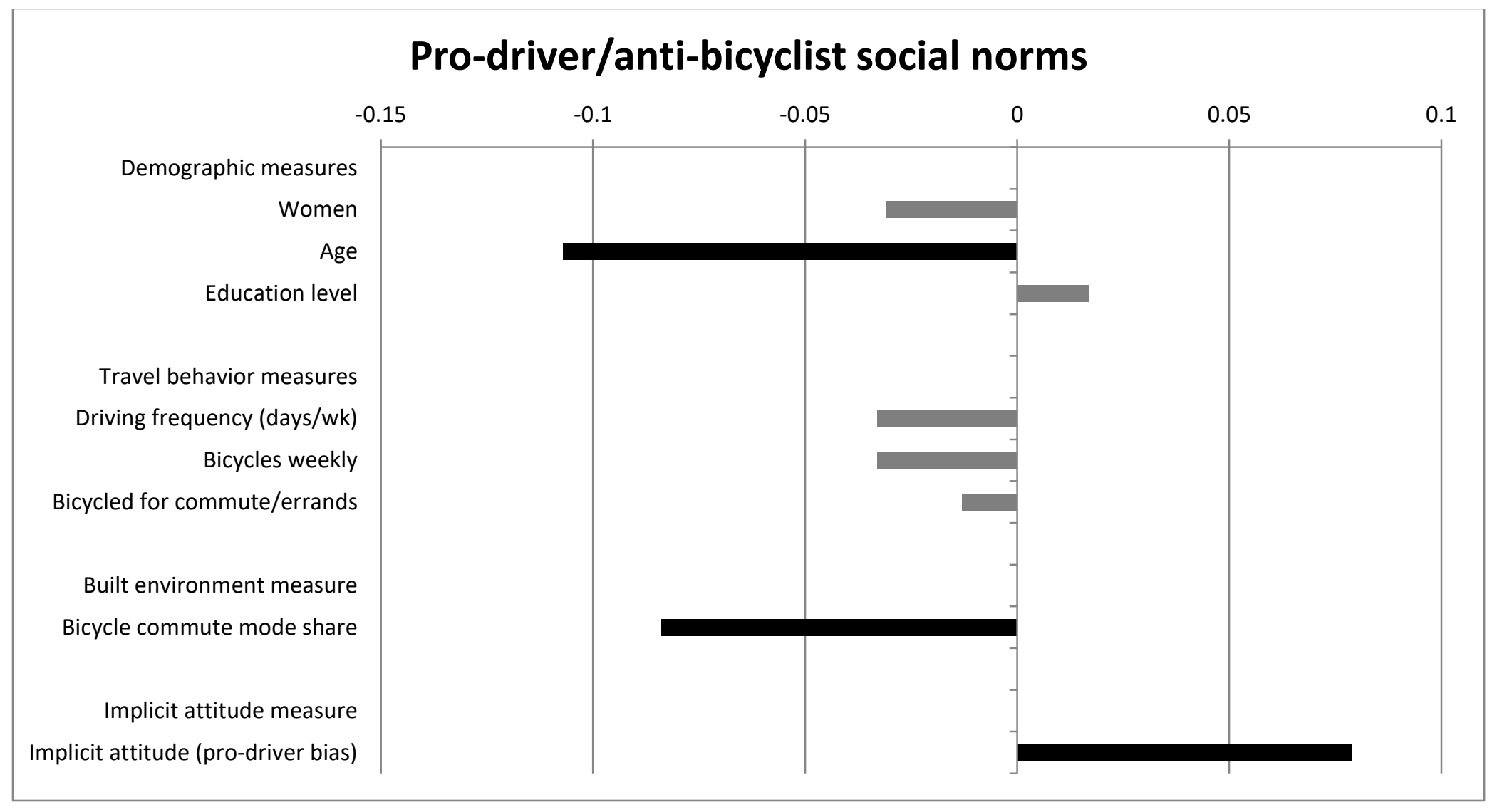

Figure 29 Graph of standardized coefficients, social norms model 


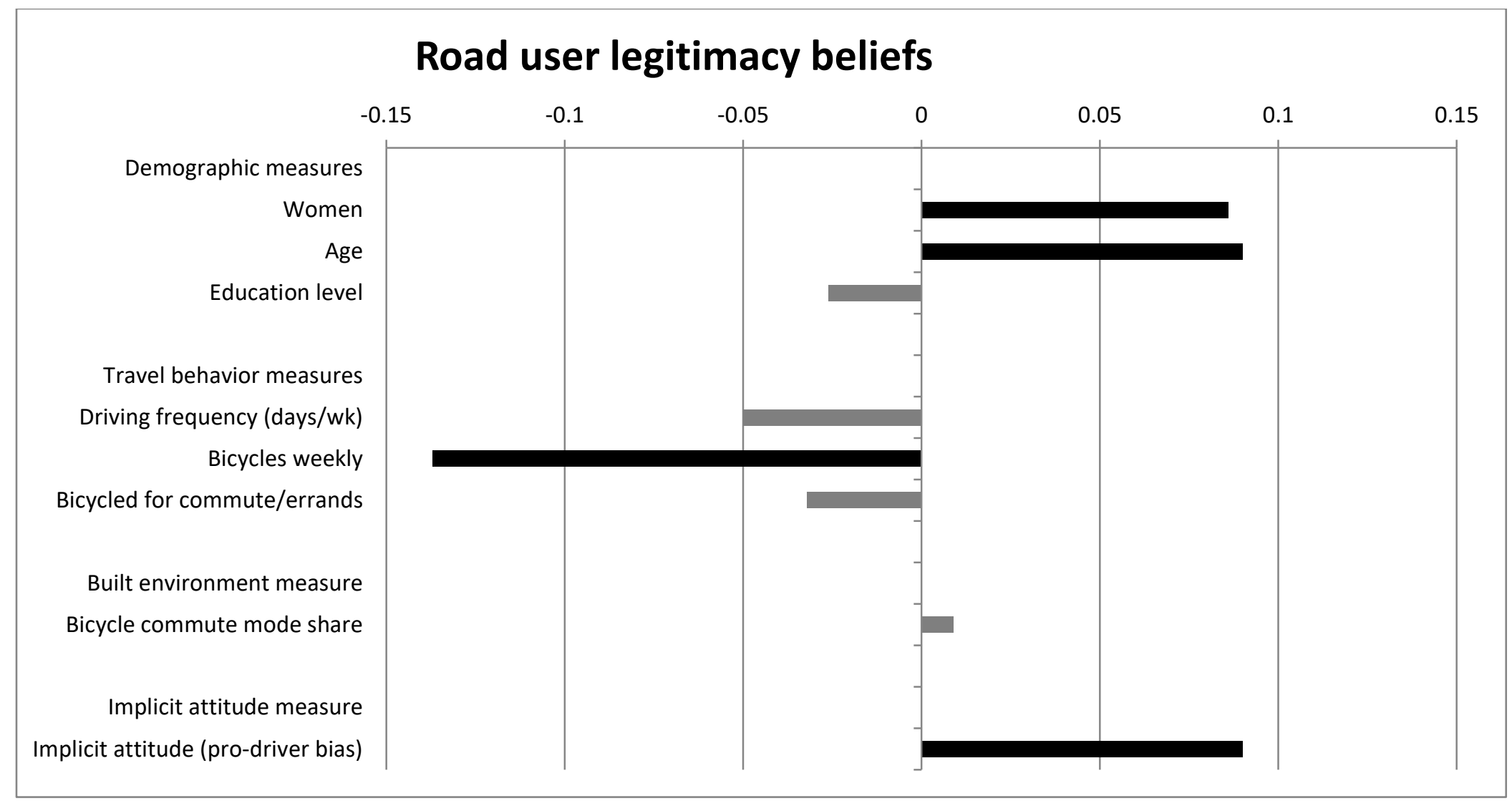

Figure 30 Graph of standardized coefficients, road user legitimacy model 


\section{Discussion of Chapter 4 Findings}

The overall findings about attitudes confirmed some hypothesizes or anecdotal evidence and refuted others. For example, as extensively documented elsewhere (Elvik, 2013), people generally view themselves as skilled drivers. However, antithetical to common refrain at public meetings or online articles about bicyclists, there was not general sentiment that bicyclists should have to register, be licensed, or pay (additional) taxes. The overall implicit attitude results were nearly normally distributed, albeit slightly skewed in favor of drivers. Encouraging, there was general overall support for public investment in bicycle infrastructure, although the question was asked abstracted from trade-offs like parking removal or auto lane reduction.

The explanatory power of the regression models of all the attitudes are extremely small, ranging from explaining $1.7 \%$ to $12.3 \%$ of the variance. This is partly due to the limits of the regression models used, which posit the attitudes as a dependent variable, while in reality, there are likely to be bi-directional influences between attitudes and personal travel behaviors and even built environment (i.e. residential self-selection). Additionally, the survey did not collect personality factors or attempt to measure cultural differences that may better explain attitudinal differences across respondents.

\section{Demographics}

Gender, age, race, and education level all played a role at some point in the models. Although the coefficients (and thus explanatory strength) of the 
demographics was typically small, being white was predictive of social dominance and gender was important in roadway legitimacy. The former findings fits with social dominance theories more generally (Pratto, Sidanius, \& Levin, 2006), and so it not surprising that it carries over into the roadway environment. That women were more likely to agree with the measures of bicyclist licensing and registration was unexpected, and warrants further exploration. It may be that women see those as tools to improve perceived problems with interacting with bicyclists. Future analyses of this data may provide more insight into the mechanisms behind this finding.

\section{Attitude factors}

The explicit attitudes loaded strongly on factors that, viewed together, fit well with social-psychological theories of intergroup relations. It was expected that the three items directly related to respondents' own driving would together form a measure that could be called driver identity. The measures regarding public investment of funds, whether they could identify with bicyclists they see, filtering through traffic (i.e. acting "outside" the system), and drivers' culpability in road crashes all reflect ways that respondents might justifying the existing automobilecentered system. Feeling angry about bicyclists' rule-breaking and believing that they shouldn't hold up drivers, paired with a willingness to excuse other drivers' rule-breaking, all support an inter-modal social dominance orientation. Finally, the measures about bicycle licensing, registration, and tax-paying were highly correlated, demonstrating what could be called an authoritarian (e.g. strict law- 
following) attitude. Since it had to do with things that drivers have to do, however, it made sense to view it as a proxy for legitimacy as a fellow roadway user.

\section{Implicit attitude}

Similar to findings about implicit attitudes in other domains (Greenwald et al., 2009), the implicit driver-bicyclist bias was significantly correlated with explicit attitudes, but with small correlational coefficients. This suggests that the implicit method did measure preferences between drivers and bicyclists, and thus related but distinct from attitudes captured in the Likert-style survey questions. Importantly, the implicit attitude was significant in all four of the regression models of explicit attitudes, demonstrating that an implicit measurement of attitudes adds predictive value about respondents' attitudes toward bicyclists. This is important because implicit bias may thus both directly and indirectly affect behavior in the roadway. Although it is not possible to add an IAT to traditional mail-out surveys, the increasing use of online survey methods provides the opportunity to incorporate an IAT into travel behavior studies without adding a significant burden of time to survey respondents.

\section{Personal travel behavior}

The addition of personal travel behavior to the models added explanatory value in all but social dominance. Driving frequency emerged as a significant predictor of driver identity and system justification attitudes, which fits with psychology theory. Identity can be an iterative process, wherein we engage in behavior with 
which we identity, and we identify with behavior in which we engage (Tajfel \& Turner, 2004). The dominance of the automobile system in the US ensures that most people drive, and the more we identify with and/or rely on that system, the more likely we are to justify it, particularly against users who we view as competition for the limited resources (Jost, Banaji, \& Nosek, 2004) of road space and transportation investment.

In contrast to that, utilization of a bicycle offers the opportunity to "switch sides" - that is, to act as a member of the out-group. Research suggests that this can help moderate attitudes (S. L. Singletary \& Hebl, 2009). Indeed, bicycling behavior was significant in predicting all but the social dominance measures. Interestingly, bicycling as a child resulted in higher driver identification scores, but drivers may be motivated to evaluate themselves as skilled, or want others to think of them as a good driver, if they associate bicycling with childhood. A heightened perception of bicyclists as vulnerable may invoke an attitude analogous to benevolent sexism (Hebl, King, Glick, Singletary, \& Kazama, 2007), and motivate drivers to positively self-evaluate their driving. System justification attitudes were lower in people who have bicycled in the last year, but only for people who have used a bicycle for utilitarian purposes like commuting or shopping. Roadway legitimacy attitudes were predicted only by weekly bicycling. These are important and novel findings. They suggest that infrequent and recreation-only bicycling may not be enough to moderate driver attitudes toward bicyclists. More research is needed to further explore the strength and the 
longevity of the effects of different types of bicycling activities in shifting attitudes and behaviors.

Neither driving frequency nor bicycling behaviors were significant in predicting beliefs about social norms. This may result from roadway-related social dominance being more a function of personality or culture, and not moderated by personal experience.

\section{The built environment}

While the bivariate analyses demonstrated associations between explicit attitudes and the built environment measures of road network, street intersection, multimodal network, and pedestrian-oriented facility densities, the built environment measures were insignificant in the regression models, with the exception of bicycle commute mode share in the model of social norms. Encouragingly, a higher bicycle commute mode share was associated with reduced pro-driver/anti-bicyclist social norms, although this analysis does not reveal the causal direction; that is, does the presence of more bicyclists improve social norms, or do improved social norms result in more people bicycling? It is possible that the answer is both. 


\section{Chapter 5: Do drivers' attitudes toward bicyclists predict their behavior toward bicyclists?}

\section{Objectives of this chapter}

Building on the analyses in the previous chapter, the objectives of the portion of the analyses were to:

- Examine the self-reported behaviors across the sample;

- Explore how various demographic, travel behavior, built environment and attitude variables affected the self-report behavior scores; and

- Test hypotheses about the strength of implicit and explicit social attitudes in their relationships with self-report behaviors.

The results presented in this chapter address the following research questions and sub-questions:

Do drivers' attitudes toward bicyclists predict their behavior toward bicyclists?

a. What are drivers' behaviors when interacting with bicyclists?

b. How do drivers' explicit attitudes toward bicyclists affect their selfreported behaviors?

c. Does an implicit measurement of drivers' attitudes explain additional variance in drivers' behaviors?

d. What are the predictors of negative safety-related behaviors toward bicyclists?

\section{Findings}

\section{Bivariate examination of behaviors}

Bivariate correlations were used to examine the relationships of the continuous independent variables with the four behavior measures (Table 30). Age was significantly and inversely associated with increased self-evaluation of performance and skills around bicyclists (via the perception scale and performing 
a head check before turning) and less perceived pressure to overtake bicyclists. These may represent increased experience and/or increased confidence in skills. The only two street density measures that were significantly associated with behaviors were pedestrian facility density and street intersection density, which were inversely correlated with not performing a head check, suggesting that increased bikeability improves drivers' expectations of and behaviors toward turning in front of bicyclists.

A pro-driver implicit bias was correlated with the three individual behavior measures. Most concerning from a safety perspective was the correlation between a negative bias toward bicyclists and not performing a head check before turning. Although performing a head check does not ensure that a driver will see a bicyclist, it improves the chances that they will, and demonstrates an expectation that bicyclists may be in a driver's blind spot. The bivariate correlations between implicit bias and self-report behaviors were very small, and a one-way ANOVA using IAT categories demonstrated that only checking for bicyclists before turning and implicit attitude had a significant relationship $(\mathrm{F}(658)=3.072$, $\mathrm{p}=.016)$. The trends between implicit bias and negative behaviors, however, were in the expected directions when examining mean self-report behavior scores (Figure 31Figure 32Figure 33Figure 34).

All four explicit attitude scales were significantly associated with perceptual issues. As might be expected, a stronger identification as a skilled driver is associated with a positive self-evaluation about ability to maneuver near 
bicyclists. Mean agreement (i.e. anti-bicyclist) on the system justification, social dominance, and roadway legitimacy scales was significantly associated with expressions of frustration and anger toward bicyclists.

Table 30 Bivariate correlations of behaviors and continuous independent variables I have honked, shouted, or

If I don't pass a gestured at bicyclist other a bicyclist who made me angry

I do not check for drivers get

Perception angry

Age

(c)

$-.132^{* *}$

$-.053$ bicyclists before I

Driving frequency $-.049$

.040 make a turn in my car

(days/week)

\begin{tabular}{lllll}
\hline Implicit attitude & .020 & $\mathbf{. 0 9 2}^{*}$ & $\mathbf{. 0 8 3}^{*}$ & $\mathbf{. 1 4 5}^{* *}$ \\
\hline Driver Identity & $\mathbf{- . 1 5 0}^{* *}$ & .053 & -.038 & -.075 \\
\hline $\begin{array}{l}\text { Support for auto-centric } \\
\text { system }\end{array}$ & $\mathbf{. 0 9 2}^{*}$ & .047 & $\mathbf{. 2 4 9}^{* *}$ & $\mathbf{. 1 3}^{* *}$ \\
\hline $\begin{array}{l}\text { Pro-driver/anti- } \\
\text { bicli }\end{array}$ & $\mathbf{. 2 0 8}^{* *}$ & $\mathbf{. 1 9}^{* *}$ & $\mathbf{. 2 4 6}^{* *}$ & -.041
\end{tabular}

bicyclist social norms

\begin{tabular}{lllll}
\hline Road user legitimacy & $\mathbf{. 2 2 6}^{* *}$ & $\mathbf{. 1 2 7}^{* *}$ & $\mathbf{. 2 2 6}^{* *}$ & .033 \\
\hline Street network density & -.042 & -.017 & .067 & $\mathbf{. . 1 0 0}^{*}$ \\
\hline Bicycle commute mode & -.039 & -.043 & .059 & $\mathbf{- . 1 2 0}^{* *}$
\end{tabular}
share

\begin{tabular}{lcccc}
\hline Perception issues & - & $\mathbf{. 1 9}^{* *}$ & $\mathbf{. 0 9 7}^{*}$ & $\mathbf{. 1 3 5}^{* *}$ \\
\hline $\begin{array}{l}\text { If I don't pass a bicyclist } \\
\text { other drivers get angry }\end{array}$ & $\mathbf{. 1 9 1}^{* *}$ & - & $\mathbf{. 1 0 2}^{*}$ & .001 \\
\hline
\end{tabular}

I have honked, shouted, or gestured at a bicyclist $.097^{*} \quad .102^{*}$ .049 who made me angry

I do not check for bicyclists before I make a turn in my car

** Correlation is significant at the 0.01 level (2-tailed).

* Correlation is significant at the 0.05 level (2-tailed). $\mathrm{n}=\{565,662\}$ 


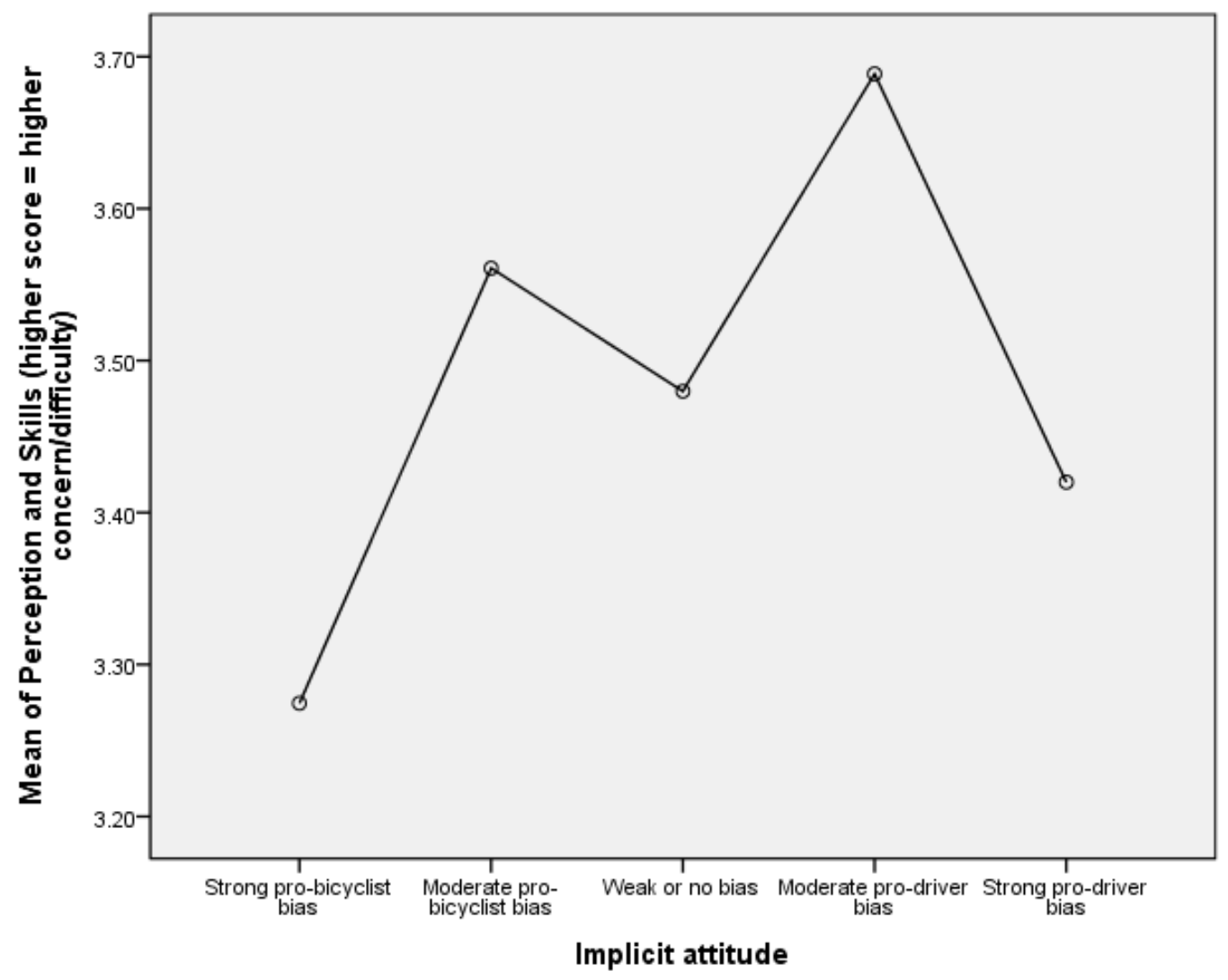

Figure 31 Relationship of implicit attitude and measure of perceptual and performance issues 


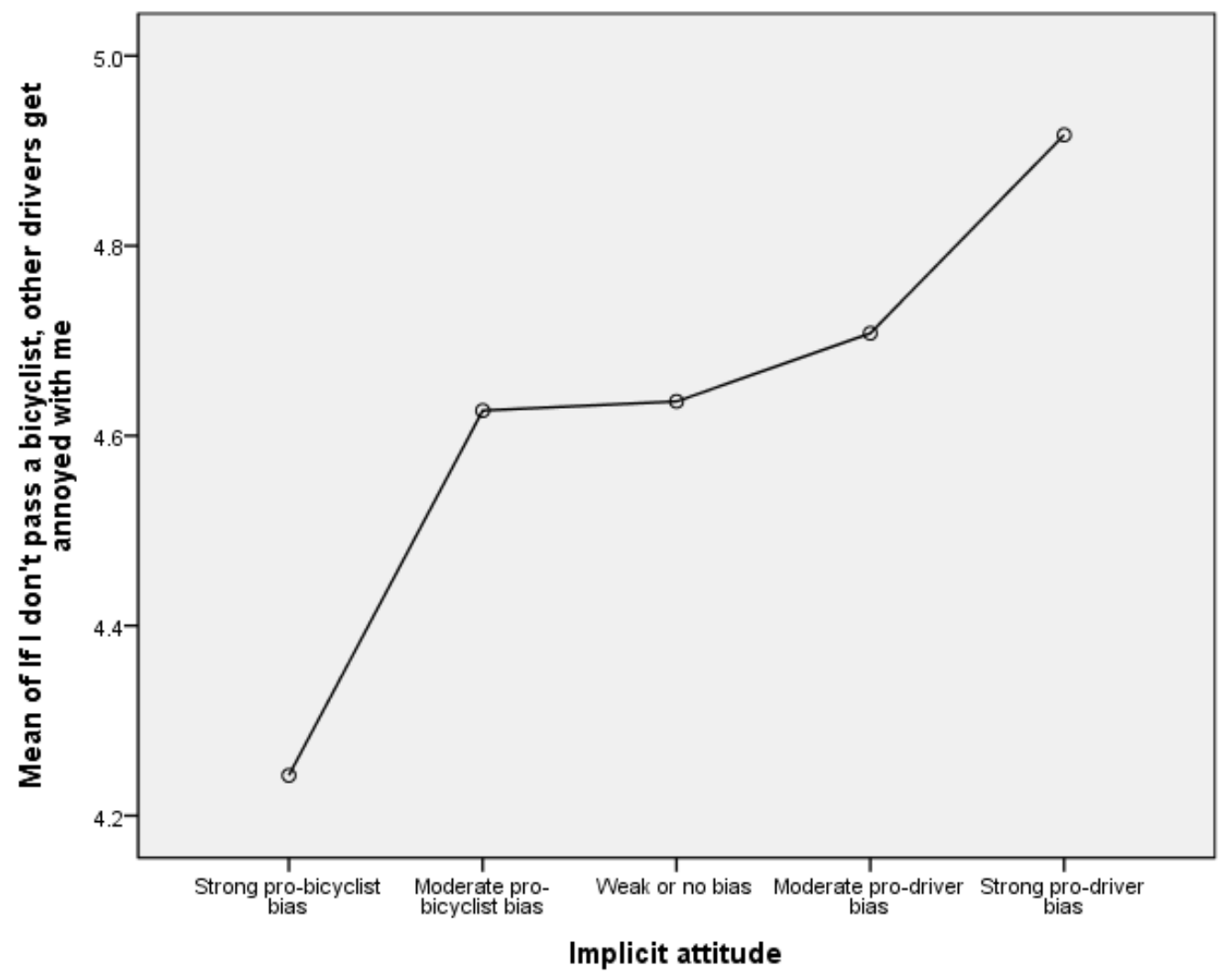

Figure 32 Relationship of implicit attitude and pressure to overtake a bicyclist 


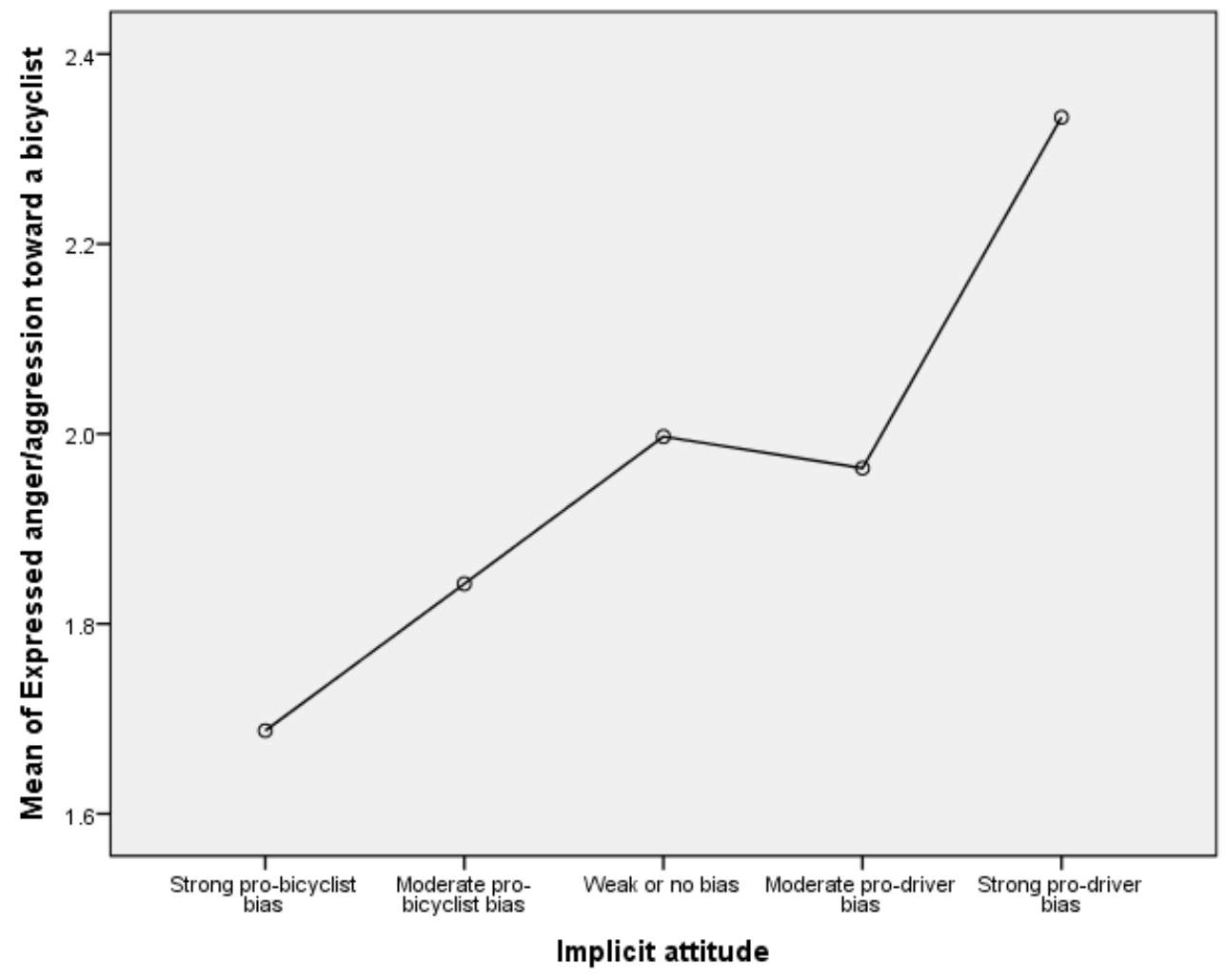

Figure 33 Relationship of implicit attitude and expression of frustration or anger toward a bicyclist 


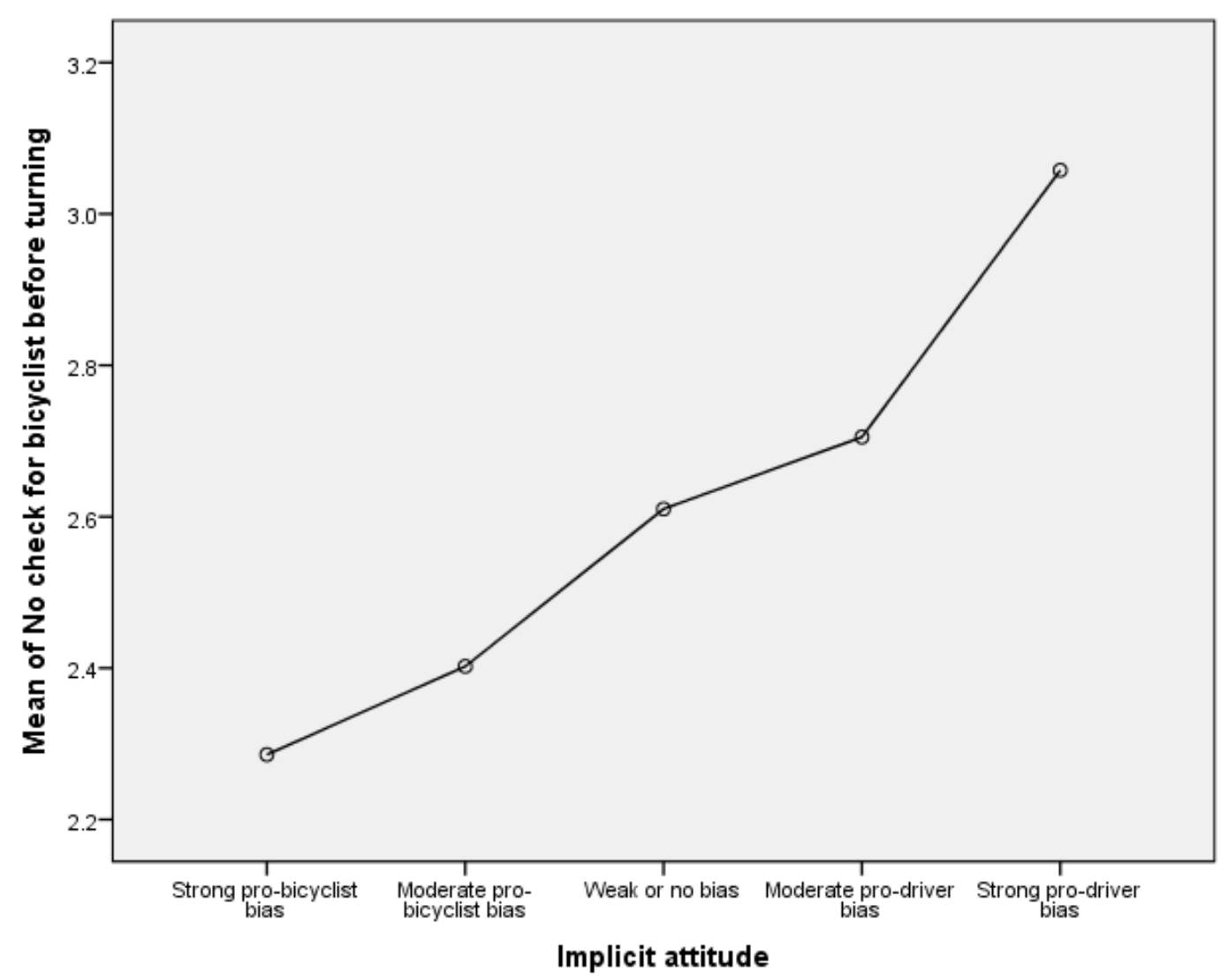

Figure 34 Relationship of implicit attitude and not checking for bicyclists before making a turn

A series of one-way ANOVAs was conducted to examine the relationships between the behavior measures and the categorical independent variables. There were moderate concerns, expressed with mean agreement on the scale, in each category with perceptual and skills issues (Table 31). Women were significantly more likely to report issues of performance and skills maneuvering around bicyclists. It cannot be determined from this data, however, whether women have higher perceived concerns and lower self-evaluation, or whether men's lower mean agreement suggests overconfidence in their skills. 
Millennials expressed significantly higher concerns about performance and skills, which may be related to fewer years of driving experience, since millennials in the sample have been driving significantly fewer years than both Baby Boomers and Generation X-ers $(F(1,646)=222.69, p=0.000)$. Millennials were no more likely to bicycle weekly or bicycle for utilitarian purposes than other generations, so it is not expected that personal bicycling experience interacting with age explains this difference on the perception scale.

Personal travel behavior for everything but bicycling for errands was significantly related to the perception scale. In all cases, not having bicycled predicted increased concerns about maneuvering around bicyclists. This demonstrates that experience as a bicyclist directly affects respondents' perception scale, independent of demographics or attitudes. While perhaps intuitive, this is a novel finding that experience as a bicyclist carries over into driver behavior. 
Table 31 Bivariate analyses of perceptual and performance skills

\begin{tabular}{|c|c|c|c|c|c|}
\hline & & $\begin{array}{l}\text { Percepti } \\
\text { Mean }\end{array}$ & $\begin{array}{l}\text { neasure } \\
\text { SD } \\
\text { (pooled) }\end{array}$ & $\begin{array}{l}\mathrm{p}- \\
\text { value* }^{*}\end{array}$ & $\begin{array}{l}\text { Effect } \\
\text { size }^{* *}\end{array}$ \\
\hline Demograpl & & & & & \\
\hline Gender & Men & 3.20 & 1.09 & 0.000 & 0.4 \\
\hline & Women & 3.65 & & & \\
\hline Race & Race (white) & 3.55 & 1.08 & 0.149 & 0.1 \\
\hline & Race (non-white & 3.40 & & & \\
\hline Children & No kids in $\mathrm{HH}$ & 3.56 & 1.09 & 0.081 & 0.1 \\
\hline & Has kids in $\mathrm{HH}$ & 3.40 & & & \\
\hline Age & Baby Boomers & 3.44 & 1.09 & 0.000 & $\begin{array}{ll}-- \\
\end{array}$ \\
\hline & Gen X-ers & $3 \cdot 31$ & & & \\
\hline & Millennials & 3.74 & & & \\
\hline Education & Some college & $3 \cdot 50$ & 1.09 & 0.190 & --- \\
\hline & 2-year degree & 3.32 & & & \\
\hline & 4-year degree & 3.55 & & & \\
\hline & Some grad school & $3 \cdot 77$ & & & \\
\hline & Master's & 3.51 & & & \\
\hline & Adv degree & 3.29 & & & \\
\hline Travel beh & vior & & & & \\
\hline & Bicycle weekly (no) & 3.61 & 1.09 & 0.000 & 0.3 \\
\hline & $\begin{array}{l}\text { Bicycle weekly (yes, } \\
n=182)\end{array}$ & 3.24 & & & \\
\hline & Bicycle for recreation (no) & 3.67 & 1.09 & 0.000 & 0.3 \\
\hline & $\begin{array}{l}\text { Bicycle for recreation } \\
\text { (yes, } n=309)\end{array}$ & $3 \cdot 32$ & & & \\
\hline & $\begin{array}{l}\text { Bicycle for } \\
\text { commute/errands (no) }\end{array}$ & 3.54 & 1.09 & 0.141 & $\mathbf{0 . 1}$ \\
\hline & $\begin{array}{l}\text { Bicycle for } \\
\text { commute/errands (yes, } \\
\text { n=135) }\end{array}$ & 3.38 & & & \\
\hline & $\begin{array}{l}\text { Bicycle to accompany child } \\
\text { (no) }\end{array}$ & 3.53 & 1.09 & $\mathbf{0 . 0 0 7}$ & 0.4 \\
\hline & $\begin{array}{l}\text { Bicycle to accompany } \\
\text { child (yes, } n=43 \text { ) }\end{array}$ & 3.07 & & & \\
\hline & Bicycled as a child (no) & 3.78 & 1.09 & 0.071 & $\mathbf{0 . 3}$ \\
\hline & $\begin{array}{l}\text { Bicycled as a child (yes, } \\
n=592)\end{array}$ & 3.48 & & & \\
\hline
\end{tabular}

${ }^{*} \mathrm{p}$-value for F-statistics for one-way ANOVA

**Effect size is calculated as the difference between the means divided by the pooled standard deviation. Conventional effect sizes are small (0.1), medium (0.3), large (0.5) 
In the case of drivers feeling pressure from other drivers to overtake (Table 32), age was the only significant categorical variable, with Millennials again reporting the highest concerns about performance and skills. Further research is needed to understand whether this is a result of less experience and confidence, or whether it speaks to larger cultural issues of not impeding traffic. 
Table 32 Bivariate analyses of pressure to overtake a bicyclist

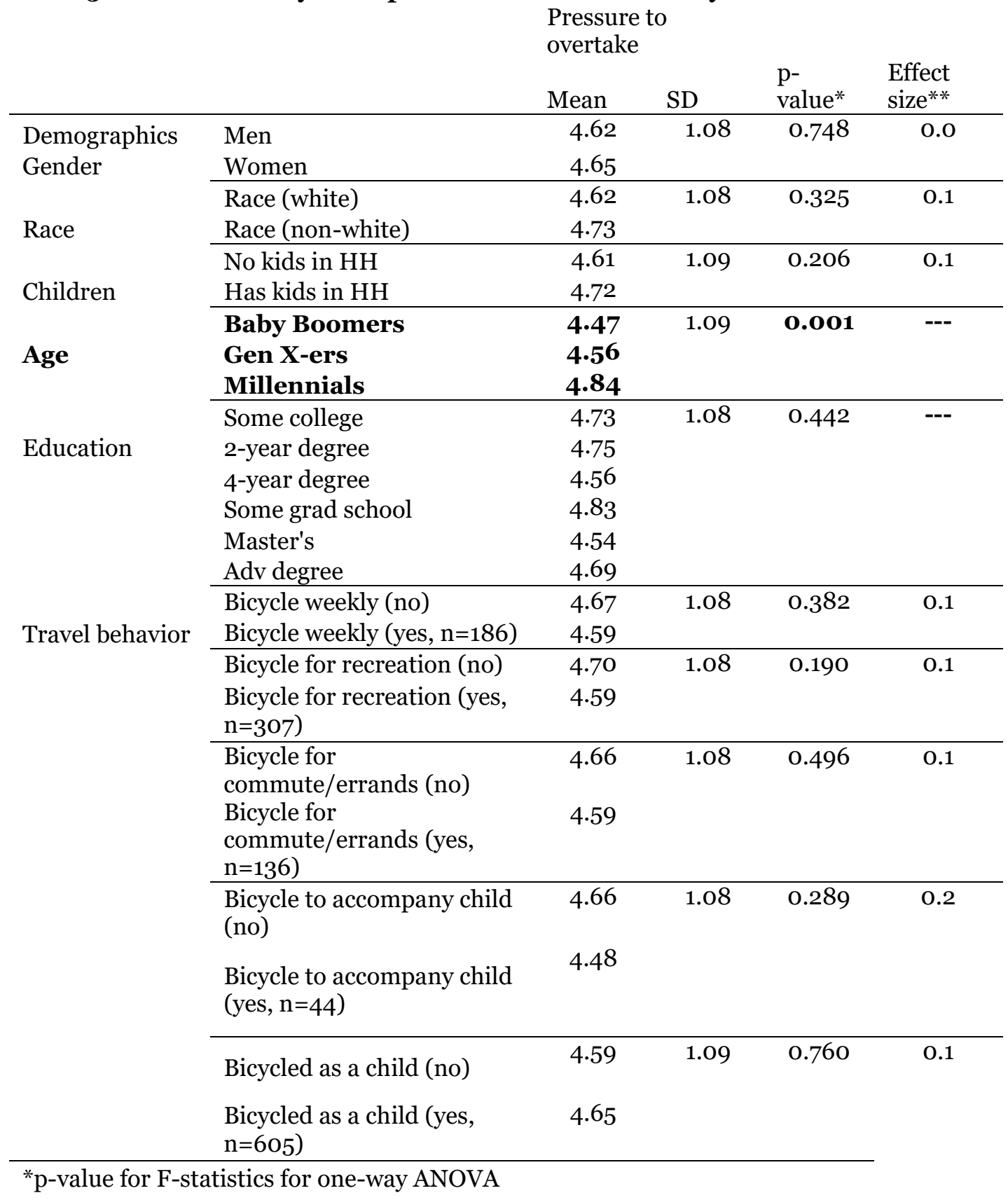

Mean agreement about expressing anger or frustration was close to "disagree" in all cases (Table 33). Race was the only demographic variable that had significant bivariate association with drivers' reporting that they had honked, shouted, or 
gestured at a bicyclist who had made them angry. One explanation is that white respondents had higher social desirability bias about reporting bad behavior. It could also reflect that a higher percentage of the non-white respondents live in parts of the country with a driving culture with difference social norms around expressions of anger like honking.

People who bicycle regularly were less likely to have expressed anger or frustration toward a bicyclist, as were people who have ridden for recreation or who had not ridden as a child. 
Table 33 Bivariate analyses of expressing frustration/anger toward a bicyclist Driver

frustration/aggression

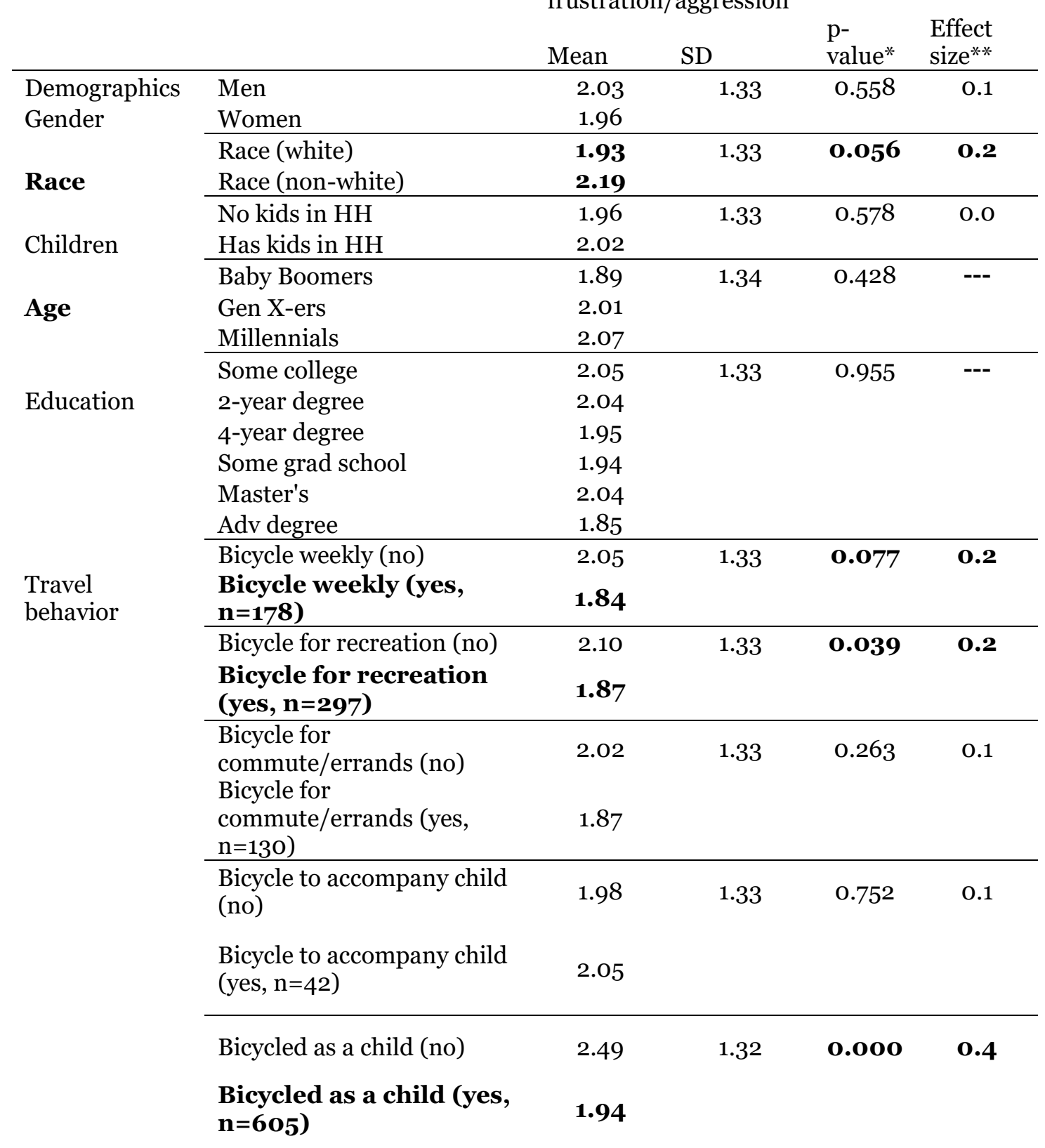

\footnotetext{
*p-value for F-statistics for one-way ANOVA
} 
Millennials were significantly less likely than Baby Boomers or Generation X-ers to agree that they perform a head check. Frequent and/or utilitarian bicycling increased the likelihood that respondents check for bicyclists before turning, with the largest effect sizes among bicyclists who bike to commute or run errands. The difference among bicyclists who had bicycled for recreation approached statistical significance $(F(1,660)=3.177, p=0.075)$, with a small effect size, suggesting that bicycling for recreation may still have a positive effect on drivers' safety behaviors, when not controlling for other factors. 
Table 34 Bivariate analyses of not performing a check for bicyclists before turning No check for a

bicyclist before

turns

\begin{tabular}{|c|c|c|c|c|c|}
\hline & & Mean & SD & $\mathrm{p}$-value & $\begin{array}{l}\text { Effect } \\
\text { size }^{* *}\end{array}$ \\
\hline \multicolumn{6}{|c|}{ Demographics } \\
\hline \multirow[t]{2}{*}{ Gender } & Men & 2.55 & 1.2 & 0.350 & 0.1 \\
\hline & Women & 2.65 & & & \\
\hline \multirow[t]{2}{*}{ Race } & Race (white) & 2.64 & 1.25 & 0.432 & 0.1 \\
\hline & Race (non-white) & 2.54 & & & \\
\hline \multirow[t]{2}{*}{ Children } & No kids in $\mathrm{HH}$ & 2.58 & 1.24 & 0.366 & 0.1 \\
\hline & Has kids in $\mathrm{HH}$ & 2.67 & & & \\
\hline \multirow[t]{3}{*}{ Age } & Baby Boomers & 2.43 & 1.24 & 0.001 & --- \\
\hline & Gen X-ers & 2.52 & & & \\
\hline & Millennials & 2.85 & & & \\
\hline \multirow[t]{6}{*}{ Education } & Some college & 2.69 & 1.24 & 0.528 & --- \\
\hline & 2-year degree & 2.48 & & & \\
\hline & 4-year degree & 2.60 & & & \\
\hline & Some grad school & 2.50 & & & \\
\hline & Master's & 2.64 & & & \\
\hline & Adv degree & 2.57 & & & \\
\hline
\end{tabular}

Travel behavior

$\begin{array}{lllll}\text { Bicycle weekly (no) } & 2.68 & 1.24 & \mathbf{0 . 0 2 7} & \mathbf{0 . 2} \\ & \mathbf{2 . 4 5} & & & \end{array}$

Bicycle weekly (yes, $\mathbf{n = 1 9 2 )}$

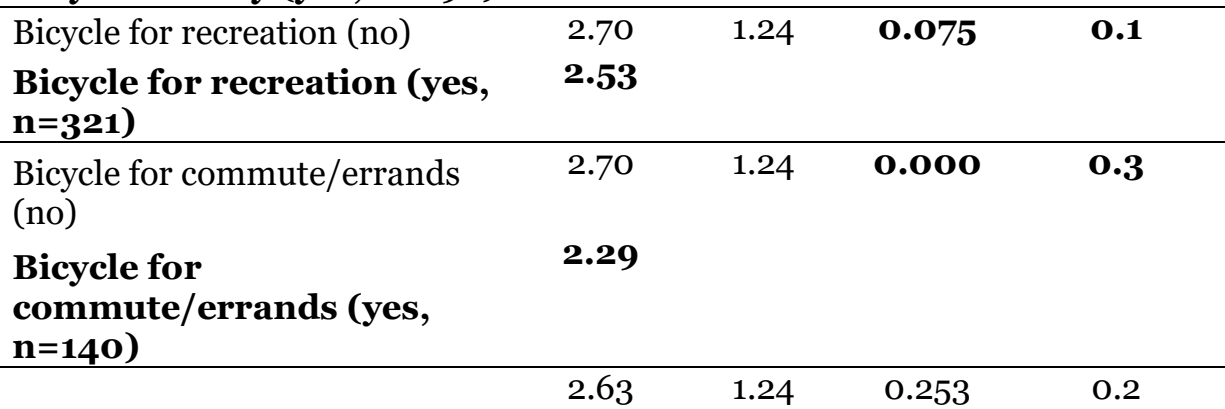

Bicycle to accompany child (no)

Bicycle to accompany child $\quad 2.41$

(yes, $\mathrm{n}=46$ )

$\begin{array}{lllll}\text { Bicycled as a child (no) } & 2.82 & 1.24 & 0.225 & 0.2\end{array}$

2.60

Bicycled as a child (yes, $\mathrm{n}=605$ )

*p-value for F-statistics for one-way ANOVA

**Effect size is calculated as the difference between the means divided by the pooled standard deviation. Conventional effect sizes are small (o.1), medium (o.3), large (0.5) 


\section{Regression models on behaviors}

To further explore the significant results of the bivariate analyses, models of each of the four behaviors were estimated using ordinary least squares regression. Initial exploration of the data confirmed that assumptions for linear regression models were acceptable, particularly with the sample size (Cohen, 2011). Two items (hold up pressure and aggression) were skewed, but using a natural log of the dependent variable did not change the model results, so the untransformed results are presented here.

\section{Perceptual issues}

In the model of the perception scale (Table 35), the social dominance attitude had the highest standardized coefficient. This factor scale represents the belief about cars not holding up traffic, anger evoked by rule-breaking bicyclists, and a willingness to excuse other drivers' rule-breaking. The roadway legitimacy factor, regarding bicyclist licensing and registration, and being a women had similar relative predictive strength, as did age and driver identity, which were both inversely related to perceptual issues. All collinearity statistics were well below the threshold of concern (i.e. VIF < 5). The final model accounted for $15 \%$ of the variance in perceptual issues.

It is notable that respondents who had bicycled for fun or exercise had fewer concerns about their performance and skills maneuvering around bicyclists, but utilitarian bicyclists did not. This could be that recreational bicyclists bike many more miles (which was not asked in the survey), and thus gain more comfort 
maneuvering around bicyclists. Conversely, they may feel more confident in their skills than is warranted, and utilitarian cycling tempers that confidence.

Table 35 Regression model for perceptual and performance issues

\begin{tabular}{lrrrr}
$\begin{array}{l}\text { Perception and performance } \\
\text { measure }\end{array}$ & Coefficient & $\begin{array}{c}\text { Standardized } \\
\text { coefficient }\end{array}$ & t-statistic & \multicolumn{1}{c}{$\begin{array}{c}\text { p- } \\
\text { value }\end{array}$} \\
\hline Constant & 2.995 & & 7.036 & $\mathbf{0 . 0 0 0}$ \\
& & & & \\
Demographic measures & & & & \\
Gender & 0.361 & 0.157 & 4.093 & $\mathbf{0 . 0 0 0}$ \\
Age & -0.009 & -0.130 & -3.012 & $\mathbf{0 . 0 0 3}$ \\
Person of color & -0.166 & -0.062 & -1.573 & 0.116 \\
Education level & 0.041 & 0.063 & 1.476 & 0.141 \\
Have child(ren) & -0.092 & -0.040 & -1.017 & 0.309 \\
\hline
\end{tabular}

Travel behavior measures

\begin{tabular}{|c|c|c|c|c|}
\hline Driving frequency (days/wk) & -0.005 & -0.008 & -0.192 & 0.848 \\
\hline Bicycles weekly & -0.074 & -0.031 & -0.622 & 0.534 \\
\hline Bicycled for fun/exercise & -0.207 & -0.095 & -2.033 & 0.043 \\
\hline Bicycled to commute/errands & 0.053 & 0.020 & 0.439 & 0.661 \\
\hline Bicycled to accompany a child & -0.281 & -0.065 & -1.640 & 0.102 \\
\hline Bicycled as a child & -0.127 & -0.031 & -0.802 & 0.423 \\
\hline
\end{tabular}

Built environment measures

$\begin{array}{lllll}\text { Street intersection density } & -0.001 & -0.079 & -1.853 & \mathbf{0 . 0 6 4}\end{array}$

Bicycle commute mode share

0.037

0.073

$1.730 \quad 0.084$

Attitude measures

\begin{tabular}{lrrrr} 
Implicit attitude & 0.006 & 0.002 & 0.055 & 0.956 \\
Driver Identity & -0.173 & -0.144 & -3.629 & $\mathbf{0 . 0 0 0}$ \\
$\begin{array}{l}\text { Support for auto-centric system } \\
\text { Pro-driver/anti-bicyclist social }\end{array}$ & 0.029 & 0.022 & 0.537 & 0.592 \\
norms & 0.233 & 0.173 & 4.243 & $\mathbf{0 . 0 0 0}$ \\
Road user legitimacy beliefs & 0.147 & 0.147 & 3.620 & $\mathbf{0 . 0 0 0}$ \\
\hline & & & & \\
n & 599 & & & \\
R-square & 0.181 & & & \\
Adjusted R-square & 0.156 & & & \\
Significance & $\mathbf{0 . 0 0 0}$ & & &
\end{tabular}




\section{Pressure to overtake a bicyclist}

In the model of pressure to overtake, only age, social dominance, and legitimacy were significant predictors (Table 36). The social dominance scale had the highest standardized coefficient. This factor scale reflects anger at bicyclist rulebreaking, willingness to excuse drivers' rule-breaking, and perhaps most importantly, the belief that bicyclists should not hold up traffic. This suggests that drivers' own feelings about bicyclists not holding up traffic may cause them to perceive, real or not, that drivers behind them are angry if they do not overtake. Another possibility is that they get angry when drivers in front of them do not pass bicyclists, and so they assume other drivers feel the same. The older the driver, the less they felt a pressure to overtake. This fits with existing research into the importance of social norms in predicting unsafe driving behavior in younger drivers, in particular (Ulleberg, 2001). Although roadway legitimacy is modelled as the predictor of overtaking pressure, it is possible that the relationship goes the other direction - drivers who feel pressure to overtake may see bicyclist licensing and registration as a way to control bicyclists or make them behave. 
Table 36 Regression model for pressure to overtake

Driver feels other drivers get annoyed if they don't overtake model

\begin{tabular}{ccrr} 
Coefficient & $\begin{array}{c}\text { Standardized } \\
\text { coefficient }\end{array}$ & t-statistic & p-value \\
\hline 3.344 & & 7.305 & o.ooo
\end{tabular}

Demographic measures

Gender

$\begin{array}{rrrr}0.008 & 0.003 & 0.082 & 0.935 \\ -0.009 & -0.129 & -2.783 & \mathbf{0 . 0 0 6} \\ 0.055 & 0.021 & 0.486 & 0.627 \\ 0.027 & 0.042 & 0.907 & 0.365 \\ 0.081 & 0.036 & 0.837 & 0.403\end{array}$

Travel behavior measures

Driving frequency (days/wk)

0.028

0.049

1.074

0.283

Bicycles weekly

0.066

0.028

$0.512 \quad 0.609$

Bicycled for fun/exercise

$-0.116$

$-0.054$

$-1.063$

0.288

Bicycled to commute/errands

Bicycled to accompany a child

0.004

0.002

0.031

0.975

$-0.097$

$-0.023$

$-0.529$

0.597

Bicycled as a child

0.087

0.021

0.509

0.611

Built environment measures

Street intersection density

Bicycle commute mode share

Attitude measures

Implicit attitude

Driver Identity

Support for auto-centric system

Pro-driver/anti-bicyclist social norms

Road user legitimacy beliefs

$\mathrm{n}$

R-square

8.04E-05

0.008

0.009

0.193

0.847

0.016

0.356

0.722

0.14

0.03

$-0.019$

0.208

0.096

583

0.072

Adjusted R-square

0.042

Significance
0.001 
Expression of anger via honking, shouting, or gesturing

In the model of drivers' expressing aggression (Table 38), the social dominance factor had the largest standardized coefficient, closely followed by the system justification factor. This suggests that expressing anger via honking, shouting, or gesturing at bicyclists is a function of more general attitudes about being angry about bicyclist rule-breaking and attitudes justifying the dominant auto-based system. Also significant were race, days per week driving, having bicycled as a child, pedestrian facility density, multimodal link density, and the legitimacy scale. There are no concerns of collinearity (all VIF $<5$ ).

The finding that the two built environment characteristics that represent a rough proxy for bikeability are positively correlated with likelihood of expressing anger toward a bicyclist may reflect driving in more congested areas, or merely more exposure to people riding and thus more likelihood of having expressed anger. 
Table 37 Regression model for expression of anger toward a bicyclist Driver has honked, shouted, or gestured at a bicyclist who made them angry

Coefficient

Standardized $\quad \mathrm{t}-$

Constant $-0.738$ coefficient statistic p-value

Demographic measures

\begin{tabular}{|c|c|c|c|c|}
\hline Gender & -0.143 & -0.051 & -1.267 & 0.206 \\
\hline Age & -0.003 & -0.032 & -0.707 & 0.480 \\
\hline Person of color & 0.279 & 0.084 & 2.052 & 0.041 \\
\hline Education level & 0.052 & 0.066 & 1.469 & 0.142 \\
\hline Have child(ren) & 0.043 & 0.015 & 0.367 & 0.714 \\
\hline
\end{tabular}

Travel behavior measures

\begin{tabular}{|c|c|c|c|c|}
\hline Driving frequency (days/wk) & 0.059 & 0.085 & 1.907 & $\mathbf{0 . 0 5 7}$ \\
\hline Bicycles weekly & 0.022 & 0.008 & 0.145 & 0.885 \\
\hline Bicycled for fun/exercise & -0.200 & -0.075 & -1.531 & 0.126 \\
\hline Bicycled to commute/errands & 0.109 & 0.033 & 0.699 & 0.485 \\
\hline Bicycled to accompany a child & 0.274 & 0.052 & 1.245 & 0.214 \\
\hline Bicycled as a child & -0.407 & -0.081 & -1.998 & 0.046 \\
\hline
\end{tabular}

Built environment measures

$\begin{array}{lllll}\text { Street intersection density } & 0.001 & 0.098 & 2.182 & \mathbf{0 . 0 3 0}\end{array}$

Bicycle commute mode share

\begin{tabular}{llll}
0.003 & 0.005 & 0.122 & 0.903 \\
\hline
\end{tabular}

Attitude measures

\begin{tabular}{lrrrr} 
Implicit attitude & 0.060 & 0.019 & 0.456 & 0.648 \\
$\begin{array}{l}\text { Driver Identity } \\
\text { Support for auto-centric }\end{array}$ & -0.084 & -0.057 & -1.379 & 0.168 \\
$\begin{array}{l}\text { system } \\
\text { Pro-driver/anti-bicyclist social }\end{array}$ & 0.303 & 0.192 & 4.404 & $\mathbf{0 . 0 0 0}$ \\
norms & 0.322 & 0.195 & 4.571 & $\mathbf{0 . 0 0 0}$ \\
Road user legitimacy beliefs & 0.177 & 0.145 & 3.398 & $\mathbf{0 . 0 0 1}$ \\
\hline & & & & \\
n & 556 & & & \\
R-square & 0.166 & & & \\
Adjusted R-square & 0.139 & & & \\
Significance & $\mathbf{0 . 0 0 0}$ & & & \\
\hline
\end{tabular}


Checking for bicyclists before turning

The largest standardized coefficient in the model of performing a "check" (e.g. checking the side mirror, or turning their head to look before turning the car) was age, suggesting that with driving experience comes an increased care taken to look for bicyclists. Conversely, respondents with higher education level, and a more pro-driver implicit attitude were significantly less likely to perform safety checks. More pro-driver/anti-bicyclist social norms, surprisingly, increased likelihood that drivers report checking for bicyclists. Increased multimodal links, and thus potential bikeability, increased the likelihood that drivers check for bicyclists, which suggests a contribution of the built environment to drivers' expectation of bicyclists. Bicycling for utilitarian purposes, but not recreation, neared significance in the model in predicted a check for bicyclists. 
Table 38 Regression model for checking for bicyclists before turning

Driver does not perform check

before turning

Standardized tCoefficient coefficient statistic value

Constant

3.910

$7.757 \quad 0.000$

Demographic measures

Gender

0.006

0.002

0.062

0.951

Age

$-0.017$

$-0.214$

$-4.776$

o.000

Person of color

$-0.264$

$-0.086$

$-2.104$

0.036

Education level

0.062

0.085

1.902

o.058

Have child(ren)

0.017

0.007

0.164

0.870

Travel behavior measures

Driving frequency (days/wk)

0.000

$0.000 \quad-0.004$

0.997

Bicycles weekly

0.041

$0.015 \quad 0.287$

0.774

Bicycled for fun/exercise

$-0.060$

$-0.024 \quad-0.500$

0.618

Bicycled to commute/errands

$-0.269$

$-0.089 \quad-1.879$

0.061

Bicycled to accompany a child

$-0.163$

$-0.033 \quad-0.804$

0.422

Bicycled as a child

$-0.106$

$-0.023$

$-0.562$

0.575

Built environment measures

Street intersection density

0.000

$-0.019$

$-0.424$

0.672

Bicycle commute mode share

$-0.083$

$-0.144$

$-3.270$

o.o01

Attitude measures

\begin{tabular}{|c|c|c|c|c|}
\hline Implicit attitude & 0.340 & 0.116 & 2.801 & 0.005 \\
\hline Driver Identity & -0.087 & -0.064 & -1.545 & 0.123 \\
\hline Support for auto-centric system & 0.096 & 0.065 & 1.509 & 0.132 \\
\hline $\begin{array}{l}\text { Pro-driver/anti-bicyclist social } \\
\text { norms }\end{array}$ & -0.159 & -0.103 & -2.443 & 0.015 \\
\hline Road user legitimacy beliefs & 0.035 & 0.031 & 0.739 & 0.460 \\
\hline $\mathrm{n}$ & 601 & & & \\
\hline R-square & 0.111 & & & \\
\hline Adjusted R-square & 0.084 & & & \\
\hline Significance & o.000 & & & \\
\hline
\end{tabular}


Simplified models for comparison

To compare across all four models, the regressions were re-run with only variables that were significant in at least one of the individual attitude models (Table 39). Standardized coefficients were not significantly different than in the full models. The same results were visualized via bar graphs (Figure 35, Figure 36Figure 37, Figure 38), where the sign indicates a direct or inverse relationship between the independent variable and the attitude measure, the color black indicates statistical significance $(\mathrm{p}<0.06)$, and the magnitude indicates the relative strength (i.e. the size of the standardized regression coefficient). 
Table 39 Simplified regression models for comparison

\begin{tabular}{l} 
Constant \\
Demographic measures \\
\hline Gender \\
Age \\
Person of color \\
Education level \\
Travel behavior measures \\
\hline Driving frequency (days/wk) \\
Bicycled for fun/exercise \\
Bicycled to commute/errands \\
Bicycled as a child \\
Built environment measures \\
\hline Street intersection density \\
Bicycle commute mode share \\
Attitude measures \\
\hline Implicit attitude \\
Driver Identity \\
Support for auto-centric system
\end{tabular}

Perception measure

Beta sig.
Pressure to overtake

Beta

0.157

$-\mathbf{0 . 1 2 7}$

$-0.057$

0.071

$-0.013$

-0.115

$-0.001$

$-0.036$

$$
-0.0
$$

$-0.08$

0.078

0.002

$-0.148$

0.018
0.060

0.066

o.ooo

o.ooo

$\mathbf{0 . 0 0 3}$

0.141

0.096

0.759

0.005

0.988

0.346

0.958

o.000

0.662 sig.

o.ooo

0.979

-0.135

0.025

0.041

0.053

$-0.044$

0.007

0.021

0.01

0.014

0.834

0.764

0.098

0.003

0.028

0.944

0.053

0.029

$-0.017$

Expressed anger

Beta sig.

0.201

(201

o.004

0.544

0.374

0.247

0.318

0.882

0.608

$-0.077$

0.220
0.489
0.71
No check for bicyclists

Beta sig.

o.ooo

0.001

$-0.216$

$-0.082$

0.086

0.000

$-0.021$

-0.09

$-0.024$

$-0.019$

$-0.144$

0.676

0.001

0.115

$-0.062$

0.063

0.006

0.131

0.143 


\begin{tabular}{|c|c|c|c|c|c|c|c|c|}
\hline \multirow{3}{*}{ Pro-driver/anti-bicyclist social norms } & \multicolumn{2}{|c|}{ Perception measure } & \multicolumn{2}{|c|}{ Pressure to overtake } & \multicolumn{2}{|c|}{ Expressed anger } & \multicolumn{2}{|c|}{ No check for bicyclists } \\
\hline & Beta & sig. & Beta & sig. & Beta & sig. & Beta & \\
\hline & 0.178 & o.ooo & 0.154 & $\mathbf{0 . 0 0 0}$ & 0.191 & o.ooo & -0.102 & 0.016 \\
\hline Road user legitimacy beliefs & 0.154 & o.ooo & 0.095 & 0.029 & 0.142 & 0.001 & 0.032 & 0.453 \\
\hline $\mathrm{n}$ & 599 & & 583 & & 556 & & 601 & \\
\hline R-square & 0.174 & & 0.070 & & 0.163 & & 0.110 & \\
\hline Adjusted R-square & 0.153 & & 0.046 & & 0.140 & & 0.087 & \\
\hline Significance & 0.000 & & 0.000 & & 0.000 & & 0.000 & \\
\hline
\end{tabular}




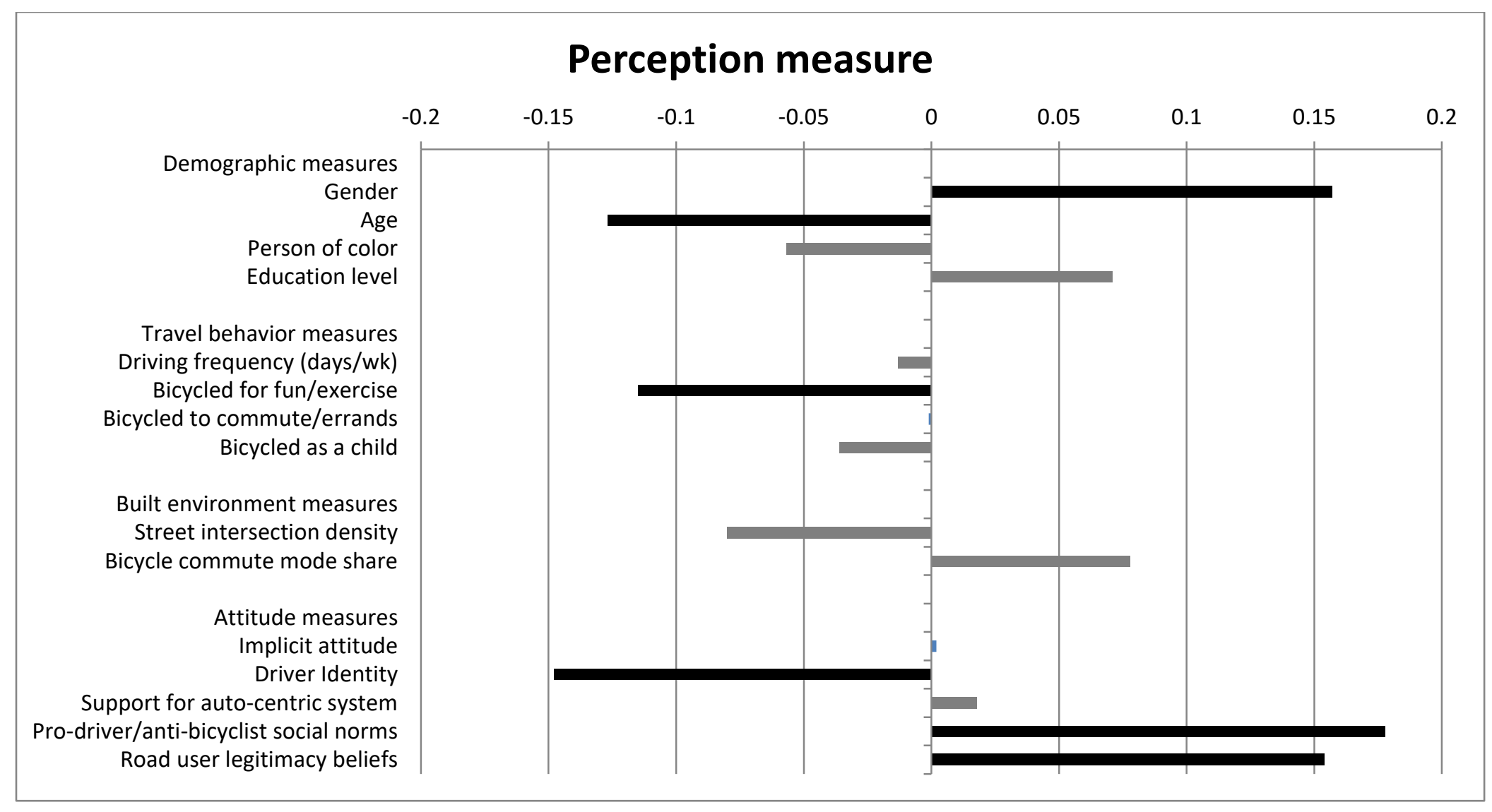

Figure 35 Graphical representation of perceptual issues model 


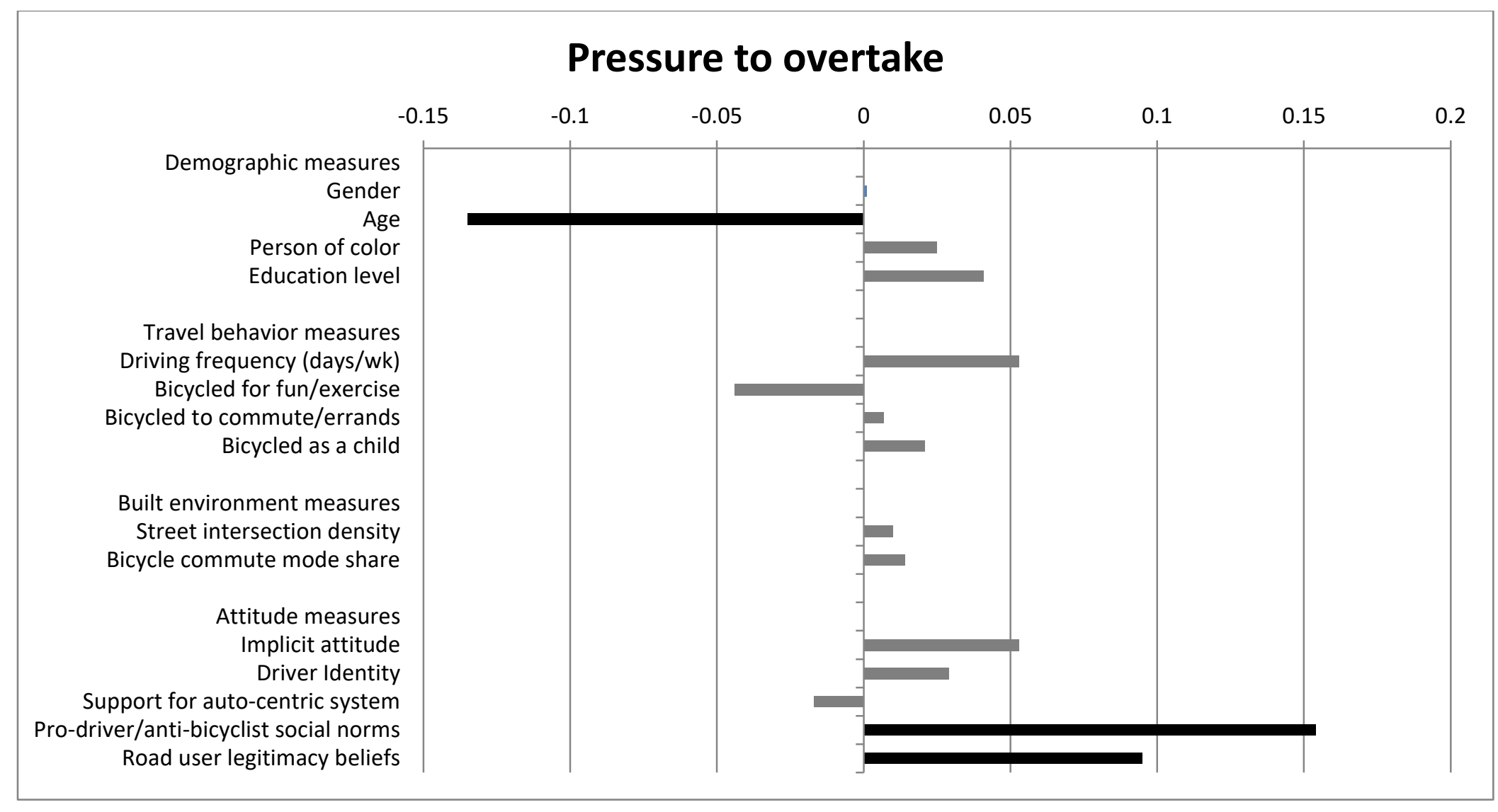

Figure 36 Graphical representation of pressure to overtake model 


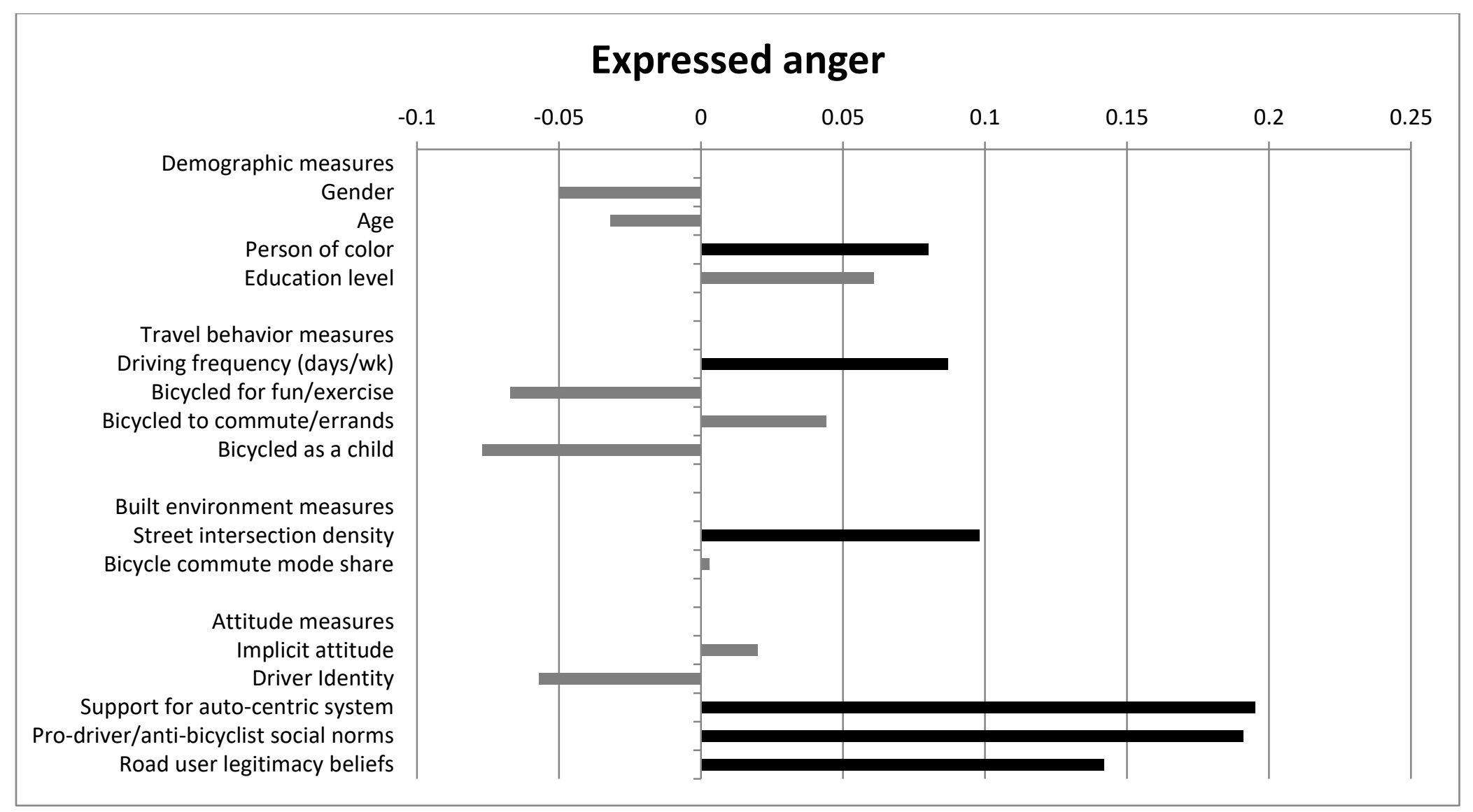

Figure 37 Graphical representation of expressed anger model 


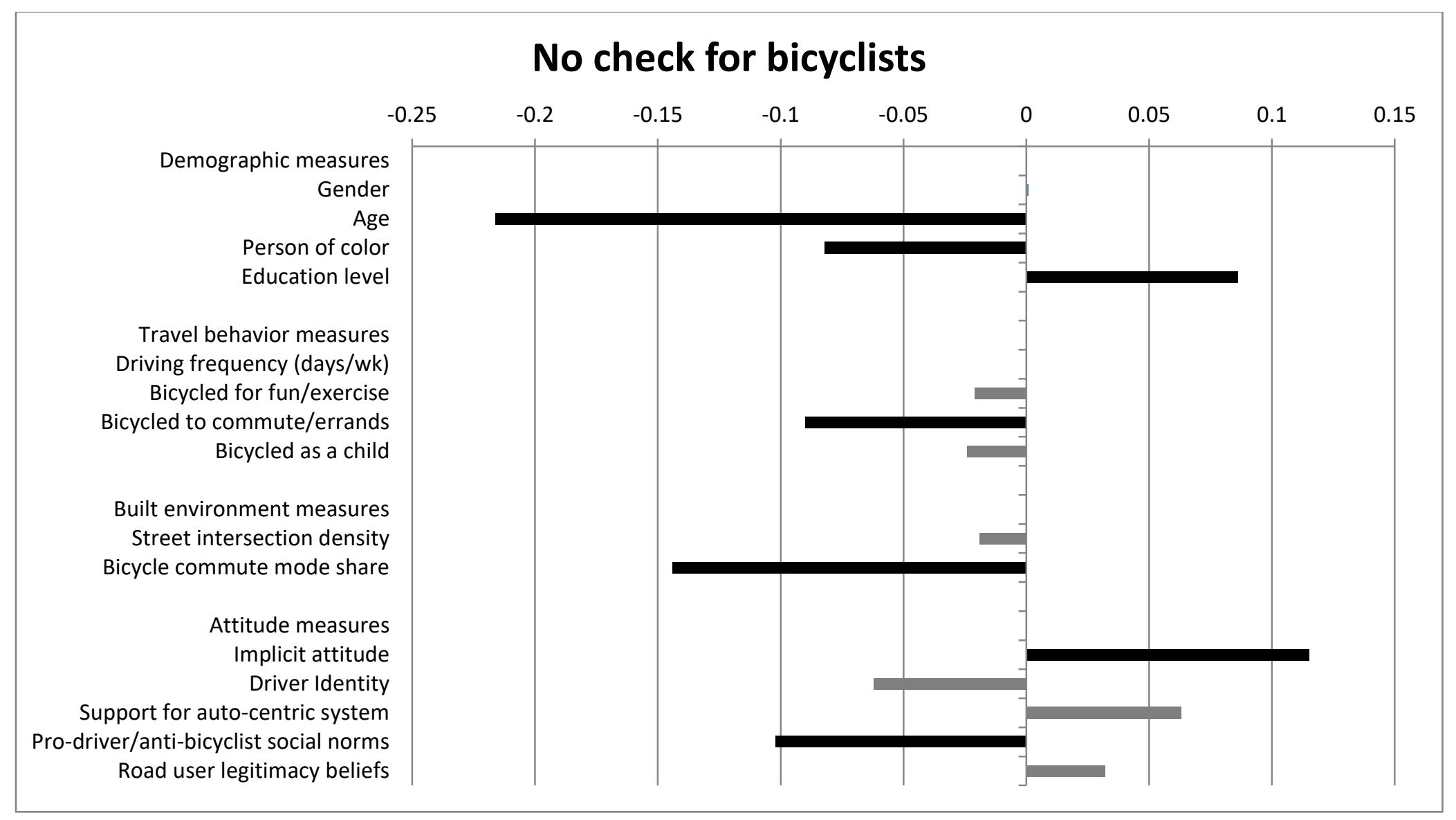

Figure 38 Graphical representation of checking for bicyclists before turning model 


\section{Chapter 5 Results discussion}

Overall, these analyses lend support to the hypotheses that both attitudes and personal behavior as a bicyclist are important to understanding driver's selfreported behavior toward bicyclists. It makes intuitive sense that personal experience as bicyclist might improve perceptual knowledge and comfort, lower frustration, and increase expectation and care toward bicyclists while driving. The study shows, however, that all types of personal experience may not have the same positive effect. This phenomenon is familiar to many advocates and planners, usually prefaced with "I'm an avid cyclist, but", followed by a negative attitude toward people on bicycles, particularly for utilitarian purposes. Considering the estimated impact on traffic safety of road rage and aggressive driving (Berdoulat, Vavassori, \& Sastre, 2013), understanding the underlying psychology in overt driver aggression toward bicyclists is an important area for continued and expanded research. Understanding the underlying processes at work can then be used to design interventions. For example, a prime area of research are potential interventions that increase understanding of other modes, particularly compensatory strategies that have shown promise in other domains (S. Singletary \& Hebl, 2009). Even if getting drivers onto bicycles regularly is not feasible, it is worth testing whether compensatory strategies that seek to build empathy and expectation might improve drivers understanding of and behavior toward bicyclists. 
Overt aggression is scary and is a deterrent to bicycling (Emond, Tang, \& Handy, 2009). It is likely far outweighed as a safety concern, however, by behaviors that result from "looked but failed to see errors" (Brown, 2005), for which we do not yet fully understand the causes. Previous research sought to measure the influence of attitudes on drivers' inattentional blindness toward motorcyclists, and whether experience as a motorcyclist would improve drivers' ability to identify and avoid conflicts with motorcyclists (Shahar, Clarke, \& Crundall, 2011). Drivers who watched videos from a motorcyclist's perspective had more empathetic and positive safety-related attitudes, and fewer negatives attitudes toward motorcyclists (Shahar et al., 2011). In another study, experience as a motorcyclist improved drivers' hazard perception, although it was not known whether motorcyclist-drivers were better at perceiving hazards via visual processing or whether they had an improved mental model about the type of hazards that a driver might encounter related to motorcyclists (Rosenbloom, Perlman, \& Pereg, 2011). While motorcycling and bicycling have some significant differences (e.g. speed, freeway use), their similarities as vulnerable road users suggests way that future research can build off existing studies in motorcyclist safety.

In the models of perceptual issues and expression of anger, there were moderately good explanatory power (i.e. adjusted R-squares) of the models, with 15.3 percent and 14 percent of the variance explained, respectively. The model of pressure to overtake, conversely, was quite modest, with an adjusted R-squared 
of 0.046 . The social norms against holding up traffic seem to be ubiquitous, and may be better understood through examination of car culture rather than demographics, built environment, individual travel behavior, and even individually-held social attitudes about the roadway environment. Considering the potential implications of the pressure to overtake a bicyclist (e.g. making an unsafe passing maneuver), and the fact it is so widely held, warrants further study.

The additional explanatory power of attitudes recommends their use in future research into interactions between roadway users. Roadway interactions, like all other human interactions, may be influenced by intergroup relations as much, or more than, by individual personalities or circumstances. The insulating effect of the bodywork of a car, the dominance of the automobile in the existing transportation system, and the visibility of the bicyclist create an imbalance in the potential for biased interactions and potential harm to people on bicycles. The potentially moderating effect, however, of personal experience with bicycling offers a direction for positive change. The frequency of that experience, and how lasting its effects, warrant attention by researchers, planners, and advocates alike. 


\section{Chapter 6: Conclusion}

This research used an online survey to test drivers' implicit bias between drivers and bicyclists, and collect explicit attitudes and self-report driving behaviors. By applying social psychological theories to inform the survey development and data analysis, the data provides a novel understanding of the underlying "intergroup relations" between drivers and bicyclists. This has implications for bicycling promotion and bicyclist safety.

\section{Research Questions and Key Findings}

Organized by the original research questions, key findings of this research are discussed below.

\section{Question 1: What are drivers' attitudes toward bicyclists as fellow} roadway users, and what predicts those attitudes?

\section{Question 1.1 Can drivers' implicit attitudes toward bicyclists be}

\section{measured?}

Key Finding 1. It is possible to measure an implicit preference for drivers or bicyclists.

This result fits with existing research into implicit attitudes in many other areas, including race, age, politics, weight, women in STEM, and more. This supports the hypothesis that roadway user groups have socially-constructed meanings, which evoke subconscious bias even abstracted from contextual issues of tradeoffs of resources like parking or funding.

\section{Question 1.2 How are drivers' explicit and implicit attitudes related?}


Key Finding 2. Implicit attitudes toward bicyclists are related to, but distinct from, consciously-held attitudes toward bicyclists.

Implicit attitudes were significantly correlated with seven of the twelve explicit attitude measures, all in the expected direction. That is, a pro-driver implicit bias was associated with a pro-driver or anti-bicyclist explicit attitude. The correlations were small in magnitude, however, which suggests that the implicit attitude is related, but measuring a different construct. This is consistent with the extensive research into implicit bias in other domains (Banaji \& Greenwald, 2013), in which explicit and implicit attitude correlations range from -0.25 to 0.6, with a mean explicit-implicit correlation of 0.19 , and explicit and implicit attitudes predicted unique variance of criterion variables (Lane et al., 2007).

Question 1.3 Does measuring drivers' implicit attitudes add value to traditional survey methods?

Key Finding 3. Implicit bias provides additional explanatory power in prediction of these intergroup attitudes, even after controlling for sociodemographics, individual travel behavior, and the built environment. Again, this is consistent with existing research into implicit bias. Implicit biases are influenced by culture, previous interactions, and societal cues about who has legitimacy and value. This, combined with the potential influence of implicit bias on behavior in the roadway, supports a systematic safety approach that seeks to change approaches to both roadway design and culture. 


\section{Question 1.4 What are drivers' explicit (self-reported) behaviors}

\section{about bicyclists as fellow roadway users?}

Key Finding 4. Drivers' attitudes toward bicyclists can be understood through social psychological theories of intergroup relations.

Consistent with previous qualitative research (Aldred, 2012; Aldred \& Dales, n.d.), drivers and bicyclists can be understood as social groups whose interactions are influenced by issues of identity, social dominance, system justification, and beliefs about legitimacy. These theories can help explain why interactions among roadway users are not always dictated by rational thought or action and the more contested the roadway space is perceived to be, the more than people may act based on their group membership. These intergroup relations have implications for programs, policy, and design aimed at increasing bicycling and improving bicyclist safety.

\section{Question 1.5 How do demographic, driving frequency, implicit} attitude, and built environment characteristics predict attitudes toward bicyclists?

Key Finding 5. Regardless of demographics, travel behavior, or location, beliefs that bicyclists should have to register, get licensed, and pay specific road taxes were not widely held. Similarly, there was broad general support for public investment in bicycle infrastructure.

Age, gender, education, personal travel behavior, the built environment, and implicit attitude all affected one or more the attitude measures. As might be 
expected, higher driving frequency and bicycling had inverse effects on attitudes. A pro-driver implicit attitude significantly predicted a more pro-driver/antibicyclist explicit attitude, even after controlling for the other variables. Contrary to anecdotal data, however, respondents were not generally in favor of bicyclists needed to be licensed and registered and pay specific road taxes, and generally felt that bicycle infrastructure is a good investment of public funds. The question was posed in the abstract, however, and did not ask respondents to choose between bicycle infrastructure and general road maintenance or parking.

\section{Question 1.6 Does personal experience as a bicyclist predict drivers' attitudes toward bicyclists?}

Key Finding 6. Personal experience as a bicyclist often improved both attitudes and behaviors toward bicyclists.

Key Finding 7. Bicycling trip purpose was relevant to which attitudes and behaviors were moderated by personal experience.

Key Finding 8. Bicycling frequency was the only bicycling behavior that improved roadway legitimacy attitudes.

The first result on effect of personal experience fits with existing research into motorcyclist attitudes and behaviors and makes intuitive sense, but is useful to confirm it also applies to bicyclists via quantitative data that takes into account demographics, the built environment, and attitudes. The latter two are novel findings that warrant further study. Trip purpose is often examined in understanding bicycling mode choice, but this research demonstrates that trip 
purpose may also have spillover effects into drivers' expectations and understanding of bicyclist behavior. The issues of bicyclist registration and licensing, captured in the roadway legitimacy scale, are often thought to be a "drivers versus bicyclists" attitude. These findings suggest, however, that it is a really between frequent bicyclists and everyone else, although even the majority of the respondents did not support licensing and registration.

Studies that collect bicycling information often ask for bicycling frequency or miles traveled, but this research suggests that bicycle trip purpose is also relevant. For example, only bicycling for errands improved drivers' likelihood of checking for bicyclists before making a turn, a potentially important behavior in reducing right-hook crashes. This finding also raises many more questions. For example, is the finding that recreation riders, but not utilitarian riders, rate themselves as better in maneuvering around bicyclists an accurate assessment of skills, or overconfidence? Why did only bicycling as a child reduce the likelihood that drivers have honked or shouted at a bicyclist?

\section{Question 2: Do drivers' attitudes toward bicyclists predict their behavior toward bicyclists? \\ Question 2.1 What are drivers' behaviors when interacting with}

\section{bicyclists?}

Key Finding 9. Social cognitions (i.e. the explicit attitude scales) help predict drivers' behaviors when interacting with bicyclists, including safety-relevant behaviors. 
This suggests that surveys aimed at understanding interactions among roadway users, particularly when those interactions including vulnerable road users, should include measures of social identity, system justification, and social dominance. Asking questions about bicycling as a mode may be less useful than asking questions about bicyclists as a user group with socially-constructed meanings.

\section{Question 2.2 How do drivers' explicit attitudes toward bicyclists affect their self-reported behaviors?}

Key Finding 10. Explicit attitude measures predicted unique variance in all four behavior models; typically, the more negative the socially-related attitude, the greater likelihood of negative behavior.

Normative beliefs about social rules on the road, including driver and bicyclist rule-breaking and bicyclists holding up traffic, significantly predicted negative behavior in all four models. Beliefs that bicyclists should do more to be "legitimate" roadway users all predicted a greater pressure to overtake and likelihood of having expressed anger toward a bicyclist. A stronger Driver Identity significantly predicted lower concerns about perception and skills around bicyclists, which may represent a potentially misplaced high selfevaluation of driving skills. Perhaps counterintuitively, a higher score on social norms predicted a greater likelihood of checking for a bicyclist before making a turn. Further study could explore the mechanism underlying this finding, and how it might be leveraged to improve drivers' visual search patterns. 


\section{Question 2.3 Does an implicit measurement of drivers' attitudes explain additional variance in drivers' behaviors?}

Key Finding 11. Implicit bias against bicyclists helped predict a lack of checking for bicyclists even after controlling for explicit attitudes.

This supports the earlier findings that fully understanding driver-bicyclist interactions benefits from an implicit measure of attitudes in addition to more traditional survey methods. That implicit bias helped predict even a self-reported behavior suggests that it may influence behaviors controlled by automatic processes, which happen during habitual behaviors like driving that occur in an environment with high cognitive demands.

\section{Question 2.4 What are the predictors of negative safety-related behaviors toward bicyclists?}

Key Finding 12. The perceived pressure to overtake a bicyclist who is going slowly is widely felt by drivers, and not related to personal travel behavior, the built environment, or most sociodemographics.

While the idea that holding up traffic is socially negative is not novel, this may be the first time this question has been asked outright. Furthermore, that it was so widely held ( $83 \%$ of respondents agreed with the statement), and not related to most of the potential predictors, suggests that the perceived pressure is a culturally-embedded belief that may be difficult to change. It is important, however, because overtaking crashes are more often fatal than other types, either 
because they are rear-end crashes that happen at high speeds, or because drivers overtake and then "right-hook" a bicyclist.

Key Finding 13. The safety-relevant behaviors in this study were differentially affected by demographics, personal travel behavior, implicit attitudes, and the built environment.

As might be expected from the extensive research into the Driver Behavior Questionnaire, behavior measures that can be viewed as perceptual (e.g. estimating passing distance) are distinct from violations (e.g. honking at a bicyclist) or knowledge (e.g. deciding how close or fast to pass). Accordingly, the effect of demographics, individual travel behavior, attitudes, and the built environment was different depending on the type of behavior. However, all behaviors were improved with age and bicycling experience, and negatively associated with negative social attitudes and driving frequency. 
Table 4o Summary of research questions and key findings What are drivers' attitudes toward bicyclists as fellow roadway users, and what predicts those attitudes?

Sub-question Key Finding

Can drivers' implicit attitudes toward

1. It is possible to measure an implicit

bicyclists be measured? preference for drivers or bicyclists.

How are drivers' explicit and implicit attitudes related?

2. Implicit attitudes toward bicyclists are related to, but distinct from, consciously-held attitudes toward bicyclists.

Does measuring drivers' implicit attitudes add 3. Implicit bias provides additional value to traditional survey methods? explanatory power in prediction of these intergroup attitudes, even after controlling for sociodemographics, individual travel behavior, and the built environment.

What are drivers' explicit (self-reported) behaviors about bicyclists as fellow roadway users?

4. Drivers attitudes toward bicyclists can be understood through social psychological theories of intergroup relations.

5. Regardless of demographics, travel

How do demographic, driving frequency, behavior, or location, beliefs that bicyclists implicit attitude, and built environment characteristics predict attitudes toward bicyclists? should have to register, get licensed, and pay specific road taxes were not widely held. Similarly, there was broad general support for public investment in bicycle infrastructure

Does personal experience as a bicyclist predict drivers' attitudes toward bicyclists? 6. Personal experience as a bicyclist often improved both attitudes and behaviors toward bicyclists.

7. Bicycling trip purpose was relevant to which attitudes and behaviors were moderated by personal experience.

8. Bicycling frequency was the only bicycling behavior that improved roadway legitimacy attitudes. 
Table 40 (continued) Do drivers' attitudes toward bicyclists predict their behavior toward bicyclists?

Sub-question Key Finding

9. Social cognitions (i.e. the explicit attitude

What are drivers' behaviors when interacting scales) help predict drivers' behaviors when

with bicyclists?

interacting with bicyclists, including safety-

relevant behaviors.

How do drivers' explicit attitudes toward

10. Explicit attitude measures predicted unique bicyclists affect their self-reported behaviors? the more negative the socially-related attitude, the greater likelihood of negative behavior.

Does an implicit measurement of drivers' attitudes explain additional variance in drivers' behaviors?

11. Implicit bias against bicyclists helped predict a lack of checking for bicyclists even after controlling for explicit attitudes.

12. The perceived pressure to overtake a

What are the predictors of negative safetybicyclist who is going slowly is widely felt by related behaviors toward bicyclists? drivers, and not related to personal travel behavior, the built environment, or most sociodemographics.

13. The safety-relevant behaviors in this study were differentially affected by demographics, personal travel behavior, implicit attitudes, and the built environment. 


\section{Implications for Practice}

This research has several lessons applicable to bicycling design, planning, and encouragement. First, while introduction of psychological theories like the Theory of Planned Behavior are useful, they are not sufficient to help explain roadway interactions (Musselwhite et al., 2014). This research suggests that even an introductory understanding of social psychological theories of intergroup relations may help explain the success or failure of certain interventions, and inform their development.

Second, this research provides more evidence that attitudes relating to social class (mode, or the intersection of mode and other social identities) play a role in behaviors toward bicyclists. While attitudes may be difficult or take time to shift, roadway design can work immediately by either fully separating modes, or slowing down interactions so that drivers can rely more on executive function and less on implicit cognitions when looking for, seeing, and behaving toward bicyclists. Infrastructure that designates portions of the roadway space to certain users may help alleviate the tensions and difficulties that drivers in this study felt when maneuvering around bicyclists. An example solution is infrastructure that reduces the need to overtake (e.g. separated bike lanes). Investment in bicyclespecific facilities, and slowing down interactions to a more equitable speed, may also to serve as a normalizing tool that reduces ideas about some roadway users being more legitimate than others. The results about difficulties of knowing how to overtake and judging distance to a bicyclist suggests that passing laws are 
important but may require additional consideration of how to promote and enforce safe passing behavior.

\section{Limitations and Caveats}

This research has several limitations that are important to note. Some of these limitations are unavoidable with this type of survey (e.g. biases related to selfreport data), while some limitations arose from choices about survey design or administration that are part of the doctoral research learning process. The limitations of the methods included a unique type of self-selection bias, in that respondents self-selected into a study of implicit bias, regardless of content; the simplicity of the IAT; the small number of survey items, which limits scale development; and the typical survey caveats about social desirability and recall biases, a function of using self-report measures.

The regression models used should be viewed with caution. By the nature in which they are specified, they can suggest "cause and effect" that is not that clear, or one-directional, in reality. Particularly when modeling attitudes, or the attitude-behavior connection, simple linear regression models, although not incorrect, can oversimplify what is likely a "messier" relationship that the models indicate. Structural equation modeling could help tease out whether some variables have a mediating or moderating effect between attitudes and behavior, for example. Additionally, for most of the models, the percent of variance explained was very small. Put another way, these attitudes and some of the selfreport behaviors are likely better explained by variables that were not collected in 
this research. Cultural issues (e.g. media messages about car culture, not ethnic culture) and beliefs or experiences of family and friends are just two areas that previous research demonstrated play a role in transportation-related attitudes (Atchley, Shi, \& Yamamoto, 2014; C. M. Monsere, McNeil, \& Dill, 2012; Nordfjærn, Şimşekoğlu, \& Rundmo, 2013, for starters).

It is important to reiterate that the "behaviors" analyzed here at self-reported behaviors, which have mixed ties to real-world behavior. Discussion of the effect of drivers' attitudes on safety outcomes is limited to informed speculation. Without observing behavior, in a simulator or naturalistically, this research cannot make any definitive conclusions about the safety-related outcomes of negative biases or even self-reported behaviors of drivers toward bicyclists. Extensive data from other domains like policing and healthcare, however, suggest that attitudes may direct behavior, particularly in cognitively-complex environments like the roadway.

The novelty of the theoretical and methodological approaches in this study, while a strength, also limit the comparability to other established driver behavior scales or studies. As in all science, replication will be necessary to determine whether the novel methods or findings of this research point to generalizable findings about driver attitudes or the implications for roadway safety. In addition to the limitations discussed above, there were several significant outright failures that must be noted. One goal of the research was to examine the association of drivers' location with their attitudes and behaviors; in particular, 
does living and driving in an area with a high density of bicycle networks, a high bicycle mode share, a large or small gender gap in bicycling, or a high share of bicyclist fatalities affect attitudes and behaviors (setting aside the potential for residential self-selection bias). There does not currently existing, however, an easily-accessibly and comprehensive database of bicycle infrastructure. Thus, it was necessary to use street network density, intersection density, and pedestrianand multi-modal link density as a rough proxy for bikeability. Additionally, because the road network data (via the EPA Smart Location Database) is provided at the census block group level, and the survey only collected zip codes, additional assumptions were made about how to aggregate the SLD data. An attempt was made to use the Alliance for Bicycling and Walking Benchmarking Report, which has data about bicycling levels and safety for the top fifty largesized and medium-sized communities. Sampling across the country, however, meant that a very small portion of the sample is in a city with one or more of those benchmark data categories. This limited the statistical analysis of the spatial data. Bicycling levels are just too low across the United States, in a nationwide sample of 676 respondents, to be useful. Future research with this survey instrument will focus on sampling people from a few cities so more direct comparisons of bicycling infrastructure and volumes are possible.

Second, there was an error by the contracted survey developers. The programmer mistakenly repeated variable names on three survey items, which resulted in those items being overwritten and the data lost. Those three items probed 
bicyclist identity; that is, they were the complementary questions to the questions about identification as a driver, self-evaluation of skill, and desire to be seen as a good driver. Because of this loss of data on the measure of bicycling identity, it was not possible to look at respondents' self-identification as a bicyclist, or use that in any of the analyses.

Thirdly, the IAT compared drivers and bicyclists as desired, but by not including a feeling thermometer about drivers, it was not possible to create a "semantic differential" to directly compare the implicit preference between drivers and bicyclists with a more explicit preference measure. Finally, the lack of an openended follow-up to the question about self-reported involvement in a near-miss or a crash (due to a need to shorten the study to meet administrative requirements by the survey administrators) missed an opportunity for some rich qualitative data about the 18 minor crashes and 67 near-misses reported by respondents.

\section{Contributions}

There are theoretical, methodological, and practical contributions from this research. The findings from this work demonstrate that theories of intergroup relations can help frame our understanding of attitudes between different types of roadway users. This complements previous research that used social psychological theories to examine travel behavior (Heinen, 2016; Van Acker, Van Wee, \& Witlox, 2010), but it is the first study to utilize intergroup relations as a framework for understanding driver-bicyclist attitudes and interactions. In 
addition to introducing new survey questions relating to roadway attitudes, this research demonstrates that using an implicit method can reveal additional information about people's attitudes, which is particularly important because of the potential effect of implicit bias in interactions between socially-constructed groups or that occur in situations with high demands on attention, perception, and motor skills. While an implicit method has been deployed in a few previous studies related to transportation attitudes (Harré \& Sibley, 2007; Hatfield, Fernandes, Faunce, \& Job, 2008; Moody, Goulet Langlois, Alexander, Campbell, \& Zhao, 2016), this is the first use of an IAT to examine evaluations of and preferences between two types of roadway user. This dissertation provides evidence that such an implicit method does indeed measure a non-random bias between drivers and bicyclists, and that it provides additional explanatory value when examining certain roadway attitudes and self-reported behaviors. From a practical perspective, it is helpful for both roadway design and bicycling promotion to understand some of the social cognitions that affect interactions and may have significant influence on bicycling uptake and bicyclist safety. Implicit bias and the automobile and roadway environment can result in interactions influenced by intergroup - rather than individual or contextual attitudes. Roadway design that slows down interactions between drivers and bicyclists may help drivers utilize more controlled mental processes that improve their ability to look for, mentally process, and act safely around vulnerable road users. One of the goals of this research is to help both practitioners and advocates 
understand the underlying dimensions and mechanisms of driver attitudes, and better inform policy, program, and design decisions related to bicycling and bicyclist safety.

\section{Directions for Future Research}

Physical space is not the only factor structuring people's transportation choices (Lugo, 2013), so the goals of increased and safer bicycling can benefit from understanding the effect of biased roadway behaviors and how those biases might be reduced or "overruled". Interventions that address social identity, stereotypes, and attitudes are needed to broaden the possibilities for improved safety and roadway relations. Understanding the underlying psychology in roadway interactions is an important area for continued and expanded research, which can then be used to design interventions.

This research provides some specific near-term lines of inquiry. From a theoretical perspective, testing theories of intergroup relations would help validate the usefulness of such theory, and point toward potential interventions. From a methodological standpoint, the inclusion of implicit methods may add valuable insight into travel behavior research (Fulcher et al., 2014), and the IAT used in this study should be replicated with different samples. Additionally, there are a variety of implicit methods that may be equally useful and even cheaper or easier to deploy in survey or experimental transportation research, including object detection, dot-probe, approach/avoidance, Linguistic Intergroup Bias, and others (Fulcher et al., 2014). 
This research also points toward various practice-relevant areas of future research. The importance of personal bicycling experience in shifting driver attitudes and behaviors, while intuitive, warrants further study of what type of experience, and how much, is necessary to have lasting effects in creating safer drivers. For example, are short bikeshare trips during lunch errands sufficient for moderating attitudes and behaviors? Does participation in "open streets" events affect driver attitudes and behaviors? If so, for how long after the event? Would bicycling as part of driver licensing and re-licensing improve bicyclist safety? The findings that bicycling behavior is important but that not all types of bicycling have equal benefit on drivers' behaviors suggests that interventions to increase bicycling may need to focus on more empathy- and expectation-building of transportation-style bicycling.

This research could not address whether these attitudes and self-reported behaviors reflect real-world behavior or safety of vulnerable road users. While on-road experimental research is neither safe nor ethical, there are many tools that could help make more direct conclusions about the effect of these attitudes and behaviors. For example, simulator research, or even desktop hazard perception and prediction tasks that probe behaviors like visual search (Underwood, Chapman, Berger, \& Crundall, 2003). Combination of laboratory driving tasks with measurement of explicit and implicit attitudes, as have been used in police shooter simulations (Kahn \& Davies, 2011), is a viable next step for examining attitude-behavior links. 


\section{Final thoughts}

Travel behavior is comprised of social interactions (Walker, 2005), and like any other social interaction are subject to automatic processing, stereotyping, and bias (Baumeister, 2008). Interactions between different types of roadway users, especially if one or more of those road users is a vulnerable road user, may be particularly influenced by social identity, social dominance and system justification, stereotypes, attentional and confirmation biases, fundamental attribution error, or other aspects of social psychology. An important question from a safety perspective is whether these socialpsychological mechanisms, including implicit attitudes, have behavioral outcomes. There is evidence in multiple domains, including smoking (Mogg, 2003), reading (Rayner, 2009), and police training simulations (Kahn \& Davies, 2011) that implicit attitudes predict behavior, particularly in stressful environments that require rapid decision-making. Considering the complexity and potential lethality of roadway interactions, particularly between drivers and vulnerable road users, implicit attitudes warrant further study.

While the evidence is strong for the effect of social cognitions on behavior in other domains, these effects have not been well-explored in the domain of roadway interactions, particularly in the United States. Bringing together existing tools for both explicit and implicit data collection, and adapting them to examine driver-bicyclist interactions in particular, is the primary contribution of this research. 


\section{References}

About The Site | Can Stock Photo. (n.d.). Retrieved January 15, 2017, from http://www.canstockphoto.com/about.php

af Wåhlberg, A. E. (2010). Social desirability effects in driver behavior inventories. Journal of Safety Research, 41(2), 99-106. https://doi.org/10.1016/j.jsr.2010.02.005

Ajzen, I. (2005). Attitudes, personality, and behavior (2nd ed.). Maidenhead, Berkshire, England ; New York: Open University Press.

Ajzen, I. (2014). The theory of planned behaviour is alive and well, and not ready to retire: a commentary on Sniehotta, Presseau, and Araújo-Soares. Health Psychology Review, 1-7. https://doi.org/10.1080/17437199.2014.883474

Aldred, R. (2012). Incompetent or Too Competent? Negotiating Everyday Cycling Identities in a Motor Dominated Society. Mobilities, 8(2), 252-271. https://doi.org/10.1080/17450101.2012.696342

Aldred, R., \& Dales, J. (n.d.). Diversifying and normalising cycling in London, UK: An exploratory study on the influence of infrastructure. Journal of Transport \& Health. https://doi.org/10.1016/j.jth.2016.11.002

Aldred, R., \& Jungnickel, K. (2014). Why culture matters for transport policy: the case of cycling in the UK. Journal of Transport Geography, 34, 78-87. https://doi.org/10.1016/j.jtrangeo.2013.11.004 
Alwin, D. F. (1997). Feeling Thermometers Versus 7-Point Scales: Which are Better? Sociological Methods \& Research, 25(3), 318-340. https://doi.org/10.1177/0049124197025003003

Atchley, P., Shi, J., \& Yamamoto, T. (2014). Cultural foundations of safety culture: A comparison of traffic safety culture in China, Japan and the United States. Transportation Research Part F: Traffic Psychology and Behaviour, 26, Part B, 317-325. https://doi.org/10.1016/j.trf.2014.01.004

Banaji, M. R., \& Greenwald, A. G. (2013). Blindspot: Hidden Biases of Good People (1 edition). New York: Delacorte Press.

Barton, B. K., Kologi, S. M., \& Siron, A. (2016). Distracted pedestrians in crosswalks: An application of the Theory of Planned Behavior. Transportation Research Part F: Traffic Psychology and Behaviour, 37, 129-137. https://doi.org/10.1016/j.trf.2015.12.012

Basford, L., Reid, S., Lester, T., Thomson, J., \& Tolmie, A. (2002). Drivers' perceptions of cyclists.

Baumeister, R. F. (2008). Social psychology and human nature. Belmont, CA: Thomson Higher Education.

Berdoulat, E., Vavassori, D., \& Sastre, M. T. M. (2013). Driving anger, emotional and instrumental aggressiveness, and impulsiveness in the prediction of aggressive and transgressive driving. Accident Analysis \& Prevention, 5o, 758-767. https://doi.org/10.1016/j.aap.2012.06.029 
Brown, I. D. (2005). Review of the "looked but failed to see" accident causation factor. Retrieved from http://trid.trb.org/view.aspx?id=1156399

Buehler, R., \& Pucher, J. (2012). Cycling to work in 90 large American cities: new evidence on the role of bike paths and lanes. Transportation, 39(2), 409432. https://doi.org/10.1007/s11116-011-9355-8

Chapman, C., \& Musselwhite, C. B. A. (2011). Equine road user safety: Public attitudes, understandings and beliefs from a qualitative study in the United Kingdom. Accident Analysis \& Prevention, 43(6), 2173-2181. https://doi.org/10.1016/j.aap.2011.06.009

Cohen, B. H. (2011). Introductory Statistics for the Behavioral Sciences. (7th ed.). Chichester: John Wiley \& Sons. Retrieved from http://public.eblib.com/choice/publicfullrecord.aspx?p=826865

Collum, K. K., \& Daigle, J. J. (2015). Combining attitude theory and segmentation analysis to understand travel mode choice at a national park. Journal of Outdoor Recreation and Tourism, 9, 17-25. https://doi.org/10.1016/j.jort.2015.03.003

Coogan, M. A., Campbell, M., Adler, T. J., \& Forward, S. (2014). Examining behavioral and attitudinal differences among groups in their traffic safety culture. Transportation Research Part F: Traffic Psychology and Behaviour, 26, Part B, 303-316. https://doi.org/10.1016/j.trf.2014.03.005 
Cordazzo, S. T. D., Scialfa, C. T., Bubric, K., \& Ross, R. J. (2014). The Driver Behaviour Questionnaire: A North American analysis. Journal of Safety Research, 50, 99-107. https://doi.org/10.1016/j.jsr.2014.05.002 Crundall, D., Bibby, P., Clarke, D., Ward, P., \& Bartle, C. (2008). Car drivers' attitudes towards motorcyclists: A survey. Accident Analysis \& Prevention, $40(3)$. Retrieved from http://trid.trb.org/view/2008/C/860689

Daniels, S., \& Risser, R. (2014). Road safety in a globalised and more sustainable world: Current issues and future challenges. Accident Analysis \& Prevention, 62, 329-330. https://doi.org/10.1016/j.aap.2013.10.004

Dillman, D. A. (2000). Mail and internet surveys: the tailored design method (2nd ed.). New York: Wiley.

Elvik, R. (2010). Why some road safety problems are more difficult to solve than others. Accident Analysis \& Prevention, 42(4), 1089-1096. https://doi.org/10.1016/j.aap.2009.12.020

Elvik, R. (2013). Can it be true that most drivers are safer than the average driver? Accident Analysis \& Prevention, 59, 301-308. https://doi.org/10.1016/j.aap.2013.06.025

Emond, C. R., Tang, W., \& Handy, S. L. (2009). Explaining Gender Difference in Bicycling Behavior. Transportation Research Record, (2125), 16-25. https://doi.org/10.3141/2125-03 
Fazio, R. H. (1990). Multiple Processes by which Attitudes Guide Behavior: The Mode Model as an Integrative Framework. In Mark P. Zanna (Ed.), Advances in Experimental Social Psychology (Vol. Volume 23, pp. 75109). Academic Press. Retrieved from http://www.sciencedirect.com/science/article/pii/Soo65260108603184

Fazio, R. H., \& Olson, M. A. (2003). IMPLICIT MEASURES IN SOCIAL COGNITION RESEARCH: Their Meaning and Use. Annual Review of Psychology, 54(1), 297.

Fulcher, G., Parkhurst, G., Alford, C., \& Musselwhite, C. (2014). The Role of Implicit Data Collection Techniques in Driver Behaviour Research. Presented at the UTSG, Newcastle, UK.

Gardner, B., \& Abraham, C. (2008). Psychological correlates of car use: A metaanalysis. Transportation Research Part F: Traffic Psychology and Behaviour, 11(4), 300-311. https://doi.org/10.1016/j.trf.2008.01.004

Gatersleben, B., \& Haddad, H. (2010). Who is the typical bicyclist? Transportation Research Part F: Traffic Psychology and Behaviour, 13(1), 41-48. https://doi.org/10.1016/j.trf.2009.10.003

Gehlert, T., Hagemeister, C., \& Özkan, T. (2014). Traffic safety climate attitudes of road users in Germany. Transportation Research Part F: Traffic Psychology and Behaviour, 26, Part B, 326-336. https://doi.org/10.1016/j.trf.2013.12.011 
Gladhill, K., \& Monsere, C. (2012). Exploring Traffic Safety and Urban Form in Portland, Oregon. Transportation Research Record: Journal of the Transportation Research Board, 2318(1), 63-74. https://doi.org/10.3141/2318-o8

Goddard, T. (2016). Theorizing bicycle justice using social psychology Examining the intersection of mode and race with the conceptual model of roadway interactions. In Bicycle justice and urban transformation: biking for all? London ; New York: Routledge Taylor \& Francis Group.

Greenwald, A. G., Mcghee, D. E., \& Schwartz, J. L. (1998). Measuring individual differences in implicit cognition: the implicit association test. Journal of Personality and Social Psychology, 74(6), 1464-80. https://doi.org/10.1037/0022-3514.74.6.1464

Greenwald, A. G., Poehlman, T. A., Uhlmann, E. L., \& Banaji, M. R. (2009). Understanding and using the Implicit Association Test: III. Meta-analysis of predictive validity. Journal of Personality and Social Psychology, 97(1), 17-41. https://doi.org/10.1037/aoo15575

Greenwald, A., Nosek, B., \& Banaji, M. (2003). Understanding and using the implicit association test: I. An improved scoring algorithm. Journal of Personality and Social Psychology, 85(2), 197-216.

Greenwald, \& Banaji, M. (1995). Implicit social cognition: attitudes, self-esteem, and stereotypes. Psychological Review, 102(1), 4-27. 
Groeger, J. A. (2002). Trafficking in cognition: applying cognitive psychology to driving. TRF Transportation Research Part F: Psychology and Behaviour, 5(4), 235-248.

Hagenzieker, M. P., Commandeur, J. J. F., \& Bijleveld, F. D. (2014). The history of road safety research: A quantitative approach. Transportation Research Part F: Traffic Psychology and Behaviour, 25, Part B, 150-162. https://doi.org/10.1016/j.trf.2013.10.004

Harris, M. A., Reynolds, C. C. O., Winters, M., Chipman, M., Cripton, P. A., Cusimano, M. D., \& Teschke, K. (2011). The Bicyclists' Injuries and the Cycling Environment study: a protocol to tackle methodological issues facing studies of bicycling safety. Injury Prevention, 17(5), 1-5. https://doi.org/10.1136/injuryprev-2011-040071

Hatfield, J., Fernandes, R., Faunce, G., \& Job, R. F. S. (2008). An implicit nonself-report measure of attitudes to speeding: Development and validation. Accident Analysis \& Prevention, 4O(2), 616-627. https://doi.org/10.1016/j.aap.2007.08.020

Haworth, N. (2012). Powered two wheelers in a changing world-Challenges and opportunities. Accident Analysis \& Prevention, 44(1), 12-18. https://doi.org/10.1016/j.aap.2010.10.031

Haworth, N., Rakotonirainy, A., Wilson, A., Schramm, A., Darvell, M., \& Haines, A. (2014). Understanding interactions between two wheelers (TW) and car 
drivers in a driving simulator. Retrieved from

http://trid.trb.org/view/2014/M/1316062

Hebl, M. R., King, E. B., Glick, P., Singletary, S. L., \& Kazama, S. (2007). Hostile and benevolent reactions toward pregnant women: Complementary interpersonal punishments and rewards that maintain traditional roles. Journal of Applied Psychology, 92(6), 1499-1511. https://doi.org/http://dx.doi.org.proxy.lib.pdx.edu/10.1037/oo219010.92.6.1499

Heinen, E. (2016). Identity and travel behaviour: A cross-sectional study on commute mode choice and intention to change. Transportation Research Part F: Traffic Psychology and Behaviour, 43, 238-253. https://doi.org/10.1016/j.trf.2016.10.016

Holland, C., \& Hill, R. (2007). The effect of age, gender and driver status on pedestrians' intentions to cross the road in risky situations. Accident Analysis \& Prevention, 39(2), 224-237. https://doi.org/10.1016/j.aap.2006.07.003

Jacobsen, P. (2003). Safety in numbers: more walkers and bicyclists, safer walking and bicycling. Injury Prevention, 9(3), 205.

Jost, J. T., Banaji, M. R., \& Nosek, B. A. (2004). A Decade of System Justification Theory: Accumulated Evidence of Conscious and Unconscious Bolstering of the Status Quo. Political Psychology, 25(6), 881-919. https://doi.org/10.1111/j.1467-9221.2004.00402.x 
Kahn, K. B., \& Davies, P. G. (2011). Differentially dangerous? Phenotypic racial stereotypicality increases implicit bias among ingroup and outgroup members. Group Processes \& Intergroup Relations, 14(4), 569-580. https://doi.org/10.1177/1368430210374609

Karsch, H. M., Hedlund, J. H., Tison, J., \& Leaf, W. A. (2012). Review of Studies on Pedestrian and Bicyclist Safety, 1991-2007. United States. National Highway Traffic Safety Administration. Retrieved from http://ntlsearch.bts.gov/ntl/md.do?id=45710

Lajunen, T., Parker, D., \& Summala, H. (2004). The Manchester Driver Behaviour Questionnaire: a cross-cultural study. Accident Analysis \& Prevention, 36(2), 231-238. https://doi.org/10.1016/Sooo14575(02)00152-5

Lajunen, T., \& Summala, H. (2003). Can we trust self-reports of driving? Effects of impression management on driver behaviour questionnaire responses. Transportation Research Part F: Traffic Psychology and Behaviour, 6(2), 97-107. https://doi.org/10.1016/S1369-8478(03)0ooo8-1

Lane, Banaji, Nosek, \& Greenwald. (2007). Understanding and Using the Implicit Association Test: IV. In Implicit Measures of Attitudes. Retrieved from http://faculty.washington.edu/agg/pdf/Lane\%20et\%20al.UUIAT4.2007.p df 
Monsere, C., Dill, J., McNeil, N., Clifton, K., Foster, N., Goddard, T., ... Parks, J. (2014). Lessons From The Green Lanes: Evaluating Protected Bike Lanes In the U.S. Retrieved from http://trid.trb.org/view/2014/M/1312752

Monsere, C. M., McNeil, N., \& Dill, J. (2012). Multiuser Perspectives on Separated, On-Street Bicycle Infrastructure. Transportation Research Record, (2314), 22-30. https://doi.org/10.3141/2314-04

Moody, J., Goulet Langlois, G., Alexander, L., Campbell, J., \& Zhao, J. (2016). Measuring Explicit and Implicit Social Status Bias in Car vs. Bus Mode Choice.

Murtagh, N., Gatersleben, B., \& Uzzell, D. (2012). Multiple identities and travel mode choice for regular journeys. Transportation Research Part F: Traffic Psychology and Behaviour, 15(5), 514-524. https://doi.org/10.1016/j.trf.2012.05.002

Musselwhite, C., Avineri, E., \& Susilo, Y. O. (2014). Legitimising risk taking: articulating dangerous behaviour on the road. Transportation Planning and Technology, 37(1), 62-82. https://doi.org/10.1080/03081060.2013.844905

NHTSA. (2016). Bicyclist and Other Cyclists, 2014 data. Retrieved April 7, 2017, from https://crashstats.nhtsa.dot.gov/Api/Public/ViewPublication/812282 
Nordback, K., Marshall, W. E., \& Janson, B. N. (2014). Bicyclist safety

performance functions for a U.S. city. Accident Analysis \& Prevention, 65, 114-122. https://doi.org/10.1016/j.aap.2013.12.016

Nordfjærn, T., Şimşekoğlu, Ö., \& Rundmo, T. (2013). Culture Related to Road Traffic Safety: A Comparison of Eight Countries Using Two Conceptualizations of Culture. Accident Analysis \& Prevention. https://doi.org/10.1016/j.aap.2013.10.018

Nosek, B. A., Greenwald, A. G., \& Banaji, M. R. (2005). Understanding and Using the Implicit Association Test: II. Method Variables and Construct Validity. Personality and Social Psychology Bulletin, 31(2), 166-180. https://doi.org/10.1177/0146167204271418

Otto, J., Ward, N., Swinford, S., \& Linkenbach, J. (2014). Engaging worksite bystanders to reduce risky driving. Transportation Research Part F: Traffic Psychology and Behaviour, 26, Part B, 370-378. https://doi.org/10.1016/j.trf.2014.02.006

Pollack, K. M., Kercher, C., Frattaroli, S., Peek-Asa, C., Sleet, D., \& Rivara, F. P. (2012). Toward environments and policies that promote injury-free active living-it wouldn't hurt. Health \& Place, 18(1), 106-114. https://doi.org/10.1016/j.healthplace.2011.07.010

Pratto, F., Sidanius, J., \& Levin, S. (2006). Social dominance theory and the dynamics of intergroup relations: Taking stock and looking forward. 
European Review of Social Psychology, 17(1), 271-320.

https://doi.org/10.1080/10463280601055772

Rakotonirainy, A., Haworth, N. L., Darvell, M., Wilson, A., \& Haines, A. (2012).

Does experience with one type of two-wheeler affect behaviours and attitudes to other types? Conference presented at the International Conference on Traffic and Transport Psychology, Groningen, The

Netherlands. Retrieved from http://eprints.qut.edu.au/58557/

Reason, J., Manstead, A., Stradling, S., Baxter, J., \& Campbell, K. (1990). Errors and violations on the roads: a real distinction? Ergonomics, 33(10-11), 1315-1332. https://doi.org/10.1080/o0140139008925335

Rosenbloom, T., Perlman, A., \& Pereg, A. (2011). Hazard perception of motorcyclists and car drivers. Accident Analysis \& Prevention, 43(3), 601-604. https://doi.org/10.1016/j.aap.2010.08.005

Rothengatter, T., \& Huguenin, R. D. (2004). Traffic and Transport Psychology: Proceedings of the ICTTP 20oo. Elsevier.

Rowe, R., Andrews, E., Harris, P. R., Armitage, C. J., McKenna, F. P., \& Norman, P. (2016). Identifying beliefs underlying pre-drivers' intentions to take risks: An application of the Theory of Planned Behaviour. Accident Analysis \& Prevention, 89, 49-56. https://doi.org/10.1016/j.aap.2015.12.024 
Schepers, J. P., \& Heinen, E. (2013). How does a modal shift from short car trips to cycling affect road safety? Accident Analysis \& Prevention, 50, 11181127. https://doi.org/10.1016/j.aap.2012.09.004

Schepers, P., Hagenzieker, M., Methorst, R., van Wee, B., \& Wegman, F. (2014). A conceptual framework for road safety and mobility applied to cycling safety. Accident Analysis \& Prevention, 62, 331-340. https://doi.org/10.1016/j.aap.2013.03.032

Shahar, A., Clarke, D., \& Crundall, D. (2011). Applying the motorcyclist's perspective to improve car drivers' attitudes towards motorcyclists. Accident Analysis \& Prevention, 43(5), 1743-1750. https://doi.org/10.1016/j.aap.2011.04.005

Singletary, S., \& Hebl, M. (2009). Compensatory strategies for reducing interpersonal discrimination: the effectiveness of acknowledgments, increased positivity, and individuating information. The Journal of Applied Psychology, 94(3), 797-805.

Singletary, S. L., \& Hebl, M. R. (2009). Compensatory strategies for reducing interpersonal discrimination: The effectiveness of acknowledgments, increased positivity, and individuating information. Journal of Applied Psychology, 94(3), 797-805. https://doi.org/http://dx.doi.org.proxy.lib.pdx.edu/10.1037/aoo14185 
Smyth, J. D., Dillman, D. A., Christian, L. M., \& Stern, M. J. (2006). Comparing Check-All and Forced-Choice Question Formats in Web Surveys. Public Opinion Quarterly, 7o(1), 66-77. https://doi.org/10.1093/poq/nfjoo7

Tajfel, H., \& Turner, J. C. (2004). The Social Identity Theory of Intergroup Behavior. (pp. 276-293). Psychology Press (New York, NY, US). Retrieved from http://search.proquest.com.proxy.lib.pdx.edu/psycinfo/docview/620389 020/8054Fo3257A94450PQ/12?accountid=13265

Underwood, G., Chapman, P., Berger, Z., \& Crundall, D. (2003). Driving experience, attentional focusing, and the recall of recently inspected events. Transportation Research Part F: Traffic Psychology and Behaviour, 6(4), 289-304. https://doi.org/10.1016/j.trf.2003.09.002 US EPA, O. (n.d.). Smart Location Database Technical Documentation and User Guide [Data and Tools]. Retrieved March 31, 2017, from https://www.epa.gov/smartgrowth/smart-location-database-technicaldocumentation-and-user-guide

Van Acker, V., Van Wee, B., \& Witlox, F. (2010). When Transport Geography Meets Social Psychology: Toward a Conceptual Model of Travel Behaviour. Transport Reviews, 3o(2), 219-240. https://doi.org/10.1080/01441640902943453

Walker, I. (2005). Signals are Informative but Slow Down Responses when Drivers meet Bicyclists at Road Junctions. Accident Analysis \& 
Prevention, 37(6). Retrieved from

http://trid.trb.org/view/2005/C/767560

Walker, I. (2007). Drivers overtaking bicyclists: Objective data on the effects of riding position, helmet use, vehicle type and apparent gender. Accident Analysis \& Prevention, 39(2). Retrieved from http://trid.trb.org/view/2007/C/797825

Winters, M., Brauer, M., Setton, E. M., \& Teschke, K. (2010). Built Environment Influences on Healthy Transportation Choices: Bicycling versus Driving. Journal of Urban Health, 87(6), 969-993. https://doi.org/10.1007/s11524-010-9509-6

Yiannakoulias, N., Bennet, S. A., \& Scott, D. M. (2012). Mapping commuter cycling risk in urban areas. Accident Analysis \& Prevention, 45, 164-172. https://doi.org/10.1016/j.aap.2011.12.002

Zhou, R., \& Horrey, W. J. (2010). Predicting adolescent pedestrians' behavioral intentions to follow the masses in risky crossing situations. Transportation Research Part F: Traffic Psychology and Behaviour, 13(3), 153-163. https://doi.org/10.1016/j.trf.2009.12.001 


\section{Appendix A: Survey instrument}

Q1 Welcome! We would like to get your help to better understand people's driving behaviors and experiences interacting with other drivers and with bicyclists on the road. The project is being carried out by researchers at Portland State University (PSU), led by Dr. Jennifer Dill. We will share your findings publicly at the completion of the study. Your input will help us better understand interactions on the roads in your city and around the United States. At the beginning of the survey, you will be asked to complete a brief timed exercise pairing images with words. This is meant to be fun and not stressful, you will not be "graded" on your answers, so do not think too hard, just answer as quickly as you can. We will give you the full instructions if you agree to participate in the survey by clicking on "Yes, I agree" below. The survey should take 15-20 minutes to complete. You don't have to participate, and you can skip any questions you don't want to answer. Your responses will be completely anonymous and it won't be possible to link you with your answers. If you have any questions about the study, please contact the study team at streets@pdx.edu. This study has been reviewed and approved by PSU's Human Subjects Research Review Committee. If you have any questions about your rights as a participant in this study, you may contact: The Office of Research Integrity, 1600 SW 4th Ave., Market Center Building, Ste. 620, Portland, OR 97201; phone (503) 7252227. We hope you will enjoy the questionnaire and look forward to receiving your responses. Many thanks! Do you certify that you are at least 18 years of age, hold a driver's license, drive at least a few days a month, and want to participate in this study?

Y Yes, I would like to participate (1)

O No, thank you (2) If No, thank you Is Selected, Then Skip To End of Survey 
Q2 Thank you for agreeing to participate in our study. We hope you enjoy the experience of the survey, and we appreciate your time. In this study you will complete an Implicit Association Test (IAT) in which you will be asked to sort pictures and words into groups as fast as you can. In addition to the IAT, there are some questions about your beliefs, attitudes, and opinions, and some standard demographic questions. This study should take about 15-20 minutes to complete. We are interested in learning more about how drivers think and feel about bicyclists, and their experiences interacting with bicyclists. To do this, the survey is structured in six short sections that ask about how you see yourself, how you feel about driving, what you think and feel about bicyclists, and what your experiences have been interacting with bicyclists as a driver. Please keep in mind that there are no right or wrong answers (we will remind you of this throughout the survey), and your answers are anonymous. Thank you for your time! 


\section{Implicit Association Test}

Welcome to the Implicit Association Test. You will use the "e" and "I" computer keys to categorize items into groups as fast as you can. These are the four groups and the items that belong to each:

\begin{tabular}{|l|l|}
\hline Category & Items \\
\hline Positive & Joyul, Lovely, Wonderul, Beautifu, , Pleasant, Happy \\
\hline Negative & Painul, Terible, Horible, Cruel, Awuil, Agony \\
\hline Driver & \\
\hline Bicyclist
\end{tabular}

There are seven parts. The instructions change for each part. Pay attention! 


\section{Part 1 of 7}

Put a left finger on the $\mathbf{E}$ key for Driver images.

Put a right finger on the I key for Bicyclist images.

Items will appear one at a time.

If you make a mistake, a red $\mathbf{X}$ will appear. Press the other key to continue. $\underline{\mathrm{Go}}$ as fast as you can while being accurate.

Press the space bar when you are ready to start.

Q60 Placeholder for remainder of Implicit Association Test 
Q3 Section 1.In this section, we would like to know a bit about what you think, if anything, about yourself as a driver and about other people on the road, specifically other drivers and people who ride bicycles. These may be bicyclists you've encountered, or whatever mental image that comes up when you think about bicyclists. It does not matter how much you drive, or whether you ride a bicycle or not, we would like to know what you think. These questions are general, and not about any particular person or situation. You will have a chance later to tell us about specific people or situations if you want.

Q4 How true are the following statements about YOU as a driver?

\begin{tabular}{|c|c|c|c|c|c|c|}
\hline $\begin{array}{l}\text { In general, } \\
\text { being a } \\
\text { driver is an } \\
\text { important } \\
\text { part of who } \\
\text { I am (4) }\end{array}$ & 0 & 0 & 0 & 0 & 0 & 0 \\
\hline $\begin{array}{l}\text { In most or } \\
\text { all } \\
\text { situations, } \\
\text { I am a } \\
\text { skilled } \\
\text { driver (6) }\end{array}$ & 0 & 0 & 0 & 0 & 0 & 0 \\
\hline $\begin{array}{c}\text { I care } \\
\text { whether } \\
\text { my friends } \\
\text { and family } \\
\text { think of me } \\
\text { as a good } \\
\text { driver (7) }\end{array}$ & 0 & 0 & 0 & 0 & 0 & 0 \\
\hline $\begin{array}{l}\text { It makes } \\
\text { me angry if } \\
\text { I see other } \\
\text { drivers } \\
\text { breaking } \\
\text { the rules of } \\
\text { the road } \\
\text { (8) }\end{array}$ & 0 & 0 & 0 & 0 & 0 & 0 \\
\hline
\end{tabular}


Q5 How true are the following statements about YOU as a bicyclist? (That's ok if any or all of these statements do not apply to you, that is one of your answer choices.)

\begin{tabular}{|c|c|c|c|c|c|c|c|}
\hline & $\begin{array}{l}\text { Strongly } \\
\text { disagree } \\
\text { (1) }\end{array}$ & $\begin{array}{c}\text { Disagree } \\
\text { (7) }\end{array}$ & $\begin{array}{c}\text { Disagree } \\
\text { somewhat } \\
\text { (2) }\end{array}$ & $\begin{array}{c}\text { Agree } \\
\text { somewhat } \\
\text { (4) }\end{array}$ & $\begin{array}{l}\text { Agree } \\
\text { (8) }\end{array}$ & $\begin{array}{l}\text { Strongly } \\
\text { Agree } \\
\text { (5) }\end{array}$ & $\begin{array}{c}\text { This } \\
\text { does } \\
\text { not } \\
\text { apply } \\
\text { to me } \\
\text { (3) }\end{array}$ \\
\hline $\begin{array}{c}\text { In } \\
\text { general, } \\
\text { being a } \\
\text { bicyclist is } \\
\text { an } \\
\text { important } \\
\text { part of } \\
\text { who I am } \\
\text { (4) }\end{array}$ & 0 & 0 & O & 0 & 0 & 0 & 0 \\
\hline $\begin{array}{c}\text { In most or } \\
\text { all } \\
\text { situations, } \\
\text { I am a } \\
\text { skilled } \\
\text { bicyclist } \\
\text { (6) }\end{array}$ & 0 & 0 & 0 & 0 & 0 & 0 & 0 \\
\hline $\begin{array}{l}\text { I care if } \\
\text { my } \\
\text { friends } \\
\text { and } \\
\text { family } \\
\text { think of } \\
\text { me as a } \\
\text { bicyclist } \\
\text { (7) } \\
\text { In } \\
\text { general, I } \\
\text { see people } \\
\text { similar to } \\
\text { me } \\
\text { bicycling } \\
\text { on city } \\
\text { streets (9) }\end{array}$ & O & O & O & 0 & $\mathrm{O}$ & $\mathrm{O}$ & 0 \\
\hline
\end{tabular}


Q6 These are some questions about your beliefs about bicyclists. How much do you disagree or agree with the following:

\begin{tabular}{|c|c|c|c|c|c|c|}
\hline & $\begin{array}{l}\text { Strongly } \\
\text { disagree } \\
\text { (1) }\end{array}$ & $\begin{array}{c}\text { Disagree } \\
\text { (6) }\end{array}$ & $\begin{array}{c}\text { Disagree } \\
\text { somewhat } \\
\text { (2) }\end{array}$ & $\begin{array}{c}\text { Agree } \\
\text { somewhat } \\
\text { (3) }\end{array}$ & $\begin{array}{l}\text { Agree } \\
\text { (4) }\end{array}$ & $\begin{array}{l}\text { Strongly } \\
\text { agree (5) }\end{array}$ \\
\hline $\begin{array}{l}\text { Bicyclists } \\
\text { should have } \\
\text { to pass a } \\
\text { license test } \\
\text { just like } \\
\text { drivers do (9) }\end{array}$ & O & O & 0 & 0 & 0 & O \\
\hline $\begin{array}{l}\text { When a } \\
\text { driver and a } \\
\text { bicyclist } \\
\text { collide, it is } \\
\text { typically the } \\
\text { fault of the } \\
\text { driver (5) }\end{array}$ & 0 & 0 & 0 & 0 & 0 & O \\
\hline $\begin{array}{l}\text { Bicyclists } \\
\text { should be } \\
\text { allowed to } \\
\text { filter forward } \\
\text { through lanes } \\
\text { of slow or } \\
\text { stopped car } \\
\text { traffic (8) }\end{array}$ & 0 & 0 & 0 & 0 & 0 & O \\
\hline $\begin{array}{l}\text { Bicyclists } \\
\text { should have } \\
\text { to register } \\
\text { and pay } \\
\text { specific road } \\
\text { taxes (12) }\end{array}$ & O & O & 0 & 0 & 0 & 0 \\
\hline $\begin{array}{l}\text { Building } \\
\text { infrastructure } \\
\text { for bicyclists } \\
\text { is a good } \\
\text { investment of } \\
\text { public funds } \\
\text { (10) }\end{array}$ & 0 & O & 0 & 0 & 0 & 0 \\
\hline $\begin{array}{l}\text { Bicyclists } \\
\text { should not } \\
\text { hold up car } \\
\text { traffic (14) }\end{array}$ & 0 & 0 & 0 & 0 & 0 & 0 \\
\hline
\end{tabular}


Q7 Section 2. In this section, we have a few questions about bicyclists. We want to know how you feel and what you think about bicyclists, so there are no right or wrong answers.

Q8 First, we would like to know what you think about bicyclists as a group. Don't think too long about it, we are interested in your general impressions. Please provide up to five (5) words or phrases that you associate with bicyclists. Terms might describe how they look, how they act, their personality, or any other word or phrase that comes to mind. Terms can be positive, negative, or neutral.For example, if we asked you about musicians, you might think of words like "stylish", "rich", "loud", "life of the party", "creative", "irresponsible" - depending on how you feel about musicians!What are five words or phrases that you think describe bicyclists?

Word/phrase \#1 (1)

Word/phrase \#2 (8)

Word/phrase \#3 (18)

Word/phrase \# 4 (19)

Word/phrase \#5 (10) 
Q9 Now, we would like to know what you think about some potentially different kinds of bicyclists. We have provided three images. We know these may not represent all bicyclists on the road, but we would like to get your thoughts about these three. We have provided a list of terms. Some of the terms are positive, some are negative. Please drag and drop any of the terms you think apply to most bicyclists that the image represents.You can choose as many or as few of the terms as you want, including adding terms of your own. Along with each image, there is a "feeling thermometer.". That is, how warm or cool do you feel toward these different kinds of bicyclists? You can slide the bar to the left if you feel cool toward that kind of bicyclist, or slide the bar to the right if you feel warm toward that kind of bicyclist. Here are the images we will ask you about in the next questions: 
Q59 Please choose (drag and drop) the terms that you most associate with this kind of bicyclist.

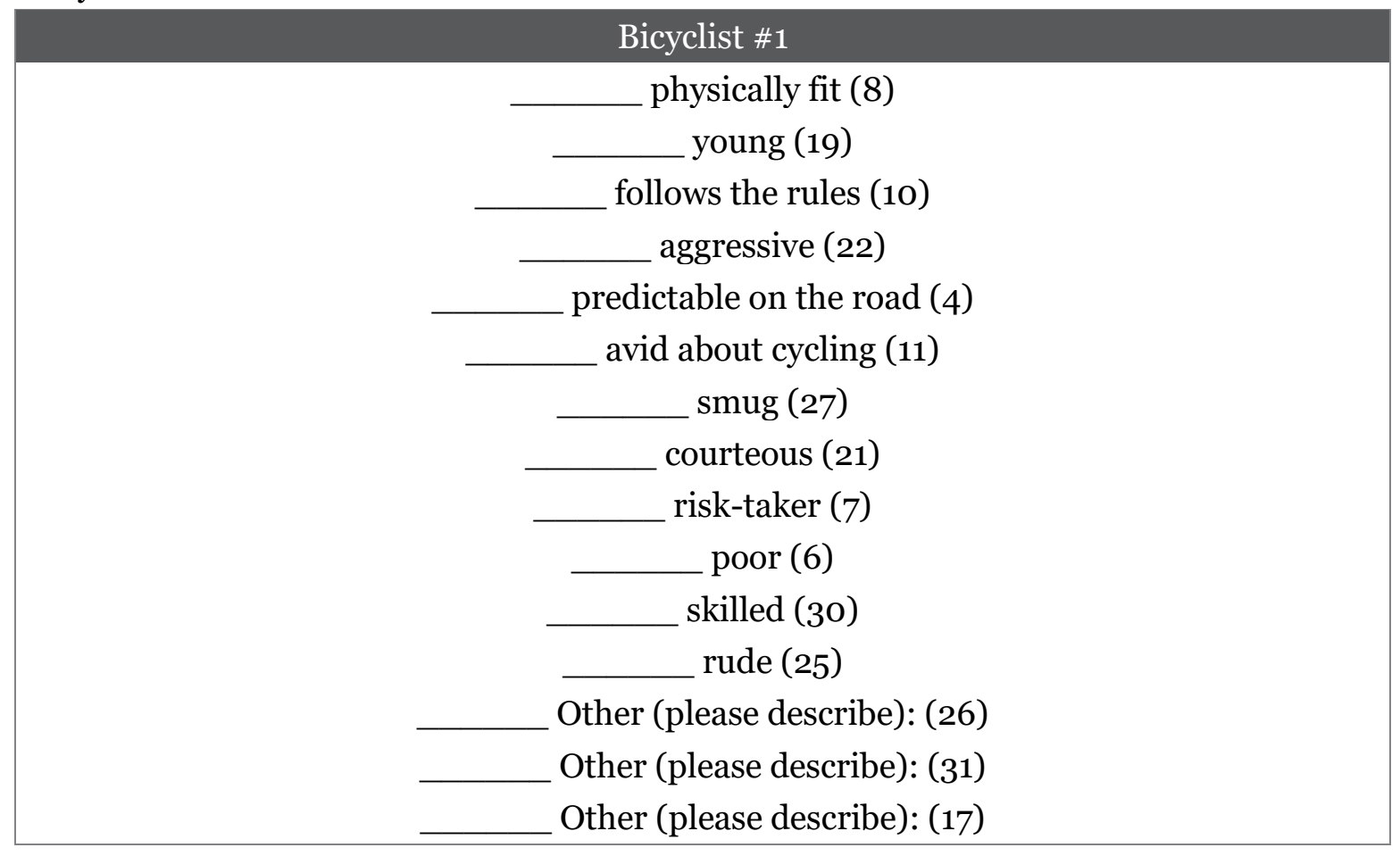

Q11 This is called a "feeling thermometer," and is a way to gauge how you feel toward a person, group, or object. How do you feel about this kind of bicyclist? $1(1)$ 
Q6o Please choose (drag and drop) the terms that you most associate with this kind of bicyclist.

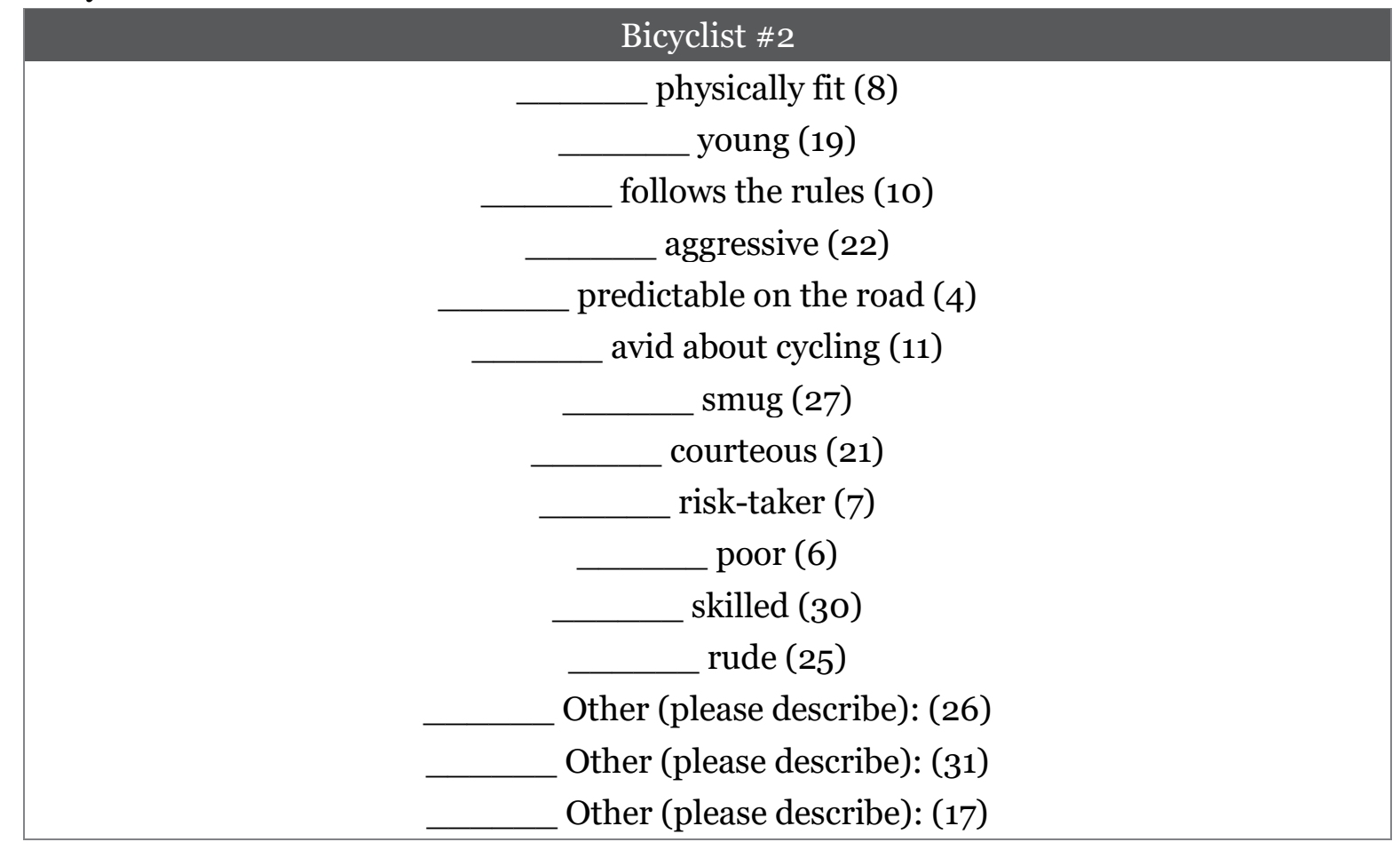

Q13 How do you feel about this kind of bicyclist? $1(1)$ 
Q61 Please choose (drag and drop) the terms that you most associate with this kind of bicyclist.

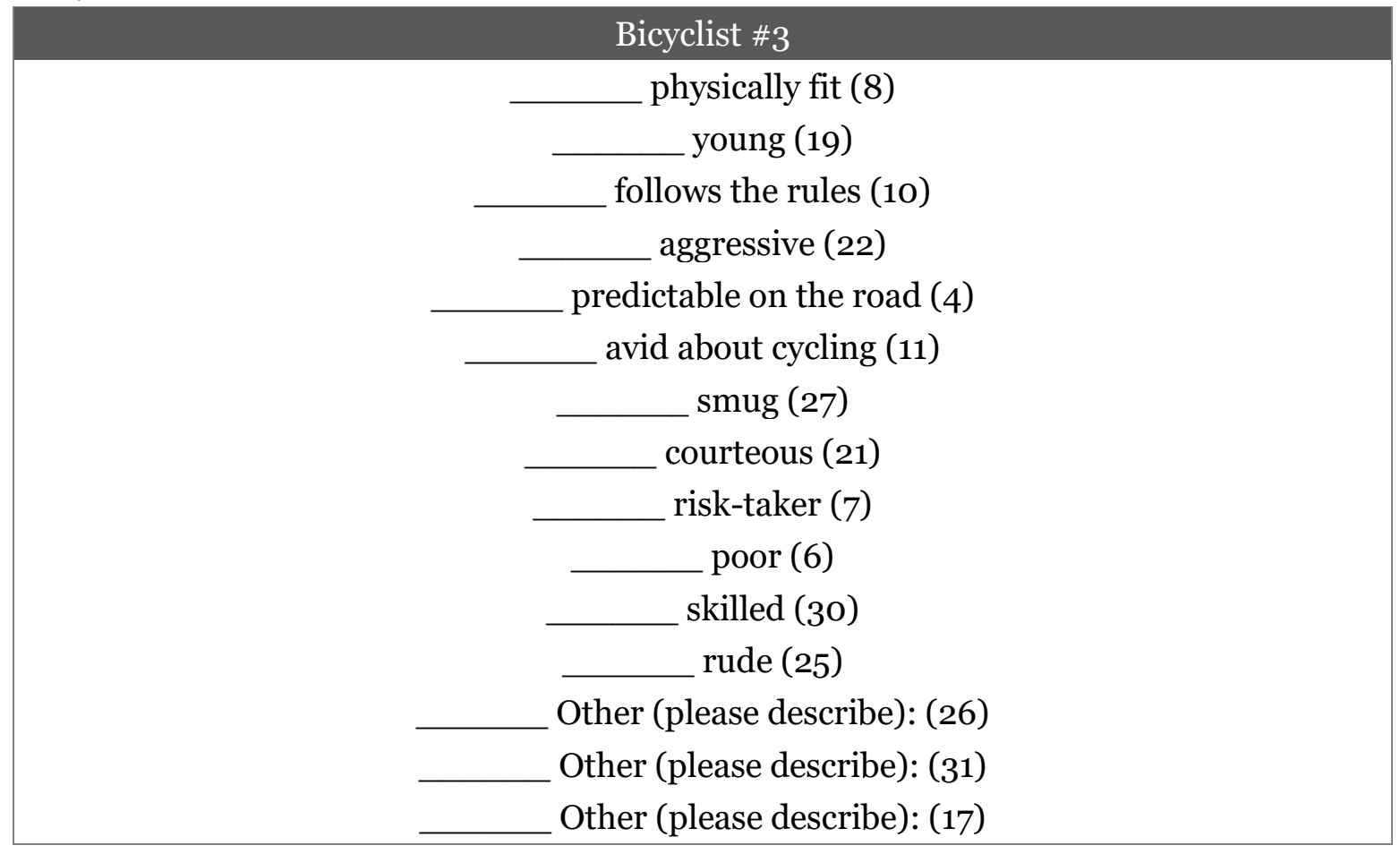

Q15 How do you feel about this kind of bicyclist? $1(1)$ 
Q16 Section 3. In this section, we would like to ask a few questions about your experiences as a driver and (if it applies) as a bicyclist. Remember, the survey is anonymous, and there are no right or wrong answers.

Q17 How many years have you been driving?

O Less than 1 year (1)

O 1 (2)

○ 2 (5)

O $3(6)$

○ $4(7)$

$5(8)$

O 6 (9)

O $7(10)$

O $8(11)$

O 9 (12)

O 10 or more years (13)

Q18 How many days do you drive a car in the average week?

O $1(2)$

○ $2(3)$

○ (4)

O $4(5)$

O $5(6)$

○ $6(7)$

$7(8)$

O 0 (1)

Q19 What vehicle(s) do you drive frequently? (Please select all that apply)

口 My own/household vehicle (5)

- Carshare vehicle (Car2Go, ZipCar, Getaround, etc) (1)

$\square$ Other, please describe (3) 
Q20 Next, we would like to ask you some questions about bicycling. Please answer these questions even if you never ride a bicycle.

Q21 When the weather is nice, how often do you:

\begin{tabular}{|c|c|c|c|c|c|}
\hline & Never (1) & Rarely (2) & $\begin{array}{c}\text { Occasionally } \\
\text { (3) }\end{array}$ & $\begin{array}{c}\text { Frequently } \\
\text { (4) }\end{array}$ & $\begin{array}{c}\text { All or } \\
\text { almost all } \\
\text { trips (5) }\end{array}$ \\
\hline $\begin{array}{l}\text { Encounter } \\
\text { bicyclists } \\
\text { when you } \\
\text { are driving } \\
\text { to work, } \\
\text { running } \\
\text { errands, or } \\
\text { otherwise } \\
\text { driving } \\
\text { around town } \\
\text { (1) }\end{array}$ & O & $\mathrm{O}$ & O & $\mathrm{O}$ & $\mathrm{O}$ \\
\hline
\end{tabular}

Q22 Are you physically able to ride a bicycle? (We are interested in physical barriers to riding, but not your level of fitness. We define "bicycle" broadly, to include hand-cycles, tricycles, electric-assist bicycles with pedals, or other types of bicycle.)

O Yes (1)

O No (2)

Other, please describe (3)

Q23 Do you know how to ride a bicycle? (We are not interested in your skill level or level of comfort on the road, but whether you know how to ride a bicycle.)

Y Yes (1)

O No (2)

Other, please describe (3)

Q24 Have you ridden a bicycle outside in the last year?

O Yes (2)

O No (1) 
Display This Question:

If Have you ridden a bicycle outside in the last year? Yes Is Selected

Q25 How many days have you ridden a bicycle outside in the last month?

O $0-31$

Display This Question:

If Have you ridden a bicycle outside in the last year? Yes Is Selected

Q26 When you have ridden a bicycle, has it been for fun or exercise, commuting, errands (like shopping)? Please select all that apply.

For fun and/or exercise (1)

Commute to work or school (2)

- Riding for other trips, like shopping, entertainment, errands, appointments (3)

- Riding to accompany children who are bicycling to school, the park, etc (4) 
Q27 Section 4.Next, we would like to ask about your perceptions or experiences driving on the road with bicyclists. If you have never experienced a particular situation, that is one of your answer choices. Remember that there are no right or wrong answers, we are interested to know about your personal experiences. 
Q28 These are some questions about your experiences and encounters with bicyclists while you are driving. How much do you disagree or agree with the following:

\begin{tabular}{|c|c|c|c|c|c|c|c|}
\hline & $\begin{array}{c}\text { Strongl } \\
y \\
\text { disagre } \\
\text { e (1) }\end{array}$ & $\begin{array}{c}\text { Disagre } \\
\text { e (6) }\end{array}$ & $\begin{array}{c}\text { Disagree } \\
\text { somewha } \\
\text { t (2) }\end{array}$ & $\begin{array}{c}\text { Agree } \\
\text { somewha } \\
\text { t (3) }\end{array}$ & $\begin{array}{l}\text { Agre } \\
\text { e (4) }\end{array}$ & $\begin{array}{c}\text { Strongl } \\
\text { y agree } \\
(7)\end{array}$ & $\begin{array}{c}\text { I've never } \\
\text { experience } \\
\mathrm{d} \text { this (5) }\end{array}$ \\
\hline $\begin{array}{c}\text { I am } \\
\text { comfortabl } \\
\text { e deciding } \\
\text { how fast or } \\
\text { close to } \\
\text { pass a } \\
\text { bicyclist } \\
\text { going the } \\
\text { same way } \\
\text { as me on a } \\
\text { street with } \\
\text { no bike } \\
\text { lane (4) }\end{array}$ & 0 & 0 & 0 & 0 & 0 & 0 & 0 \\
\hline $\begin{array}{l}\text { If I drive } \\
\text { slowly } \\
\text { behind a } \\
\text { bicyclist } \\
\text { without } \\
\text { passing } \\
\text { them, } \\
\text { other } \\
\text { drivers get } \\
\text { annoyed } \\
\text { with me } \\
(13)\end{array}$ & 0 & 0 & 0 & 0 & 0 & 0 & 0 \\
\hline $\begin{array}{l}\text { I check for } \\
\text { bicyclists } \\
\text { before I } \\
\text { make a } \\
\text { turn in my } \\
\text { car (6) }\end{array}$ & 0 & 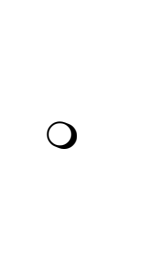 & 0 & 0 & 0 & 0 & 0 \\
\hline $\begin{array}{l}\text { When my } \\
\text { car is } \\
\text { moving, it } \\
\text { is difficult } \\
\text { to judge } \\
\text { how far a } \\
\text { bicyclist is } \\
\text { from my } \\
\text { passenger }\end{array}$ & 0 & 0 & 0 & 0 & 0 & 0 & 0 \\
\hline
\end{tabular}




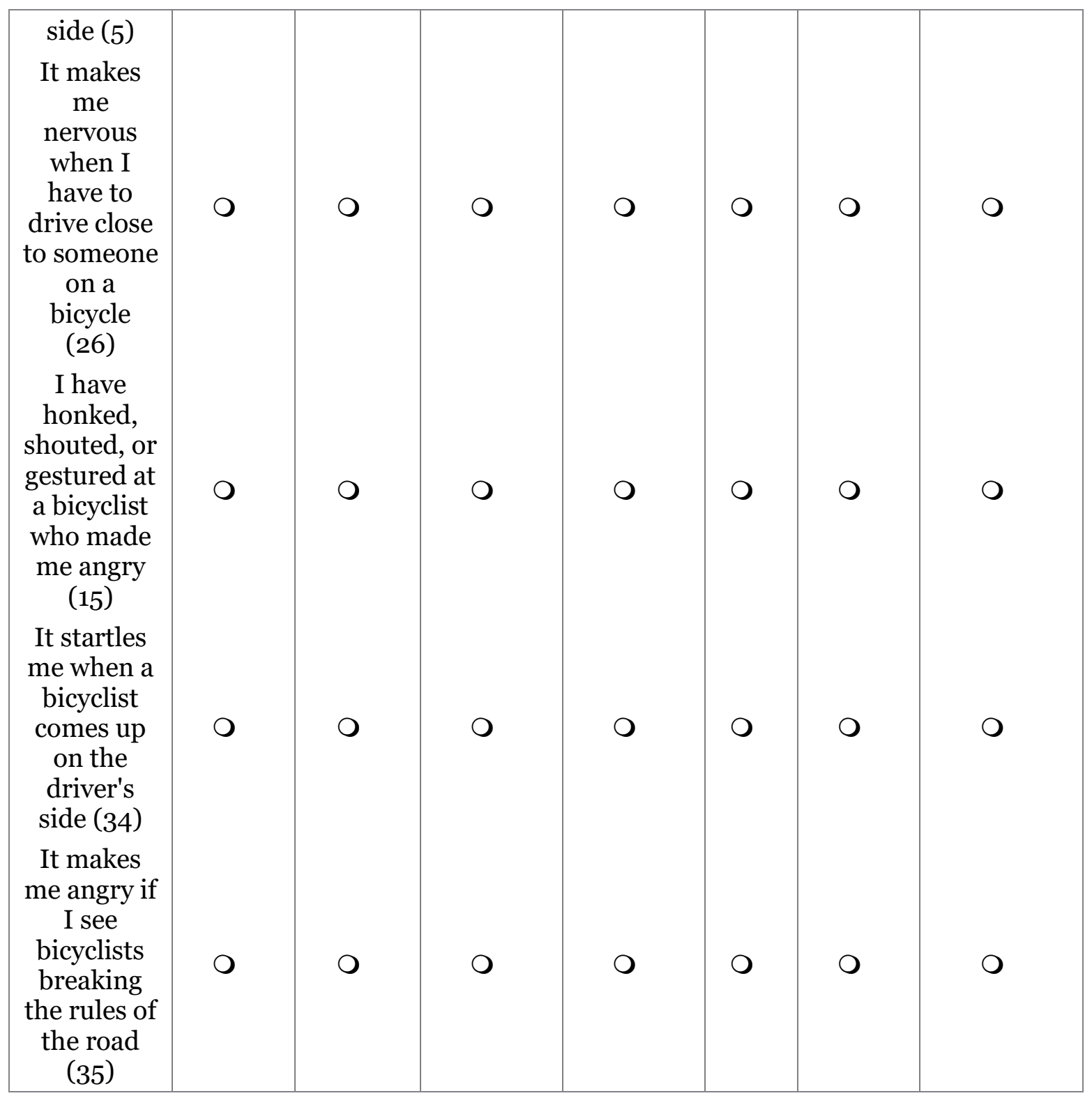


Q29 This is the final question about your driving. We would like to know about your experience in a collision or near-collision, if you have had any. Please remember that no identifying information is being collected, so your responses are anonymous.For the purposes of this study, a collision is any time there was a physical impact between your car and a bicyclist or their bicycle, no matter how minor. A near-collision is any time that you, another driver, or a bicyclist had to brake suddenly, swerve suddenly, or otherwise made a sudden move to avoid a collision.

Q30 While driving, have you ever been involved in a collision or near-collision with a bicyclist?

Yes, a crash that resulted in the death or major injuries (ambulance required) of the bicyclist (2)

- Yes, a crash that resulted in only minor injuries or no injuries to the bicyclist (3)

Y Yes, a near-collision with a bicyclist (4)

$\square$ No (5)

Q31 In your own words, please describe what happened when you got into a collision(s) or near-collision(s) with a bicyclist. You can describe as many situations as you want. If you have never had any collisions or near-collisions with a bicyclist, you can leave this blank. 
Q32 Section 5. DemographicsYou are almost done! Now we just have a few questions about you to help us with the research. This demographic information will be pooled together to report general trends and to make sure we provided an opportunity for a variety of people to participate in this survey.

Q33 What is your zip code? (This is just to determine your general location, it will not be used to identify you or link you with your answers.)

Q34 INCLUDING YOURSELF, how many adults (18 years or older) live in your household?
O 1 (1)
O 2 (2)
○ 3 (3)
$4+(4)$

Q35 How many children (under age 18) live in your household?

O 0 (1)

O $1(2)$

O 2 (3)

O $3(4)$

O $4+(5)$

Q36 Do you consider yourself: (select all that apply)

A American Indian or Alaska Native (5)

Asian (4)

- Black or African American (1)

- Hispanic or Latino/a (3)

- White or Caucasian (2)

I I prefer not to provide this information (8)

O Other: (7)

Q37 What is your age group?

O 18-25 (1)

O $26-34$ (2)

O $35-44$ (3)

O 45-54 (4)

○ 55-64 (5)

O $65-70(6)$ 
Q38 Please select your gender:

O Man (1)

O Woman (2)

○ (3)

Q39 What is the highest level of school you have completed?

O Some high school or less (1)

O High school diploma or GED (2)

O Some College (3)

O Trade/Vocational School Certificate or Degree (4)

O Associate Degree (5)

Four-year college degree (6)

O Graduate degree (8)

Other (please specify): (7)

Q40 What is your annual household income?

O Less than $\$ 15,000$ (1)

O $\$ 15,000$ to $\$ 24,999$ (2)

O $\$ 25,000$ to $\$ 49,999$ (3)

O $\$ 50,000$ to $\$ 74,999$ (4)

○ $\$ 75,000$ to $\$ 99,999$ (5)

O $\$ 100,000$ to $\$ 149,999$ (6)

O $\$ 150,000$ to $\$ 199,999$ (7)

O $\$ 200,000$ to $\$ 249,999$ (8)

O $\$ 250,000$ to $\$ 299,999$ (10)

O $\$ 300,00$ or more (11)

I prefer not to provide this information (9)

Q41 Thank you so much for your time. Before you go, is there anything else you would like to tell us? 


\section{Appendix B: Driver Attitude Questionnaire (Crundall et al., 20o8)}

Appendix A. Twenty-six items (1-2 are general driving, 3-26 are motorcycle specific)

Q1 'I do find driving a car is enjoyable and rewarding.'

Q2 'I perform all appropriate visual checks when driving or riding, e.g. mirror use, blind-spot checks, etc.'

Q3. 'When driving in interweaving streams of fast moving traffic with many other drivers often changing lanes I am constantly aware that motorcycles can be more difficult to spot than under normal driving conditions.'

Q4 'It is easier for motorcyclists to make sudden swerves to avoid an accident than car drivers.'

Q5 'Motorcyclists are allowed to 'filter' past stationary or slow moving traffic.

Q6 'It is difficult to estimate the speed of approaching motorcycles while waiting to turn at a junction onto a main carriageway.'

Q7 'I do (or expect that I would) find riding a motorcycle is enjoyable and rewarding.'

Q8 'When waiting to turn at a junction onto a main carriageway I find that approaching motorcycles are as easy to spot as approaching cars.'

Q9 'When riding a motorcycle, taking risks is part of the thrill.'

Q10 'Motorcycles are as easy to see at night as cars.'

Q11 'Motorcyclists tend to have headlights on more often than car drivers in the daytime to increase visibility.'

Q12 'Other motorists should take extra care to look for motorcyclists.'

Q13 'The average motorcyclist takes greater precautions than the average car driver in wet weather conditions.'

Q14 'Motorcyclists often perform manoeuvres that are inappropriate.'

Q15 'When a car and a motorcycle collide it is typically the fault of the motorcyclist.'

Q16 'On the open road you can be suddenly surprised by the appearance of a motorcycle coming from behind you.'

Q17 'Motorcycles are easily hidden from view by parked vehicles and other parts of the road environment, e.g. buildings or overgrown vegetation.'

Q18 'It is easier to pass the current motorcycle test than the current car driving test.'

Q19 'I have similar personal characteristics to the average motorcyclist.' This is regardless of whether you actually ride a motorcycle yourself.

Q20 'Motorcycles are usually easy to spot even against a 'cluttered' background (containing road signs, adverts, etc.)'

Q21 'It costs less to repair the average motorcycle after a minor accident, compared with an average car.'

Q22 'Car drivers are typically more law-abiding than motorcyclists.

Q23 'When in slow moving traffic I am often surprised by motorcyclists filtering through the traffic.'

Q24 Motorcycles should travel in which of the following positions within a lane? 
Q25 When a motorcyclist overtakes a car at $40 \mathrm{mph}$ what size of gap should be left between the car and the passing motorcycle in order to remain safe? (Response options ranged from 1 to 7 feet)

Q26 'What proportion of the width of a car does a motorcycle occupy?' (e.g. 20\% would indicate that a motorcycle was a fifth of the width of a car and $100 \%$ would mean it was the same width as the car) (Response options ranged from 10 to $70 \%$ ) 


\title{
Appendix C: Driver Behavior Questionnaire
}

\author{
Original: (Reason et al., 1990)
}

This version from: Lajunen, T., Parker, D., \& Summala, H. (2004). The Manchester Driver

Behavior Questionnaire: A cross-cultural study. Accident Analysis, and Prevention, 36, 231-238.

Respondents were asked to indicate how often they themselves do each of the violations and errors when driving. Responses were on a six-point scale from "Never" to "Nearly all the time".

1=Never $\quad$ 2=Hardly Ever $\quad 3=$ Occasionally $\quad 4=$ =uite Often $\quad 5=$ =Frequently $\quad 6=$ Nearly All The Time

Begin each question with "How often do you"

Aggressive Violations

7. Sound your horn to indicate your annoyance to another road user

17. Become angered by another driver and give chase with the intention of giving him/her a piece of your mind

25. Become angered by a certain type of a driver and indicate your hostility by whatever means you can

\section{“Ordinary" Violations}

10. Pull out of a junction so far that the driver with right of way has to stop and let you out 11. Disregard the speed limit on a residential road

18. Stay in a motorway lane that you know will be closed ahead until the last minute before forcing your way into the other lane

20. Overtake a slow driver on the inside

21. Race away from traffic lights with the intention of beating the driver next to you

23. Drive so close to the car in front that it would be difficult to stop in an emergency

24. Cross a junction knowing that the traffic lights have already turned against you

28. Disregard the speed limit on a motorway

Errors

5. Queuing to turn left onto a main road, you pay such close attention to the main stream of traffic that you nearly hit the car in front of you

6. Fail to notice that pedestrians are crossing when turning into a side street from a main road

8. Fail to check your rear-view mirror before pulling out, changing lanes, etc.

9. Brake too quickly on a slippery road or steer the wrong way in a skid

13. On turning left nearly hit a cyclist who has come up on your inside

14. Miss "Give Way" signs and narrowly avoid colliding with traffic having right of way

16. Attempt to overtake someone that you had not noticed to be signaling a right turn

27. Underestimate the speed of an oncoming vehicle when overtaking 
Lapses

1. Hit something when reversing that you had not previously seen

2. Intending to drive to destination A, you "wake up" to find yourself on the road to destination B

4. Get into the wrong lane approaching a roundabout or a junction

12. Switch one thing, such as the headlights, when you meant to switch on something else, such as the wipers

15. Attempt to drive away from the traffic lights in third gear

19. Forget where you left your car in a car park

22. Misread the signs and exit from a roundabout on the wrong road

26. Realize that you have no clear recollection of the road along which you have just been traveling 